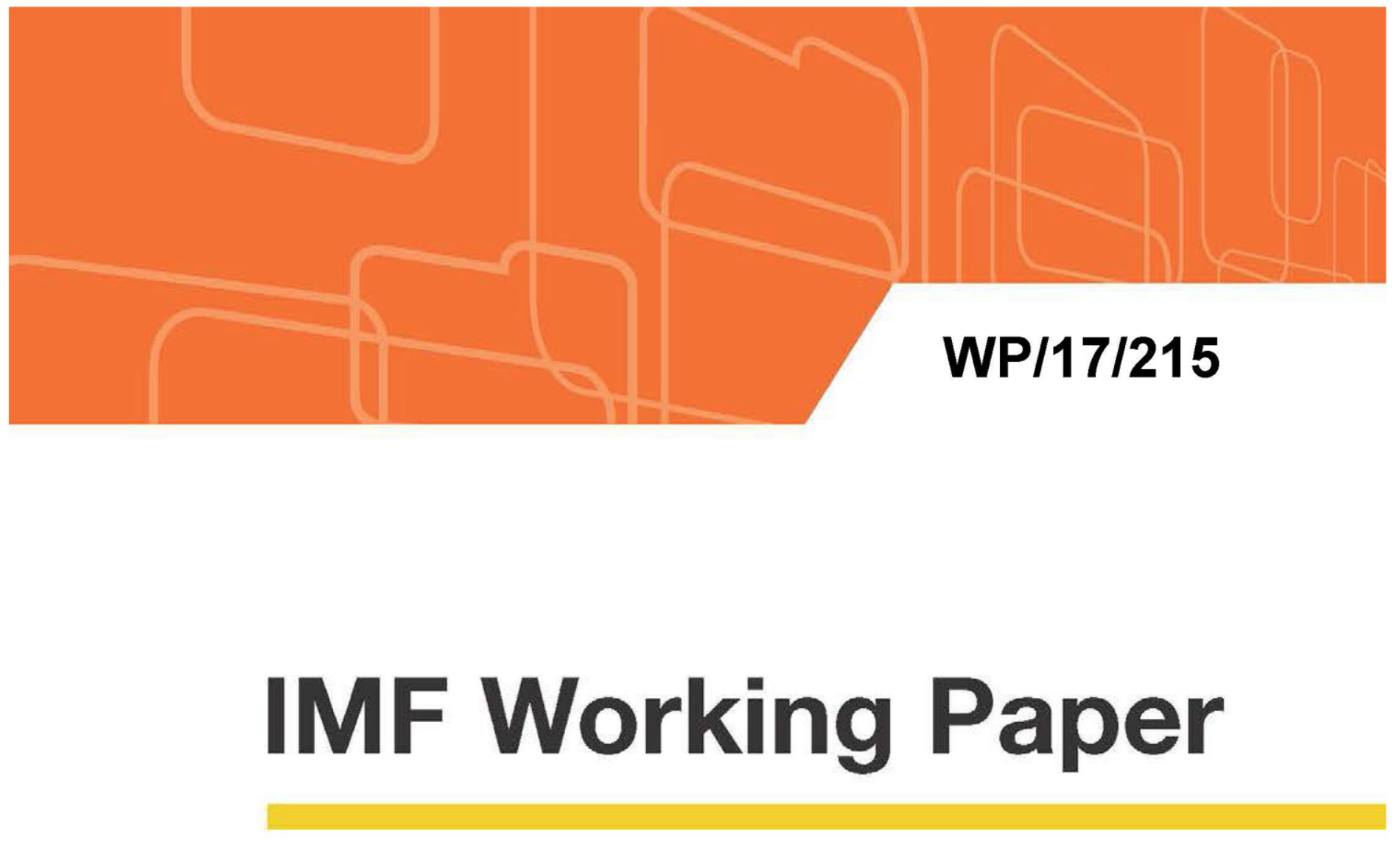

\title{
Market Reforms at the Zero Lower Bound
}

by Matteo Cacciatore, Romain Duval, Giuseppe Fiori, and Fabio Ghironi

IMF Working Papers describe research in progress by the author(s) and are published to elicit comments and to encourage debate. The views expressed in IMF Working Papers are those of the author(s) and do not necessarily represent the views of the IMF, its Executive Board, or IMF management. 


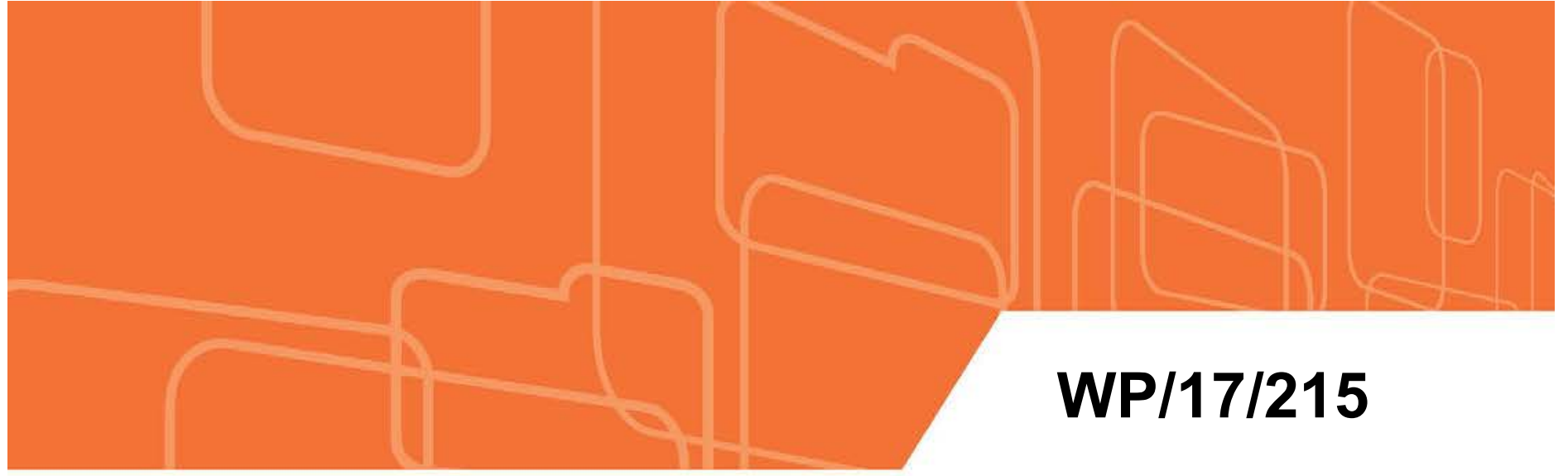

\section{IMF Working Paper}

\section{Market Reforms at the Zero Lower Bound}

by Matteo Cacciatore, Romain Duval, Giuseppe Fiori, and Fabio Ghironi

IMF Working Papers describe research in progress by the author(s) and are published to elicit comments and to encourage debate. The views expressed in IMF Working Papers are those of the author(s) and do not necessarily represent the views of the IMF, its Executive Board, or IMF management.

I N T E R N A T I O N A L M O N E T A R Y F U N D 


\title{
IMF Working Paper
}

\author{
Research Department
}

\section{Market Reforms at the Zero Lower Bound}

\section{Prepared by Matteo Cacciatore, Romain Duval, Giuseppe Fiori, and Fabio Ghironi*}

\author{
Authorized for distribution by Romain Duval
}

October 2017

\begin{abstract}
IMF Working Papers describe research in progress by the author(s) and are published to elicit comments and to encourage debate. The views expressed in IMF Working Papers are those of the author(s) and do not necessarily represent the views of the IMF, its Executive Board, or IMF management.
\end{abstract}

\begin{abstract}
This paper studies the impact of product and labor market reforms when the economy faces major slack and a binding constraint on monetary policy easing. such as the zero lower bound. To this end, we build a two-country model with endogenous producer entry, labor market frictions, and nominal rigidities. We find that while the effect of market reforms depends on the cyclical conditions under which they are implemented, the zero lower bound itself does not appear to matter. In fact, when carried out in a recession, the impact of reforms is typically stronger when the zero lower bound is binding. The reason is that reforms are inflationary in our structural model (or they have no noticeable deflationary effects). Thus, contrary to the implications of reduced-form modeling of product and labor market reforms as exogenous reductions in price and wage markups, our analysis shows that there is no simple across-the-board relationship between market reforms and the behavior of real marginal costs. This significantly alters the consequences of the zero (or any effective) lower bound on policy rates.
\end{abstract}

JEL Classification Numbers: E24, E32, E52, F41, J64

Keywords: Employment protection; Monetary policy; Producer entry; Product market regulation; Structural reforms; Unemployment benefits; Zero lower bound.

Authors' e-mail addresses: matteo.cacciatore@hec.ca; rduval@imf.org; gfiori@ncsu.edu; ghiro@uw.edu

\footnotetext{
*We thank Olivier Blanchard, Maury Obstfeld, and many others at the IMF who helped this project with comments and suggestions. We also thank our discussants Zeno Enders, Gernot Müller, and Yongseung Jung, as well as participants in seminars and conferences at Banque de France, Bank of Korea-Korea University BK21 Conference, CEPR Leuven Workshop 2016, Collegio Carlo Alberto, Concordia University, DFG-Hertie SchoolIMF Structural Reforms Conference, the European Central Bank, the European Commission, the International Monetary Fund, the Nederlandsche Bank, UC Irvine, University of Cergy-Pontoise, the Third MACFINROBODS Workshop, the XIII INTECO Workshop-Castellon, and the XXII ENSAI Economics Day. The views in this paper are those of the authors and do not represent the views or policies of the CEPR, IMF, and NBER.
} 


\section{Contents}

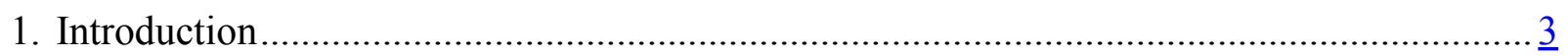

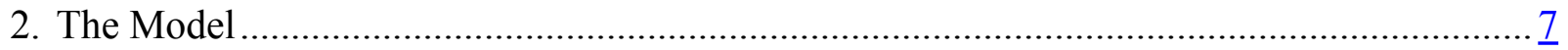

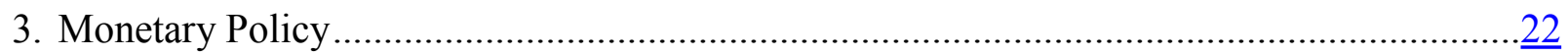

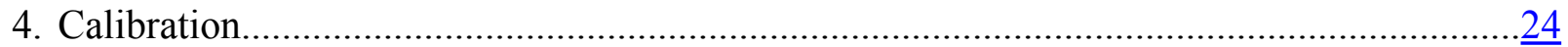

5. Market Reforms in Normal Times ................................................................................ 27

6. Market Deregulation at the Zero Lower Bound..........................................................

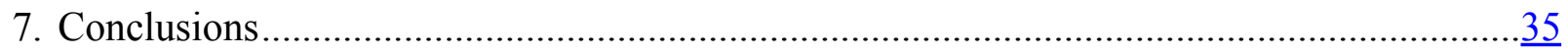

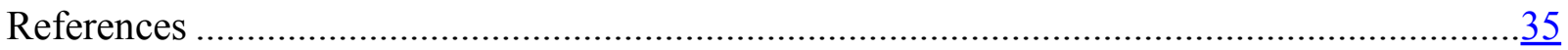

\section{Tables}

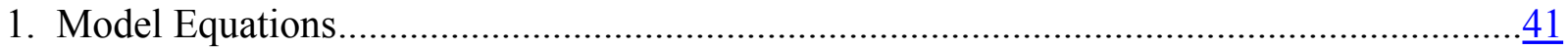

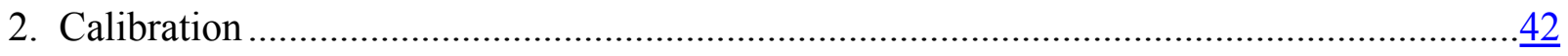

\section{Figures}

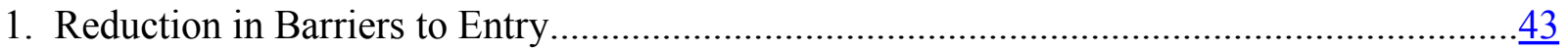

2. Reduction in Firing Cost ................................................................................... 44

3. Reduction in Unemployment Benefit .................................................................. 45

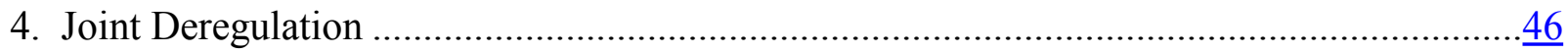

5. Productivity Effects of Market Reforms .................................................................... 47 


\section{Introduction}

The protracted slowdown in economic growth since the 2008-2009 global financial crisis and the limited room for monetary and fiscal stimulus have put structural reforms at the center of the policy agenda in many advanced economies (e.g. Draghi, 2015, IMF, 2016, and OECD, 2015). A large body of theoretical and empirical research supports the view that such reforms would raise output and employment in the long run. ${ }^{1}$ However, there is an active debate regarding short-term outcomes of market reform. A central issue in the post-crisis environment involves the consequences of structural reforms at a time in which central banks face binding constraints on monetary policy easing, in particular because of the impossibility in pushing policy rates into negative territory unlimitedly - the so-called zero lower bound (ZLB) on nominal interest rates. ${ }^{2}$ Two geographic areas where structural reforms have been advocated most forcefully, namely the euro area and Japan, are in such a situation. At the heart of the debate ultimately lies the question of whether market reforms have important deflationary effects. As argued by Eggertsson (2010), in a liquidity trap expectations of deflation increase real interest rates, thus depressing current demand - what he calls the paradox of toil. Building on this insight, Eggertsson, Ferrero and Raffo (2014, EFR) show that if structural reforms are interpreted as exogenous reductions in price and wage markups, deregulation may entail near-term contractionary effects when monetary policy is constrained by the ZLB, since reforms fuel expectations of prolonged deflation. ${ }^{3}$ Even more disappointingly, if agents foresee that such reforms are not permanent (due to lack of political credibility), short-term output losses are even larger, further deepening the ongoing recession.

The analysis in EFR maintains the assumption that market reforms act as exogenous reductions in price and wage markups. However, from an empirical perspective, market regulation affects the incentives to create and destroy products and jobs. Price and wage dynamics are an endogenous outcome of market reform. The goal of this paper is to address the consequences of primitive changes in market regulation when the economy is in a deep recession that has triggered the ZLB on nominal interest rates.

To this end, we build a two-country, two-sector model of a monetary union featuring endogenous

\footnotetext{
${ }^{1}$ See for instance the influential paper by Blanchard and Giavazzi (2003). Other theoretical papers include, for product market reforms, Ebell and Haefke (2009), Fang and Rogerson (2011), and Felbermayr and Prat (2011); for labor market reforms, Alessandria and Delacroix (2008), Alvarez and Veracierto (2000), Bentolila and Bertola (1990), and Hopenhayn and Rogerson (1993).

${ }^{2}$ All the arguments and analysis in the paper extend to any (negative) effective lower bound on the monetary policy rate.

${ }^{3}$ Eggertsson (2012) argues that New Deal policies facilitated the recovery from the Great Depression by temporarily granting monopoly power to firms and unions.
} 
producer entry, search-and-matching frictions in labor market, and nominal rigidities. ${ }^{4}$ Endogenous variation in the number of monopolistically competitive firms builds on Bilbiie, Ghironi and Melitz (2012) and Ghironi and Melitz (2005). Labor markets are characterized by search-and-matching frictions with endogenous job creation and destruction as in Mortensen and Pissarides (1994) and den Haan, Ramey and Watson (2000). We calibrate the model to match features of the euro-area macroeconomic data.

We then analyze the dynamic response of the economy to three different reforms that have featured prominently in policy debates over the years: i) product market reform, modeled as a reduction in regulatory costs of entry in the non-tradable sector; ii) employment protection legislation reform, namely a reduction in firing costs; iii) a decline in the generosity of unemployment benefits, that is a cut in the average replacement rate over an unemployment spell. For each reform, we consider two alternative scenarios: i) market reform happens in normal times, i.e., when the economy is not in a recession and the ZLB is not binding; ii) in a crisis that pushes the nominal interest rate to its lower bound.

Our main conclusion is that while business cycle conditions at the time of deregulation matter for the adjustment, the presence of the ZLB does not per-se induce recessionary effects of market reforms. In fact, some reforms can be more beneficial when the ZLB is binding, as observed for product market reform and joint deregulation in product and labor markets.

This result reflects the fact that reforms do not have deflationary effects in the first place, and some are indeed inflationary, at least in the first phase of the transition. The intuition behind this result is easily understood. Consider first a reduction in barriers to entry. While such reform reduces price mark-ups through well-understood pro-competitive effects, the downward pressure on prices is initially more than offset by two inflationary forces. First, lower entry barriers trigger entry of new producers, which increases demand for factors of production and thereby marginal costs. Second, incumbent producers lay off less productive workers in response to increased competition. Since remaining workers have higher wages on average, marginal labor costs rise. The latter effect also explains why lower firing costs - which induce firms to lay off less productive workers - are not deflationary either, even though layoffs reduce aggregate demand all else equal. Finally, while unemployment benefit cuts have a negative impact on wages and aggregate demand by weakening workers' outside option in the wage bargaining process, this deflationary effect is offset by the positive general equilibrium impact of the reform on labor demand, which increases wages other

\footnotetext{
${ }^{4}$ The two-country assumption captures features of the euro-area core and periphery.
} 
things equal.

Our results highlight that prevailing business cycle conditions and not constraints on monetary policy represent the key dimension to consider when evaluating the short- to medium-run effects of market reform. Moreover, our analysis shows that, contrary to what is implied by the conventional modeling of product and labor market reforms - exogenous price and wage mark-up reductionsthere is no simple across-the-board relationship between market reforms and the behavior of the real marginal cost. This is because reforms affect both supply and demand in complex ways. Output and employment responses to reform vary widely across specific areas already in normal times, and how these responses are altered by the presence of a recession with a binding zero lower bound also differs across reforms. This reflects important differences, highlighted by our model, in the nature and transmission of different reforms. For instance, while reductions in firing costs and unemployment benefits both qualify as "labor market reforms", their short-term effects differ noticeably, and there is a significant "difference in this difference" between normal times and a recession with a binding ZLB.

Our paper relates to a burgeoning theoretical literature on the short-term effects of structural reforms, both in general and at the ZLB more specifically. Considering only normal times, Cacciatore and Fiori (2016) explore the short-term effects of the reforms discussed here, while Cacciatore, Duval, Fiori and Ghironi (2016a) and Cacciatore, Fiori and Ghironi (2016) assess the role of monetary policy for short-run adjustment to these reforms. Cacciatore, Duval, Fiori and Ghironi (2016b) explore the role of business cycle conditions for the short-term effect of market deregulation in a real model that ignores the role of monetary policy altogether. A number of large-scale DSGE models have also been used to analyze the dynamic impact of reforms in normal times (Varga and in't Veld, 2011; Everaert and Schule, 2008; Gomes, Jacquinot, Mohr and Pisani, 2013), although their focus is on exogenous reductions in price and wage markups.

A few recent papers study how the impact of reforms differs at the zero lower bound. Using a simple New Keynesian model with wage and price rigidities, Eggertsson, Ferrero and Raffo (2014) find that the impact of reforms that would be expansionary in normal times becomes a priori ambiguous, and possibly contractionary, at the ZLB. However, they model reforms in reduced-form fashion as exogenous reductions in price and wage markups; this makes reforms automatically deflationary in their basic setup. ${ }^{5}$ Using larger-scale models of the euro area featuring richer trans-

\footnotetext{
${ }^{5}$ See also Fernández-Villaverde, Guerrón-Quintana, and Rubio-Ramírez (2011). Andrés, Arce, and Thomas (2014) study the consequences of market reforms in an environment of debt deleveraging These papers - and others that have appeared in the literature - do not feature producer entry dynamics and DMP labor market frictions.
} 
mission mechanisms - including investment, trade with the rest of the world, liquidity-constrained versus optimizing households - Gerali, Notarpietro and Pisani (2015), Gomes (2014), and Vogel (2014) reassess this result and find a smaller role of the ZLB. Explicit modeling of product and labor market dynamics and the primitive features of regulation differentiates our paper from these recent studies. As illustrated above, such modeling has major implications for the effects of reforms at the ZLB and how they vary across different areas. ${ }^{6}$

A few caveats are in order. Our analysis shows that market reform increases labor productivity both in the long run and in the short run, even when implemented at the ZLB. However, our modeling of product market reforms does not factor in possible productivity gains that may stem from reduced X-inefficiency among incumbent firms or from stronger incentives for them to innovate. Therefore, if anything, these other possible transmission channels suggest we may under-estimate the short-term effects of reforms, including at the ZLB. ${ }^{7}$ Another possible limitation of our analysis is that we consider only one regulated non-tradable sector, while in practice the resource costs, and therefore the aggregate demand effects, of firm entry may differ across sectors - for example, they are likely to be higher in the telecommunications sector than in some professional services such as taxis. Therefore our results should be seen as aiming to capture an average impact of product market deregulation in the non-tradable sector. Finally, our finding that unemployment benefit cuts do not have deflationary effects - and therefore that their effectiveness is not reduced by the presence of a binding ZLB - reflects the strong responsiveness of labor demand, and thereby of aggregate demand, to such reforms. The relevance of the firm hiring channel, highlighted also by Mitman and Rabinovich (2015), stresses more broadly the beneficial effects of labor market policies promoting wage flexibility (through reductions in the generosity of wage replacement) as opposed to employment flexibility during downturns. This result is consistent with the empirical evidence in Gnocchi, Lagerborg, and Pappa (2015) and echoes the discussion in Boeri and Jimeno (2015). However, the model abstracts from a potential counteracting force: a cut in unemployment benefits affects more severely lower-income, credit-constrained households, inducing them to curtail consumption. Furthermore, households typically become more credit-constrained - and therefore the counteracting force could become stronger - in recessions (Mian and Sufi, 2011). As argued by Kollmann, Ratto, Roeger, in't Veld, and Vogel (2015), even if the government fully redistributes

\footnotetext{
${ }^{6}$ This recent literature on the effect of supply-side policies at the ZLB falls within the broader context of a growing body of work on how the ZLB may alter the impact of shocks relative to normal times. For fiscal policy shocks, see Christiano, Eichenbaum and Rebelo (2011), Erceg and Linde (2012), and Woodford (2011).

${ }^{7}$ Notice that productivity shocks are expansionary in our model, even at the ZLB - albeit less so than in normal times due to their depressing impact on prices.
} 
the fiscal gain from benefit reductions through broad-based tax cuts, aggregate consumption may still decline and output fall.

The remainder of this paper is structured as follows. Section 2 presents the model, except for the specification of monetary policy. Section 3 describes monetary policy. Section 4 presents the calibration of the model. Section 5 simulates the impact of the different labor and product market reforms under normal economic conditions. Section 6 focuses on the consequences of reforms during recessions, with a binding zero lower bound or without it (counterfactual). Section 7 concludes.

\section{The Model}

We model a monetary union that consists of two countries, Home and Foreign. Foreign variables are denoted with a superscript star. We use the subscript $D$ to denote quantities and prices of a country's own goods consumed domestically, and the subscript $X$ to denote quantities and prices of exports. We focus on the Home economy in presenting our model, with the understanding that analogous equations hold for Foreign. We abstract from monetary frictions that would motivate a demand for cash currency in each country, and we resort to a cashless economy following Woodford (2003).

\section{Household Preferences}

Each economy in the union is populated by a unit mass of atomistic, identical households. Each household is thought of as a large extended family containing a continuum of members along a unit interval. The household does not choose how many family members work; the measure of family members who work is determined by a labor matching process. Unemployed workers receive a fixed amount $h_{p}>0$ of household production units. Following Andolfatto (1996), Merz (1995), and much of the subsequent literature, we assume full consumption insurance between employed and unemployed individuals, so that there is no ex-post heterogeneity across individuals in the household. We assume habit persistence in consumption utility as this improves the quantitative performance of the model by slowing down the response of consumption to shocks.

The representative household maximizes expected intertemporal utility,

$$
E_{t}\left[\sum_{s=t}^{\infty} \beta^{s-t} \frac{\left(C_{s}^{H}-h_{C} C_{s-1}^{H}\right)^{1-\gamma}}{1-\gamma}\right],
$$

where the discount factor $\beta$ and habit parameter $h_{C}$ both lie between 0 and 1 , and $\gamma>0$. We 
assume habit persistence in consumption utility as this improves the quantitative performance of the model by slowing down the response of consumption to shocks. Household consumption $C_{t}^{H}$ is defined as

$$
C_{t}^{H} \equiv C_{t}+h_{p}\left(1-L_{t}\right)
$$

where $C_{t}$ is consumption of market goods, and $L_{t}$ denotes the number of employed workers.

Market consumption is a composite of tradable and non-tradable baskets, $C_{t}^{T}$ and $C_{t}^{N}$ :

$$
C_{t}=\left[\left(1-\alpha_{N}\right)^{\frac{1}{\phi_{N}}}\left(C_{t}^{T}\right)^{\frac{\phi_{N}-1}{\phi_{N}}}+\alpha_{N}^{\frac{1}{\phi_{N}}}\left(C_{t}^{N}\right)^{\frac{\phi_{N}-1}{\phi_{N}}}\right]^{\frac{\phi_{N}}{\phi_{N}-1}}, \quad 0<\alpha_{N}<1
$$

where $\alpha_{N} \in(0,1]$ is the share of non-tradables in total market consumption, and $\phi_{N}$ denotes the constant elasticity of substitution. ${ }^{8}$ The consumption-based price index is

$$
P_{t}=\left[\left(1-\alpha_{N}\right)\left(P_{t}^{T}\right)^{1-\phi_{N}}+\alpha_{N}\left(P_{t}^{N}\right)^{1-\phi_{N}}\right]^{\frac{1}{1-\phi_{N}}}
$$

where $P_{t}^{T}$ is the price of the tradable basket, and $P_{t}^{N}$ is the price of the non-tradable basket. The domestic demand for tradables is $C_{t}^{T}=\left(1-\alpha_{N}\right)\left(P_{t}^{T} / P_{t}\right)^{-\phi_{N}} C_{t}$; the domestic demand for non-tradables is $C_{t}^{N}=\alpha_{N}\left(P_{t}^{N} / P_{t}\right)^{-\phi_{N}} C_{t}$.

The tradable consumption basket $C_{t}^{T}$ aggregates homogenous Home and Foreign consumption goods in Armington form with elasticity of substitution $\phi_{T}>0$ :

$$
C_{t}^{T}=\left[\left(1-\alpha_{X}\right)^{\frac{1}{\phi_{T}}}\left(C_{D, t}^{T}\right)^{\frac{\phi_{T}-1}{\phi_{T}}}+\alpha_{X}^{\frac{1}{\phi_{T}}}\left(C_{X, t}^{T^{*}}\right)^{\frac{\phi_{T}-1}{\phi_{T}}}\right]^{\frac{\phi_{T}}{\phi_{T}-1}}, \quad 0<\alpha_{X}<1
$$

A similar basket describes consumption in the Foreign country. Importantly, in each country's tradable consumption basket, $1-\alpha_{X}$ is the weight attached to the country's own good. Therefore, preferences are biased in favor of domestic goods whenever $\alpha_{X}<1 / 2$. The tradable consumptionbased price index that corresponds to the basket $C_{t}^{T}$ is given by

$$
P_{t}^{T}=\left[\left(1-\alpha_{X}\right)\left(P_{D, t}^{T}\right)^{1-\phi_{T}}+\alpha_{X}\left(P_{X, t}^{T^{*}}\right)^{1-\phi_{T}}\right]^{\frac{1}{1-\phi_{T}}}
$$

The demand for Home tradable consumption is $C_{D, t}^{T}=\left(1-\alpha_{X}\right)\left(P_{D, t}^{T} / P_{t}^{T}\right)^{-\phi_{T}} C_{t}^{T}$, while the

\footnotetext{
${ }^{8}$ Differently from Ghironi and Melitz (2005), we do not model the endogenous determination of the subset of traded goods within a tradable set, since this is not central to the analysis in this paper.
} 
demand for Foreign tradable consumption is $C_{X, t}^{T}=\alpha_{X}\left(P_{X, t}^{T^{*}} / P_{t}^{T}\right)^{-\phi T} C_{t}^{T}$.

At any given point in time, only a subset of non-tradable goods $\Omega_{t} \in \Omega$ is available. We assume that the aggregator $C_{t}^{N}$ takes a translog form following Feenstra (2003b). As a result, the elasticity of substitution across varieties within the basket $C_{t}^{N}$ is an increasing function of the number of goods available. The translog assumption allows us to capture the pro-competitive effect of deregulating in the goods market on markups, documented by the empirical literature - see Griffith, Harrison, and Macartney (2007). ${ }^{9}$ Translog preferences are characterized by defining the unit expenditure function (i.e., the price index) associated with the preference aggregator. Let $p_{\omega, t}^{N}$ be the nominal price for the good $\omega \in \Omega_{t}$. The unit expenditure function on the basket of goods $C_{t}^{N}$ is given by:

$\ln P_{t}^{N}=\frac{1}{2 \sigma}\left(\frac{1}{N_{t}}-\frac{1}{\tilde{N}}\right)+\frac{1}{N_{t}} \int_{\omega \in \Omega_{t}} \ln p_{t}^{N}(\omega) d \omega+\frac{\sigma}{2 N_{t}} \int_{\omega \in \Omega_{t}} \int_{\omega^{\prime} \in \Omega_{t}} \ln p_{t}^{N}(\omega)\left(\ln p_{t}^{N}(\omega)-\ln p_{t}^{N}\left(\omega^{\prime}\right)\right) d \omega d \omega^{\prime}$,

where $\sigma>0$ denotes the price-elasticity of the spending share on an individual good, $N_{t}$ is the total number of products available at time $t$, and $\tilde{N}$ is the mass of $\Omega$.

\section{Production}

In each country, there are two vertically integrated production stages. At the upstream level, perfectly competitive firms use capital and labor to produce a non-tradable intermediate input. At the downstream level, there are two sectors producing final consumption goods. In one sector, monopolistically competitive firms purchase intermediate inputs and produce differentiated nontradable varieties. In the second sector, perfectly competitive firms combine intermediate inputs and non-tradable goods to produce a consumption good that is sold to consumers in both countries. This production structure is consistent with the evidence provided by Boeri, Castanheira, Faini, and Galasso (2006), who document how service industries are a key supplier of the manufacturing sector.

\footnotetext{
${ }^{9} \mathrm{~A}$ demand-, preference-based explanation for time-varying, flexible-price markups is empirically appealing because the data shows that most entering and exiting firms are small, and much of the change in the product space is due to product switching within existing firms, pointing to a limited role for supply-driven competitive pressures in markup dynamics. Bilbiie, Ghironi, and Melitz (2012) find that translog preferences result in markup dynamics that are remarkably close to U.S. data. Bergin and Feenstra (2000) show that a translog expenditure function generate plausible endogenous persistence in macro models. For a review of the applications of translog preferences in the trade literature, see Feenstra (2003a).
} 


\section{Intermediate Goods Production}

There is a unit mass of perfectly competitive intermediate producers. Production requires capital and labor. Within each firm there is a continuum of jobs; each job is executed by one worker. Following Gertler and Trigari (2009) and den Haan, Ramey, and Watson (2000), we assume that capital is perfectly mobile across firms and jobs and that there is a competitive rental market in capital. While firms are "large" as they employ a continuum of workers, firms are still of measure zero relative to the aggregate size of the economy.

A filled job $i$ produces $Z_{t} z_{t}^{i}\left(k_{t}^{i}\right)^{a}$ units of output, where $Z_{t}$ denotes aggregate productivity, $z_{t}^{i}$ represents a random disturbance that is specific to match $i$, and $k_{t}^{i}$ is the stock of capital allocated to the job. Within each firm, jobs with identical productivity $z_{t}^{i}$ produce the same amount of output. For this reason, in the remainder of the paper we suppress the job index $i$ and identify a job with its idiosyncratic productivity $z_{t}$. As common practice in the literature, we assume that $z_{t}$ is a per-period i.i.d. draw from a time-invariant distribution with c.d.f. $G(z)$, positive support, and density $g(z) .{ }^{10}$ When solving the model, we assume that $G(z)$ is lognormal with $\log$-scale $\mu_{z_{i}}$ and shape $\sigma_{z_{i}}$. Aggregate productivity $Z_{t}$ is exogenous and common to all firms. We assume that $Z_{t}$ and $Z_{t}^{*}$ follow a bivariate $A R(1)$ process in logs, with Home (Foreign) productivity subject to innovations $\epsilon_{Z t}\left(\epsilon_{Z t}^{*}\right)$. The diagonal elements of the autoregressive matrix $\Phi, \Phi_{11}$ and $\Phi_{22}$, measure the persistence of exogenous productivity and are strictly between 0 and 1 , and the off-diagonal elements $\Phi_{12}$ and $\Phi_{21}$ measure productivity spillovers. The productivity innovations $\epsilon_{Z t}$ and $\epsilon_{Z t}^{*}$ are normally distributed with zero mean and variance-covariance matrix $\Sigma_{\epsilon_{Z}, \epsilon_{Z}^{*}}$.

The representative intermediate firm produces output

$$
Y_{t}^{I}=Z_{t} L_{t} \frac{1}{1-G\left(z_{t}^{c}\right)} \int_{z_{t}^{c}}^{\infty} z k_{t}^{\alpha}(z) g(z) d z
$$

where $L_{t}$ is the measure of jobs within the firm, $k_{t}(z)$ is the amount of capital allocated to a job with idiosyncratic productivity $z$, and the term $z_{t}^{c}$ represents an endogenously determined critical threshold below which jobs that draw $z_{t}<z_{t}^{c}$ are not profitable. In this case, the value to the firm of continuing the match is less than the value of separation, and the job is destroyed. When terminating a job, each firm incurs a real cost $F_{t}$. Firing costs are not a transfer to workers here and

\footnotetext{
${ }^{10}$ The assumption that the idiosyncratic productivity shocks are independently and identically distributed over time simplifies the analysis of the model by eliminating the need to consider match-specific state variables for continuing relationships. Results in den Haan, Ramey, and Watson (2000) lead us to conjecture that this would not affect our results significantly.
} 
are treated as a pure loss (administrative costs of layoff procedures). Severance transfers from firms to workers would have no allocative effects with wage bargaining as assumed below (see Mortensen and Pissarides, 2002). Finally, the relationship between a firm and a worker can also be severed for exogenous reasons; in which case, no firing costs are paid. Denote with $\lambda$ the fraction of jobs that are exogenously separated from each firm in each period.

Job creation is subject to matching frictions. To hire a new worker, firms have to post a vacancy, incurring a real fixed cost $\kappa$. The probability of finding a worker depends on a constant returns to scale matching technology, which converts aggregate unemployed workers $U_{t}$ and aggregate vacancies $V_{t}$ into aggregate matches $M_{t}=\chi U_{t}^{\varepsilon} V_{t}^{1-\varepsilon}$, where $0<\varepsilon<1$. Each firm meets unemployed workers at a rate $q_{t} \equiv M_{t} / V_{t}$. Searching workers in period $t$ are equal to the mass of unemployed workers: $U_{t}=\left(1-L_{t}\right)$.

The timing of events proceeds as follows. At the beginning of each period, a fraction $\lambda$ of jobs are exogenously separated. Aggregate and idiosyncratic shocks are then realized, after which the representative firm chooses the productivity threshold $z_{t}^{c}$ that determines the measure of jobs endogenously destroyed, $G\left(z_{t}^{c}\right)$. Once the firing round has taken place, firms post vacancies, $V_{t}$, and select their total capital stock, $K_{t}=L_{t} \tilde{k}_{t}$, where $\tilde{k}_{t} \equiv \int_{z_{t}^{c}}^{\infty} k_{t}(z) g(z) d z /\left[1-G\left(z_{t}^{c}\right)\right] .{ }^{11}$ The assumption that firms select capital after observing aggregate and idiosyncratic shocks follows den Haan, Ramey, and Watson (2000).

The inflow of new workers and the outflow of workers due to separations jointly determine the evolution of firm-level employment:

$$
L_{t}=(1-\lambda)\left(1-G\left(z_{t}^{c}\right)\right)\left(L_{t-1}+q_{t-1} V_{t-1}\right)
$$

All separated workers are assumed to immediately reenter the unemployment pool.

As shown in Cacciatore and Fiori (2016), owing to perfectly mobile capital rented in a competitive market, the producer's output exhibits constant returns to scale in labor and capital:

$$
Y_{t}^{I}=Z_{t} \tilde{z}_{t} K_{t}^{\alpha} L_{t}^{1-\alpha}
$$

\footnotetext{
${ }^{11}$ With full capital mobility and price-taker firms in the capital market, it is irrelevant whether producers choose the total stock of capital $K_{t}$, or, instead, determine the optimal capital stock for each existing job, $k_{t}(z)$. See Cacciatore and Fiori (2016) for the proof.
} 
where

$$
\tilde{z}_{t} \equiv\left[\frac{1}{1-G\left(z_{t}^{c}\right)} \int_{z_{t}^{c}}^{\infty} z^{1 /(1-\alpha)} g(z) d z\right]^{1-\alpha}
$$

is a weighted average of the idiosyncratic productivity of individual jobs. Intermediate goods producers sell their output to final producers at a real price $\varphi_{t}$ in units of consumption. Per-period real profits are given by

$$
d_{t}^{I}=\varphi_{t} Z_{t} \tilde{z}_{t} K_{t}^{\alpha} L_{t}^{1-\alpha}-\tilde{w}_{t} L_{t}-r_{t}^{K} K_{t}-\kappa V_{t}-G\left(z_{t}^{c}\right)(1-\lambda)\left(L_{t-1}+q_{t-1} V_{t-1}\right) F_{t},
$$

where $r_{t}^{K}$ is the rental rate of capital and $\tilde{w}_{t} \equiv \int_{z_{t}^{c}}^{\infty} w_{t}(z) g(z) d z /\left[1-G\left(z_{t}^{c}\right)\right]$ is the average wage paid by the firm, weighted according to the distribution of the idiosyncratic job productivities. Given the constraint in (3), the representative intermediate input producer chooses employment $L_{t}$, capital $K_{t}$, the number of vacancies to be posted $V_{t}$, and the job destruction threshold $z_{t}^{c}$ to maximize the present discounted value of real profits: $E_{t}\left(\sum_{s=t}^{\infty} \beta_{s, t} d_{t}^{I}\right)$, where $\beta_{s, t} \equiv \beta^{s-t} u_{C^{H}, s} / u_{C^{H}, t}$ denotes the stochastic discount factor of Home households, who are assumed to own intermediate input firms. The term $u_{C^{H}, t}$ denotes the marginal utility of consumption:

$$
u_{C^{H}, t} \equiv\left(C_{t}^{H}-h_{C} C_{t-1}^{H}\right)^{-\gamma}-h_{C} \beta E_{t}\left[\left(C_{t+1}^{H}-h_{C} C_{t}^{H}\right)^{-\gamma}\right] .
$$

By combining the first-order conditions for $L_{t}$ and $V_{t}$, we obtain the following job creation equation:

$$
\frac{\kappa}{q_{t}}=(1-\lambda) E_{t}\left\{\beta_{t, t+1}\left[\left(1-G\left(z_{t+1}^{c}\right)\right)\left((1-\alpha) \varphi_{t+1} \frac{Y_{t+1}^{I}}{L_{t+1}}-\tilde{w}_{t+1}+\frac{\kappa}{q_{t+1}}\right)-G\left(z_{t+1}^{c}\right) F_{t+1}\right]\right\} .
$$

Equation (4) equalizes the marginal cost and the marginal benefit of posting a vacancy. With probability $q_{t}$ the vacancy is filled; in which case, two events are possible: either the new recruit will be fired in period $t+1$, and the firm will pay firing costs, or the match will survive job destruction, generating value for the firm. The marginal benefit of a filled vacancy includes expected discounted savings on future vacancy postings, plus the average profits generated by a match. Profits from the match take into account the marginal revenue product from the match and its wage cost. Forward looking iteration of equation (4) implies that, at the optimum, the expected discounted value of the stream of profits generated by a match over its expected lifetime is equal to $\kappa / q_{t}$.

The first-order condition for the job-productivity threshold $z_{t}^{c}$ implies the following job destruc- 
tion equation:

$$
(1-\alpha) \varphi_{t} \frac{Y_{t}^{I}}{L_{t}}\left(\frac{z_{t}^{c}}{\tilde{z}_{t}}\right)^{\frac{1}{1-\alpha}}-w\left(z_{t}^{c}\right)+\frac{\kappa}{q_{t}}=-F_{t} .
$$

At the optimum, the value to the firm of a job with productivity $z_{t}^{c}$ must be equal to zero, implying that the contribution of the match to current and expected future profits is exactly equal to the firm outside option - firing the worker, paying $F_{t}$. When unprofitable jobs are terminated, the firm loses current and expected profits it would have earned had it kept the laid-off workers. At the same time, however, the firm benefits from job destruction, as unproductive jobs are removed and the distribution of job productivities within the firm is improved. ${ }^{12}$

The optimal capital demand implied by the first-order condition for $K_{t}$ equates the marginal revenue product of capital to its marginal cost: $\alpha \varphi_{t} Y_{t}^{I} / K_{t}=r_{t}^{K}$.

\section{Wage Setting}

As is standard practice in the literature, we assume surplus splitting between an individual worker and the firm. The surplus-splitting rule divides the surplus of each match in shares determined by an exogenous bargaining weight $\eta \in(0,1)$, which identifies the workers' bargaining power. ${ }^{13}$ The analytical derivation of the wage equation is presented in the Appendix. We show there that the wage payment to each worker is a weighted average between the marginal revenue product of the match (plus a firing costs component) and the worker's outside option, denoted with $\varpi_{t}$ :

$$
w_{t}(z)=\eta\left[(1-\alpha) \varphi_{t} \frac{Y_{t}^{I}}{L_{t}}\left(\frac{z}{\tilde{z}_{t}}\right)^{1 /(1-\alpha)}+F_{t}-(1-\lambda) E_{t}\left(\beta_{t, t+1} F_{t+1}\right)\right]+(1-\eta) \varpi_{t}
$$

The worker's outside option $\varpi_{t}$ corresponds to the value of unemployment, which includes home production, $h_{p}$, unemployment benefit from the government, $b_{t}$, and the expected discounted value of searching for other jobs:

$$
\varpi_{t} \equiv h_{p}+b_{t}+\iota_{t}(1-\lambda) E_{t}\left\{\beta_{t, t+1}\left[1-G\left(z_{t+1}^{c}\right)\right] \tilde{\Delta}_{t+1}^{W}\right\}
$$

\footnotetext{
${ }^{12}$ Equation (5) implies that the firm keeps some currently unprofitable jobs occupied. This happens because current job productivity can improve in the future, and the firm has to incur firing and recruitment costs in order to replace a worker.

${ }^{13}$ Following standard practice in the literature, we formulate the problem as though the worker is interested in maximizing expected discounted income. As pointed out by Rogerson, Shimer, and Wright (2005), this is the same as maximizing expected utility if the worker is risk neutral, of course, but also if (s)he is risk averse and markets are complete, since then (s)he can maximize utility by first maximizing income and then smoothing consumption.
} 
where $\iota_{t} \equiv M_{t} / U_{t}$ is the job-finding probability. Unemployment benefits, in units of final consumption, are a transfer from the government financed with lump-sum taxes. ${ }^{14}$ The term $\tilde{\Delta}_{t+1}^{W}$ denotes the average worker surplus:

$$
\tilde{\Delta}_{t}^{W}=\tilde{w}_{t}-\varpi_{t}+(1-\lambda) E_{t}\left\{\beta_{t, t+1}\left[1-G\left(z_{t+1}^{c}\right)\right] \tilde{\Delta}_{t+1}^{W}\right\}
$$

Finally, notice that firing costs affect the wage payment in the following way: The firm rewards the worker for the saving in firing costs today (the $F_{t}$ term in the square bracket in equation (6)), but it penalizes the worker for the fact that, in the case of firing, it will have to pay firing costs tomorrow.

In equilibrium, the worker's outside option is

$$
\varpi_{t} \equiv h_{p}+b_{t}+\left(\frac{\eta}{1-\eta}\right)\left[\kappa \vartheta_{t}+(1-\lambda) \iota_{t} E_{t}\left(\beta_{t, t+1} F_{t+1}\right)\right]
$$

which implies:

$w_{t}(z)=\eta\left[(1-\alpha) \varphi_{t} \frac{Y_{t}^{I}}{L_{t}}\left(\frac{z}{\tilde{z}_{t}}\right)^{1 /(1-\alpha)}+\kappa \vartheta_{t}+F_{t}-(1-\lambda)\left(1-\iota_{t}\right) E_{t} \beta_{t, t+1} F_{t+1}\right]+(1-\eta)\left(h_{p}+b_{t}\right)$,

where $\vartheta_{t} \equiv V_{t} / U_{t}$ denotes labor market tightness.

\section{Non-Tradable Sector}

There is a continuum of monopolistically competitive firms, each producing a different non-traded variety $\omega$. Following the language convention of most of the macroeconomic literature, we assume coincidence between a producer, a product, and a firm. However, as in Bilbiie, Ghironi, and Melitz (2012), each unit in the model is best interpreted as a production line that could be part of a multi-product firm whose boundary is left undetermined. In this interpretation, producer entry and exit capture the product-switching dynamics within firms documented by Bernard, Redding, and Schott (2010).

The number of firms serving the market is endogenous. Prior to entry, firms face a sunk entry cost $f_{E, t}$, in units of consumption. ${ }^{15}$ Sunk entry costs reflect both a technological constraint $\left(f_{T, t}\right)$

\footnotetext{
${ }^{14}$ The distinction between home production and unemployment benefits follows Mortensen and Pissarides (2002).

${ }^{15}$ Bilbiie, Ghironi, and Melitz (2012) and Ghironi and Melitz (2005) assume that the same input is used to produce existing varieties and create new ones. We considered an alternative version of the model in which entry costs are denominated in units of the intermediate input. None of our results is significantly affected by the denomination of
} 
and administrative costs related to regulation $\left(f_{R, t}\right)$, i.e., $f_{E, t} \equiv f_{T, t}+f_{R, t}$. In every period $t$, there is an unbounded mass of prospective entrants in the final goods sector in each country. All firms that enter the economy produce in every period until they are hit by a "death" shock, which occurs with probability $\delta \in(0,1)$ in every period. As noted by Bilbiie, Ghironi, and Melitz (2012), the assumption of exogenous exit is a reasonable starting point for analysis, since, in the data, product destruction and plant exit rates are much less cyclical than product creation and plant entry (see Lee and Mukoyama, 2008 and Broda and Weinstein, 2010).

Denote with $Y_{t}^{N}$ aggregate demand of the consumption basket of non-tradable goods. Aggregate demand includes sources other than household consumption but takes the same translog form as the consumption bundle $C_{t}^{N}$. This ensures that the non-tradable consumption price index is also the price index for aggregate demand of the non-tradable basket. The producer $\omega$ faces the following demand for its output:

$$
y_{t}^{N}(\omega)=\sigma \ln \left(\frac{\bar{p}_{t}^{N}}{p_{t}^{N}(\omega)}\right) \frac{P_{t}^{N} Y_{t}^{N}}{p_{t}^{N}(\omega)},
$$

where $\ln \bar{p}_{t}^{N} \equiv\left(1 / \sigma N_{t}\right)+\left(1 / N_{t}\right) \int_{\omega \in \Omega_{t}} \ln p_{t}^{N}(\omega) d \omega$ is the maximum price that a domestic producer can charge while still having a positive market share. To gain some intuition about the firm demand structure, notice that firm revenue, $p_{t}^{N}(\omega) y_{t}^{N}(\omega)$, is a time-varying fraction of the aggregate demand $P_{t}^{N} Y_{t}^{N}$. The firm's time-varying market share, $\sigma \ln \left(\bar{p}_{t}^{N} / p_{t}^{N}(\omega)\right)$, depends on the price chosen by the firm relative to the maximum admissible price.

We introduce price stickiness by following Rotemberg (1982) and assuming that final producers must pay a quadratic price adjustment cost $\Gamma_{t}^{N}(\omega) \equiv \nu\left(\pi_{t}^{N}(\omega)\right)^{2} p_{t}^{N}(\omega) y_{t}^{N}(\omega) / 2$, where $\nu \geq 0$ determines the size of the adjustment cost (prices are flexible if $\nu=0$ ) and $\pi_{t}^{N}(\omega) \equiv$ $\left(p_{t}^{N}(\omega) / p_{\omega, t-1}^{N}(\omega)\right)-1 .^{16}$ When a new final-good firm sets the price of its output for the first time, we appeal to symmetry across producers and interpret the $t-1$ price in the expression of the price adjustment cost as the notional price that the firm would have set at time $t-1$ if it had been producing in that period. An intuition for this simplifying assumption is that all producers (even those that are setting the price for the first time) must buy the bundle of goods $\Gamma_{t}^{N}(\omega) / P_{t}$ when implementing a price decision. ${ }^{17}$

\footnotetext{
sunk entry costs.

${ }^{16}$ The total real adjustment cost can be interpreted as the bundle of goods that the firm needs to purchase when implementing a price change. The size of this bundle is assumed to be larger when the size of the firm (measured by its revenue) increases.

${ }^{17}$ As noted in Bilbiie, Ghironi and Melitz (2008), this assumption is consistent with both Rotemberg (1982) and our timing assumption below. Specifically, new entrants behave as the (constant number of) price setters in Rotemberg, where an initial condition for the price is dictated by nature. In our framework, new entrants at any time $t$ who start producing and setting prices at $t+1$ are subject to an analogous assumption. Moreover, the assumption that
} 
Per-period (real) profits are given by

$$
d_{t}^{N}(\omega)=\left(\frac{p_{t}^{N}(\omega)}{P_{t}}-\varphi_{t}\right) y_{t}^{N}(\omega)-\frac{\Gamma_{t}^{N}(\omega)}{P_{t}}
$$

All profits are returned to households as dividends. Firms maximize the expected present discounted value of the stream of current and future real profits: $E_{t}\left[\sum_{s=t}^{\infty} \beta_{t, s}(1-\delta)^{s-t} d_{s}^{N}(\omega)\right]$. Future profits are discounted with the Home household's stochastic discount factor, as Home households are assumed to own Home final goods firms. As discussed below, there is a probability $\delta \in(0,1)$ that each final good producer is hit by an exogenous, exit-inducing shock at the end of each period. Therefore, discounting is adjusted for the probability of firm survival.

Optimal price setting implies that the real output price is equal to a markup $\mu_{t}(\omega)$ over marginal $\operatorname{cost} \varphi_{t}$ :

$$
\frac{p_{t}^{N}(\omega)}{P_{t}}=\mu_{t}^{N}(\omega) \varphi_{t}
$$

The endogenous, time-varying markup $\mu_{t}^{N}(\omega)$ is given by

$$
\mu_{t}^{N}(\omega) \equiv \frac{\theta_{t}^{N}(\omega)}{\left[\theta_{t}^{N}(\omega)-1\right] \Xi_{t}^{N}(\omega)}
$$

where $\theta_{t}^{N}(\omega) \equiv-\partial \ln y_{t}^{N}(\omega) / \partial \ln \left(p_{t}^{N}(\omega) / P_{t}\right)$ denotes the price elasticity of total demand for variety $\omega$, and:

$\Xi_{t}^{N}(\omega) \equiv 1-\frac{\nu}{2}\left(\pi_{t}^{N}(\omega)\right)^{2}+\frac{\nu}{\theta_{t}(\omega)-1}\left\{\begin{array}{c}\left(\pi_{t}^{N}(\omega)+1\right) \pi_{t}^{N}(\omega) \\ -E_{t}\left[\beta_{t, t+1}(1-\delta)\left(\pi_{t+1}^{N}(\omega)+1\right) \pi_{t+1}^{N}(\omega) \frac{\rho_{t+1}^{N}(\omega)}{\rho_{t}^{N}(\omega)}\left(\frac{y_{t+1}^{N}(\omega)}{y_{t}^{N}(\omega)}\right)\right]\end{array}\right\}$

There are two sources of endogenous markup variation in our model: First, translog preferences imply that substitutability across varieties increases with the number of available varieties. As a consequence, the price elasticity of total demand facing producer $\omega$ increases when the number of Home producers is larger. Second, price stickiness introduces an additional source of markup variation as the cost of adjusting prices gives firms an incentive to change their markups over time in order to smooth price changes across periods. When prices are flexible $(\nu=0)$, only the first

a new entrant, at the time of its first price decision, knows what will turn out to be the average Home product price last period is consistent with the assumption that entrants start producing only one period after entry, hence being able to observe the average product price during the entry period. Symmetry of the equilibrium will imply $p_{t-1}^{N}(\omega)=p_{t-1}^{N} \forall \omega$. Bilbiie, Ghironi and Melitz (2008) show that relaxing the assumption that new price setters are subject to the same rigidity as incumbents yields significantly different results only if the average rate of product turnover is unrealistically high. 
source of markup variation is present, and the markup reduces to $\theta_{t}^{N}(\omega) /\left(\theta_{t}^{N}(\omega)-1\right)$.

Producer Entry and Exit Prospective entrants are forward-looking and form rational expectations of their future profits $d_{s}$ in any period $s>t$ subject to the exogenous probability $\delta$ of incurring an exit-inducing shock at the end of each period. Following BGM and Ghironi and Melitz (2005), we introduce a time-to-build lag in the model and assume that entrants at time $t$ will start producing only at $t+1$. Our assumptions on exit shocks and the timing of entry and production imply that the law of motion for the number of producing Home firms is given by $N_{t}=(1-\delta)\left(N_{t-1}+N_{E, t-1}\right)$.

Prospective entrants compute their expected post-entry value $e_{t}^{N}$, given by the expected present discounted value of the stream of per-period profits: $e_{t}^{N}(\omega)=E_{t}\left[\sum_{s=t+1}^{\infty} \beta_{t, s}(1-\delta)^{s-t} d_{s}^{N}(\omega)\right]$. Entry occurs until firm value is equalized to the entry cost, leading to the free entry condition $e_{t}^{N}(\omega)=f_{E, t}$, which in turn implies symmetry across incumbents, i.e., $e_{t}^{N}(\omega)=e_{t}^{N}$ for any $\omega$.

Equality of prices across firms implies $p_{t}^{N}(\omega)=p_{t}^{N}$. Denote the real price of each variety, in units of consumption, with $\rho_{\omega, t}^{N} \equiv p_{t}^{N} / P_{t}$, where we maintain the subscript $\omega$ to avoid confusion with the real price of the non-tradable consumption basket, $\rho_{t}^{N} \equiv P_{t}^{N} / P_{t}$. Household's preferences imply that the non-tradable price index $P_{t}^{N}$ and the firm-level price $p_{t}^{N}$ are such that

$$
\frac{p_{t}^{N}}{P_{t}^{N}} \equiv \frac{\rho_{\omega, t}^{N}}{\rho_{t}^{N}}=\exp \left\{-\frac{\tilde{N}-N_{t}}{2 \sigma \tilde{N} N_{t}}\right\}
$$

where $\exp (X)$ denotes the exponential of $X$ to avoid confusion with the notation for firm value. Producer output is $y_{t}^{N}=\left(\rho_{t}^{N} / \rho_{\omega, t}^{N}\right)\left(Y_{t}^{N} / N_{t}\right)$, while the real quadratic cost of adjusting prices is given by $\Gamma_{t}^{N} / P_{t} \equiv \nu\left(\pi_{\omega, t}^{N}\right)^{2} \rho_{t}^{N}\left(Y_{t}^{N} / N_{t}\right) / 2$. Finally, the elasticity of substitution across non-tradable varieties is $\theta_{t}^{N}=1+\sigma N_{t}$, while the endogenous, time-varying markup is $\mu_{t}^{N} \equiv \theta_{t}^{N} /\left[\left(\theta_{t}^{N}-1\right) \Xi_{t}^{N}\right]$, where

$\Xi_{t}^{N} \equiv 1-\frac{\nu}{2}\left(\pi_{\omega, t}^{N}\right)^{2}+\frac{\nu}{\theta_{t}^{N}-1}\left\{\left(\pi_{\omega, t}^{N}+1\right) \pi_{\omega, t}^{N}-(1-\delta) E_{t}\left[\beta_{t, t+1}\left(\pi_{\omega, t+1}^{N}+1\right) \pi_{\omega, t+1}^{N} \frac{\rho_{t+1}^{N} Y_{t+1}^{N}}{\rho_{t}^{N} Y_{t}^{N}} \frac{N_{t}}{N_{t+1}}\right]\right\}$.

\section{Tradable Sector}

In each country, a unit mass of perfectly competitive, symmetric firms produce a tradable consumption good, $Y_{t}^{T}$. Production requires both intermediate inputs and non-tradable goods. When serving the export market, producers face per-unit iceberg trade costs, $\tau_{t}>1$. Thus, in equilibrium, $Y_{t}^{T}=C_{D, t}^{T}+\tau_{t} C_{X, t}^{T}$, where $C_{D, t}^{T}$ and $C_{X, t}^{T}$ denote, respectively, the domestic and foreign demand 
for the Home tradable good, introduced before. The production function is

$$
Y_{t}^{T}=\left(Y_{T, t}^{I}\right)^{\xi}\left(Y_{T, t}^{N}\right)^{1-\xi}
$$

where $Y_{T, t}^{I}$ and $Y_{T, t}^{N}$ denote, respectively, the amount of intermediate inputs and non-tradable goods used in the production of the tradable good.

Under perfect competition, Home and Foreign producers take the price of output as given, both in the domestic and export markets. No arbitrage implies that the price of export (in units of Foreign currency) is $P_{X, t}^{T}=\tau_{t} P_{D, t}^{T} / S_{t}$, where $S_{t}$ denotes the nominal exchange rate. Let $d_{t}^{T}$ denote per-period profits, defined by $d_{t}^{T}=\left(P_{D, t}^{T} / P_{t}\right) C_{D, t}^{T}+\left(S_{t} P_{X, t}^{T} / P_{t}\right) C_{X, t}^{T}-\varphi_{t} Y_{T, t}^{I}-\left(P_{t}^{N} / P_{t}\right) Y_{T, t}^{N}$. Notice that, using the above results, $d_{t}^{T}$ can be expressed as

$$
d_{t}^{T}=\rho_{D, t}^{T}\left(Y_{T, t}^{I}\right)^{\xi}\left(Y_{T, t}^{N}\right)^{1-\xi}-\left(\varphi_{t} Y_{T, t}^{I}+\rho_{t}^{N} Y_{T, t}^{N}\right)
$$

where $\rho_{D, t}^{T} \equiv P_{D, t}^{T} / P_{t}$ is the real price, in units of Home consumption, of the tradable consumption basket. The representative producer chooses the production inputs in order to maximize the expected present discounted value of the stream of real profits, $E_{t}\left(\sum_{s=t}^{\infty} \beta_{s, t} d_{s}^{T}\right)$. The first-order, optimal conditions for $Y_{T t}^{I}$ and $Y_{T s}^{N}$ imply, respectively:

$$
\begin{gathered}
\xi \rho_{D, t}^{T}\left(C_{D, t}^{T}+\tau_{t} C_{X, t}^{T}\right)=\varphi_{t} Y_{T, t}^{I} \\
(1-\xi) \rho_{D, t}^{T}\left(C_{D, t}^{T}+\tau_{t} C_{X, t}^{T}\right)=\rho_{t}^{N} Y_{T, t}^{N} .
\end{gathered}
$$

Finally, the real export price, in units of Foreign consumption, is $\rho_{X, t}^{T} \equiv P_{X, t}^{T} / P_{t}^{*}=\tau_{t} P_{D, t}^{T} / Q_{t}$, where $Q_{t} \equiv P_{t}^{*} S_{t} / P_{t}$ denotes the consumption-based real exchange rate. ${ }^{18}$

\section{Household Budget Constraint and Intertemporal Decisions}

The representative household can invest in two types of financial assets: shares in a mutual fund of non-tradable-sector firms and a non-contingent, internationally traded bond denominated in units of the common currency. ${ }^{19}$ In addition, the household owns the total stock of capital of the economy.

Investment in the mutual fund of non-tradable-sector firms in the stock market is the mech-

\footnotetext{
${ }^{18}$ To see this, recall that $P_{X, t}^{T}=\tau_{t} P_{D, t}^{T} / S_{t}$. Thus: $\rho_{X, t}^{T} \equiv\left(P_{X, t}^{T} / P_{t}^{*}\right)=\left(\tau_{t} P_{D, t}^{T} / P_{t}\right)\left(P_{t} / S_{t} P_{t}^{*}\right)=\tau_{t} \rho_{D, t}^{T} / Q_{t}$.

${ }^{19}$ For simplicity, we assume extreme home bias in equity holdings and rule out international trade in firm shares.
} 
anism through which household savings are made available to prospective entrants to cover their entry costs. Since there is no entry in the intermediate and tradable sectors (and, therefore, no need to channel resources from households for the financing of such entry), we do not model trade in intermediate- and tradable-sector equities explicitly. We also assume that the profits of intermediate-sector firms are rebated to households in lump-sum fashion. ${ }^{20}$ Profits in the tradable sector are zero in equilibrium.

Let $x_{t}$ be the share in the mutual fund of Home non-tradable-sector firms held by the representative household entering period $t$. The mutual fund pays a total profit in each period (in units of currency) that is equal to the total profit of all firms that produce in that period, $N_{t} d_{t}^{N}$. During period $t$, the representative household buys $x_{t+1}$ shares in a mutual fund of $N_{t}+N_{E, t}$ firms (those already operating at time $t$ and the new entrants). Only a fraction $1-\delta$ of these firms will produce and pay dividends at time $t+1$. Since the household does not know which firms will be hit by the exogenous exit shock $\delta$ at the end of period $t$, it finances the continuing operation of all pre-existing firms and all new entrants during period $t$. The date $t$ price of a claim to the future profit stream of the mutual fund of $N_{t}+N_{E, t}$ firms is equal to the nominal price of claims to future profits of Home firms, $P_{t} e_{t}^{N}$.

International asset markets are incomplete, since only a non-contingent bond is traded across countries. Let $A_{t+1}\left(A_{t+1}^{*}\right)$ denote nominal bond holdings at Home (Foreign) entering period $t+1$. To induce steady-state determinacy and stationary responses to temporary shocks in the model, we follow Turnovsky (1985) and, more recently, Benigno (2009), and we assume a quadratic cost of adjusting bond holdings $\psi\left(A_{t+1} / P_{t}\right)^{2} / 2$ (in units of Home consumption). This cost is paid to financial intermediaries whose only function is to collect these transaction fees and rebate the revenue to households in lump-sum fashion.

The household accumulates the physical capital and rents it to intermediate input producers in a competitive capital market. Investment in the physical capital stock, $I_{K, t}$, requires the use of the same composite of all available varieties as the basket $C_{t}$. As standard practice in the literature, we introduce convex adjustment costs in physical investment and variable capital utilization in order to account for the smooth behavior of aggregate investment and the pronounced cyclical variability in capacity utilization observed in the data. ${ }^{21}$ We assume that the utilization rate of

\footnotetext{
${ }^{20}$ As long as the wage negotiated by workers and firms is inside the bargaining set (and, therefore, smaller than or equal to the firm's outside option), the surplus from a match that goes to the firm is positive, even if intermediate producers are perfectly competitive. Since all workers are identical, the total surplus of the intermediate sector is positive, and so is the profit rebated to households.

${ }^{21}$ For simplicity, we do not provide a microfoundation of capital market frictions. Reduced-form investment adjust-
} 
capital is set by the household. ${ }^{22}$ Thus, effective capital rented to firms, $K_{t}$, is the product of physical capital, $\tilde{K}_{t}$, and the utilization rate, $u_{K, t}: K_{t}=u_{K, t} \tilde{K}_{t}$. Increases in the utilization rate are costly because higher utilization rates imply faster depreciation rates. Following Greenwood, Hercowitz, and Huffman (1988) and Burnside and Eichenbaum (1996), we assume the following convex depreciation function: $\delta_{K, t} \equiv \varkappa u_{K, t}^{1+\varsigma} /(1+\varsigma)$. Physical capital, $\tilde{K}_{t}$, obeys a standard law of motion:

$$
\tilde{K}_{t+1}=\left(1-\delta_{K, t}\right) \tilde{K}_{t}+I_{K, t}\left[1-\frac{\nu_{K}}{2}\left(\frac{I_{K, t}}{I_{K, t-1}}-1\right)^{2}\right],
$$

where $\nu>0$ is a scale parameter.

The per-period real household's budget constraint is:

$$
\begin{gathered}
\left.A_{t+1}+P_{t} \frac{A_{t+1}}{P_{t}}\right)^{2}+P_{t} C_{t}+x_{t+1}\left(N_{t}+N_{E, t}\right) P_{t} e_{t}^{N}+P_{t} I_{K, t}= \\
=\left(1+i_{t}\right) A_{t}+P_{t}\left(d_{t}^{N}+e_{t}^{N}\right) N_{t} x_{t}+P_{t} \tilde{w}_{t} L_{t}+P_{t} r_{t} K_{t}+P_{t} b\left(1-L_{t}\right)+P_{t} d_{t}^{I}+T_{t}^{g}+T_{t}^{A},
\end{gathered}
$$

where $i_{t}$ is the nominal interest rate on the internationally traded bond, $T_{t}^{g}$ is a nominal lumpsum transfer (or tax) from the government, and $T_{t}^{A}$ is the lump-sum rebate of the nominal cost of adjusting bond holdings from the financial intermediaries. We use the timing convention in Obstfeld and Rogoff (1995) for the nominal interest rate: $i_{t+1}$ is the interest rate between $t$ and $t+1$, and it is known with certainty in period $t$.

The household maximizes its expected intertemporal utility subject to (10) and (11). The Euler equation for capital accumulation requires: $\zeta_{K, t}=E_{t}\left\{\beta_{t, t+1}\left[r_{t+1} u_{K, t+1}+\left(1-\delta_{K, t+1}\right) \zeta_{K, t+1}\right]\right\}$, where $\zeta_{K, t}$ denotes the shadow value of capital (in units of consumption), defined by the first-order condition for investment $I_{K, t}$ :

$$
\begin{aligned}
\zeta_{K, t}^{-1} & =\left[1-\frac{\nu_{K}}{2}\left(\frac{I_{K, t}}{I_{K, t-1}}-1\right)^{2}-\nu_{K}\left(\frac{I_{K, t}}{I_{K, t-1}}-1\right)\left(\frac{I_{K, t}}{I_{K, t-1}}\right)\right] \\
& +\nu_{K} \beta_{t, t+1} E_{t}\left[\frac{\zeta_{K, t+1}}{\zeta_{K, t}}\left(\frac{I_{K, t+1}}{I_{K, t}}-1\right)\left(\frac{I_{K, t+1}}{I_{K, t}}\right)^{2}\right] .
\end{aligned}
$$

The optimality condition for capital utilization implies: $r_{t}=\varkappa u_{K, t}^{1+\varsigma} \zeta_{K, t}$. Finally, let $a_{t+1} \equiv A_{t+1} / P_{t}$ ment costs feature prominently in the literature on dynamic stochastic general equilibrium models; see Fiori (2012) and references therein.

${ }^{22}$ Our assumption that households make the capital accumulation and utilization decisions is standard in the literature. At the cost of more complicated notation, we could work with an alternative decentralization scheme in which firms make these decisions (leaving the model unaffected). 
denote Home real bond holdings. Euler equations for bond and share holdings are:

$$
1+\psi a_{t+1}+\Lambda_{a t}=\left(1+i_{t+1}\right) E_{t}\left(\frac{\beta_{t, t+1}}{1+\pi_{C, t+1}}\right) \quad \text { and } \quad e_{t}^{N}=(1-\delta) E_{t}\left[\beta_{t, t+1}\left(d_{t+1}^{N}+e_{t+1}^{N}\right)\right]
$$

where the term $\Lambda_{a t}$ captures a risk-premium shock that affects households' demand for risk-free assets. We assume that $\Lambda_{a t}$ follows a zero-mean autoregressive process: $\Lambda_{a t}=\rho_{\varepsilon_{a}} \Lambda_{a t-1}+\epsilon_{a t}$, where $\epsilon_{a t} \stackrel{i . i . d .}{\sim} N\left(0, \sigma_{\epsilon_{a}}^{2}\right)$. As in Smets and Wouters (2007) and subsequent literature, the shock is specified as an exogenous term appended to the representative household's Euler equation for bond holdings. As shown by Fisher (2015), the shock $\Lambda_{a t}$ can be interpreted as a structural shock to the demand for safe and liquid assets, i.e., $\Lambda_{a t}$ captures, in reduced form, stochastic fluctuations in household's preferences for holding one-period nominally risk-free assets. ${ }^{23}$ The Euler equation for bond holdings in the Foreign economy features a similar risk-premium shock, denoted with $\Lambda_{a t}^{*}$. For the purposes of our exercise, we assume that $\Lambda_{a t}$ and $\Lambda_{a t}^{*}$ are perfectly correlated, i.e., $\Lambda_{a t}=\Lambda_{a t}^{*}$ in each period.

\section{Equilibrium}

In equilibrium, $x_{t}=x_{t+1}=1, T_{t}^{g}=-P_{t} b\left(1-L_{t}\right)$, and $T_{t}^{A}=P_{t}(\psi / 2)\left(A_{t+1} / P_{t}\right)^{2}$. Aggregate demand of the final consumption basket must be equal to the sum of market consumption, investment in physical capital, and the costs associated to product creation, job creation, and job destruction:

$$
Y_{t}^{C}=C_{t}+I_{K, t}+\kappa V_{t}+\frac{G\left(z_{t}^{c}\right) L_{t}}{1-G\left(z_{t}^{c}\right)} F_{t}
$$

Labor market clearing requires:

$$
Z_{t} \tilde{z}_{t} K_{t}^{\alpha} L_{t}^{1-\alpha}=\exp \left\{\frac{\tilde{N}-N_{t}}{2 \sigma \tilde{N} N_{t}}\right\} Y_{t}^{N}+Y_{T, t}^{I} .
$$

In equilibrium, total aggregate demand for the non-tradable good is

$$
Y_{t}^{N}=\left(1-\frac{\nu}{2}\left(\pi_{\omega, t}^{N}\right)^{2}\right)^{-1}\left(C_{t}^{N}+Y_{T, t}^{N}\right)
$$

\footnotetext{
${ }^{23}$ Notice that the risk-premium shock is isomorphic to a discount factor shock (a "beta shock") only up to a firstorder approximation. With a flexible exchange rate, the risk-premium shock could also be interpreted as a shock to the uncovered interest rate parity (adjusted for the presence of bond adjustment costs). Details are available upon request.
} 
while market clearing in the tradable sector requires $C_{D, t}^{T}+C_{X, t}^{T}=\left(Y_{T, t}^{I}\right)^{\xi}\left(Y_{T, t}^{N}\right)^{1-\xi}$. The equilibrium price indexes imply:

$$
\begin{gathered}
1=\left(1-\alpha_{N}\right)\left(\rho_{t}^{T}\right)^{1-\phi_{N}}+\alpha_{N}\left(\rho_{t}^{N}\right)^{1-\phi_{N}}, \\
\rho_{t}^{T}=\left(1-\alpha_{X}\right)\left(\rho_{D, t}^{T}\right)^{1-\phi_{T}}+\alpha_{X}\left(\rho_{X, t}^{T^{*}}\right)^{1-\phi_{T}} .
\end{gathered}
$$

Bonds are in zero net supply, which implies the equilibrium condition $a_{t+1}+Q_{t} a_{t+1}^{*}=0$ in all periods. Net foreign assets are determined by:

$$
a_{t+1}=\frac{1+i_{t}}{1+\pi_{C t}} a_{t}+T B_{t}
$$

where $T B_{t} \equiv Q_{t} \rho_{X, t}^{T} C_{X, t}^{T}-\rho_{X, t}^{T^{*}} C_{X, t}^{T^{*}}$ denotes the trade balance. Finally, since in the currency union the nominal exchange rate is constant and equal to one, the dynamics of the real exchange rate are tied to the inflation differential between Home and Foreign: $Q_{t} / Q_{t-1}=\left(1+\pi_{C, t}^{*}\right) /\left(1+\pi_{C, t}\right)$.

\section{Monetary Policy}

The ECB has a mandate of price stability defined in terms of a (harmonized) index of consumer price inflation. Since we will calibrate the model to features of EMU, we specify historical interest rate setting for our model ECB as a rule in which policy responds to movements in a country-weighted average of CPI inflation and GDP gaps relative to the equilibrium with flexible prices.

In the presence of endogenous producer entry and preferences that exhibit "love for variety," an issue concerns the empirically relevant variables that enter the theoretical representation of monetary policy. As highlighted by Ghironi and Melitz (2005), when the economy experiences entry of Home and Foreign firms, the welfare-consistent non-tradable price index $P_{t}^{N}$ can fluctuate even if product prices remain constant. ${ }^{24}$ In the data, however, aggregate price indexes do not take these variety effects into account. ${ }^{25}$ To resolve this issue, we follow Ghironi and Melitz (2005) and introduce the data-consistent price index, $\tilde{P}_{t}$. In turn, given any variable $X_{t}$ in units of consumption,

\footnotetext{
${ }^{24}$ The term $(1 / 2 \sigma)\left(1 / N_{t}-1 / \tilde{N}\right)$ in equation (1) implies that even if prices are the same for all goods, the expenditure needed to reach a certain level of consumption declines with $N_{t}$. Thus, provided that $\sigma>0$, the utility function from the translog expenditure function exhibits love of variety.

${ }^{25}$ There is much empirical evidence that gains from variety are mostly unmeasured in CPI data, as documented most recently by Broda and Weinstein (2010). Furthermore, the adjustment for variety neither happens at the frequency represented by periods in the model, nor using the specific functional form for preferences that the model assumes.
} 
we then construct its data-consistent counterpart as $X_{R t} \equiv X_{t} \tilde{\rho}_{t}$, where $\tilde{\rho}_{t} \equiv P_{t} / \tilde{P}_{t}$. (Additional details, including the analytical expression for $\tilde{\rho}_{t}$, are presented in the Appendix.)

We assume that the central bank sets the nominal interest rate for the entire union following the rule:

$$
1+i_{t+1}=\left(1+i_{t}\right)^{\varrho_{i}}\left[(1+i)\left(1+\tilde{\pi}_{C, t}^{U}\right)^{\varrho_{\pi}}\left(\tilde{Y}_{g, t}^{U}\right)^{\varrho_{Y}}\right]^{1-\varrho_{i}}
$$

where $i$ denotes the steady-state value of the nominal interest rate, $\tilde{\pi}_{C, t}^{U} \equiv \tilde{\pi}_{C, t}^{\gamma_{\pi}} \tilde{\pi}_{C, t}^{*^{1-\gamma_{\pi}}}$ is the dataconsistent, union-wide CPI inflation, and $\tilde{Y}_{g, t}^{U} \equiv \tilde{Y}_{g, t}^{\gamma_{\tilde{Y}}} \tilde{Y}_{g, t}^{* 1-\gamma_{\tilde{Y}}}$ is the data-consistent, union-wide GDP gap. Home data-consistent CPI inflation is given by

$$
1+\tilde{\pi}_{C t} \equiv \frac{\tilde{P}_{t}}{\tilde{P}_{t-1}}=\frac{\tilde{\rho}_{t}}{\tilde{\rho}_{t-1}}\left(1+\pi_{C t}\right) .
$$

The data-consistent Home output gap, $\tilde{Y}_{g t} \equiv Y_{R t} / Y_{R}$, represents deviations of data-consistent GDP, $Y_{R t} \equiv Y_{t} / \tilde{\rho}_{t}$, from its level under flexible prices. We use the NIPA definition of GDP as total income: $Y_{t} \equiv \tilde{w}_{t} L_{t}+r_{t} K_{t}+N_{t} d_{t}^{N}+d_{t}^{I}$, which equals the sum of consumption, investment in physical capital, product creation expenses, and the trade balance: $Y_{t}=C_{t}+I_{t}+T B_{t}$, where $I_{t} \equiv I_{K, t}+N_{E, t}\left(f_{R, t}+f_{T}\right)$ denotes total investment (the sum of investment in physical capital and product creation). ${ }^{26}$

We take explicitly into account the possibility that the nominal interest rate cannot fall below some lower bound $i^{z l b}$, so that in each period $i_{t+1} \geqslant i^{z l b}$. Therefore, the interest rate in the currency union satisfies:

$$
1+i_{t+1}=\max \left\{1+i^{z l b},\left(1+i_{t}\right)^{\varrho_{i}}\left[(1+i)\left(1+\tilde{\pi}_{C, t}^{U}\right)^{\varrho_{\pi}}\left(\tilde{Y}_{g, t}^{U}\right)^{\varrho_{Y}}\right]^{1-\varrho_{i}}\right\}
$$

In equilibrium, there is a total of 58 equations that determine 58 endogenous variables: $C_{t}$, $C_{t}^{N}, C_{t}^{T}, C_{D, t}^{T}, C_{X, t}^{T}, \varphi_{t}, \rho_{t}^{N}, \rho_{\omega, t}^{N}, \rho_{t}^{T}, \rho_{D, t}^{T}, Y_{T t}^{I}, Y_{T t}^{N}, Y_{t}^{C}, Y_{t}^{T}, Y_{t}^{N}, \pi_{t}^{C}, \pi_{\omega, t}^{N}, N_{t+1}, N_{E t}, L_{t}, V_{t}$, $M_{t}, z_{t}^{c}, \tilde{K}_{t+1}, u_{K, t}, I_{K, t}, \zeta_{K, t}, a_{t+1}$, their Foreign counterparts, and $i_{t+1}$ and $Q_{t}$. Additionally, the model features nine exogenous variable: the aggregate productivity processes, $Z_{t}$ and $Z_{t}^{*}$, the risk-premium shock, $\Lambda_{a t}$, and the exogenous stochastic processes for market regulation: red-tape

\footnotetext{
${ }^{26}$ The inclusion of product creation expenses in $Y_{t}$ is consistent with the fact that intangible capital and nonresidential structures (the technological components of the entry cost) are accounted for by statistical agencies when constructing GDP; see the documentation available at http://ec.europa.eu/eurostat/statistics-explained. Moreover, the cost of complying with legal requirements of market entry involves the purchase of goods and services, over and beyond licence fees; see Djankov, Porta, Lopez-De-Silanes, and Shleifer (2002).
} 
entry costs, $f_{R t}$ and $f_{R t}^{*}$, unemployment benefits, $b_{t}$ and $b_{t}^{*}$, and firing costs, $F_{t}$ and $F_{t}^{*}$. Table 1 summarizes the key equilibrium conditions of the model. (For brevity, the Foreign counterparts of the first 27 equations are omitted. The variables $s_{t}, q_{t}, \tilde{z}_{t}, \mu_{t}, \rho_{X}^{T}, \tilde{\pi}_{C, t}$, and $\tilde{Y}_{g, t}$ that appear in the table depend on the above variables as previously described.)

\section{Calibration}

Given the nonlinear nature of the equilibrium conditions, the decision rules that determine present and future values of all the variables cannot be solved for analytically. Thus, we must assign specific values to the model parameters and solve for the decision rules numerically.

We assume a symmetric calibration across countries. ${ }^{27}$ We interpret periods as quarters and choose parameter values from the literature and to match features of euro area macroeconomic data from 1995:Q1 to 2013:Q1. Unless otherwise noted, data are taken from the Eurostat database. ${ }^{28}$ We use the NIPA definition of GDP as total income: $Y_{t}^{g} \equiv \tilde{w}_{t} L_{t}+r_{t}^{K} K_{t}+N_{t} d_{t}^{N}+d_{t}^{I}$, which equals the sum of consumption, investment in physical capital, product creation expenses, and the trade balance: $Y_{t}^{g}=C_{t}+I_{K t}+N_{E, t}\left(f_{R, t}+f_{T}\right)+T B_{t} \cdot{ }^{29}$ Below, variables without a time subscript denote steady-state values.

We use standard values for all the parameters that are conventional in the business cycle literature. We set the discount factor $\beta$ equal to 0.99 , the risk aversion $\gamma$ equal to 1 , the "share" parameter on capital in the Cobb-Douglas production function $\alpha$ equal to 0.33 , the capital depreciation rate $\delta_{K}$ equal to 0.025 , and the elasticity of marginal depreciation with respect to the utilization rate $\varsigma$ equal to $0.41 .^{30}$ We set consumption habit, $h_{C}$, equal to 0.6 , as estimated by Smets and Wouters (2004) for the euro area. We calibrate the elasticity of substitution between tradable and non-tradable goods, $\phi_{N}$, equal to 0.5 , consistent with the estimates for industrialized countries in Mendoza (1991). We set the elasticity of substitution between tradable goods pro-

\footnotetext{
${ }^{27}$ Our choice is motivated by the fact that the level of product and labor market regulation in the euro-area is rather homogenous across countries; see the Appendix for details. For robustness, we have repeated our exercises by considering an asymmetric calibration in which Home and Foreign feature characteristics of the periphery and core of the euro are, respectively. None of our results are significantly affected by this alternative parameterization. Details are available upon request.

${ }^{28}$ Data are available at http://epp.eurostat.ec.europa.eu

${ }^{29}$ The inclusion of product creation expenses in $Y_{t}^{g}$ is consistent with the fact that intangible capital and nonresidential structures (the technological components of the entry cost) are accounted for by statistical agencies when constructing GDP; see the documentation available at http://ec.europa.eu/eurostat/statistics-explained. Moreover, the cost of complying with legal requirements of market entry involves the purchase of goods and services, over and beyond licence fees; see Djankov, Porta, Lopez-De-Silanes, and Shleifer (2002).

${ }^{30}$ Although the term $1-\alpha$ does not necessarily correspond to the labor share (since the labor share in general depends on the outcome of the bargaining process), our conventional choice for $\alpha$ implies that $\tilde{w} L / Y=0.61$, in line with the data. For the period 1995-2013, the average labor share in the euro area is 0.62 .
} 
duced in Home and Foreign, $\phi_{T}$, equal to 6 , consistent with recent estimates provided by Imbs and Mejean (2015). ${ }^{31}$ For the bivariate productivity process, we set persistence and spillover parameters consistent with Baxter and Farr (2005), implying zero spillovers across countries and persistence equal to 0.999 . We set the elasticity of matches to unemployment, $\varepsilon$, equal to 0.6, the midpoint of estimates reported by Petrongolo and Pissarides (2006). To maintain comparability with much of the existing literature, we choose the worker's bargaining power parameter, $\eta$, such that the so-called Hosios condition is satisfied, i.e., $\eta=\varepsilon .^{32}$ The scale parameter for the cost of adjusting prices, $\nu$, is set is equal to 80, as in Bilbiie, Ghironi, and Melitz (2008). We set the lower-bound on the nominal interest rate such that $i^{z l b}=0$ and assume that $\pi_{C}=0 .{ }^{33}$ For comparability with EFG, we assume a zero-inflation targeting regime, i.e., we set the smoothing parameter and GDP gap weights, $\varrho_{i}$ and $\varrho_{Y}$, equal to zero, and set $\varrho_{\pi}$ arbitrarily large. ${ }^{34}$ Finally, we set $\tau=1$, which implies that the law of one price holds exactly for tradable goods. ${ }^{35}$

We calibrate the remaining parameters to match statistics from simulated data to empirical targets. Concerning the parameters that are specific to the product market, we set the firm exit rate, $\delta$, such that gross steady-state job destruction accounted for by firm exit is 25 percent, the midpoint of estimates in Haltiwanger, Scarpetta, and Schweiger (2006). (Their estimates for France, Germany, and Italy range between 20 and 30 percent.) In order to calibrate the entry costs related to regulation, $f_{R}$, we update the procedure in Ebell and Haefke (2009) and convert into months of lost output the OECD indicator for administrative burdens on start-ups (OECD, Product Market Regulation Database). See the Appendix for details. Following this procedure, the aggregate cost of product market regulation is 2 percent of GDP. ${ }^{36}$ We choose $f_{T}$ such that aggregate R\&D

\footnotetext{
${ }^{31}$ None of our main results are significantly affected if we use $\phi_{T}=1.5$, the standard value in the international business cycle literature.

${ }^{32}$ Absent other distortions, the Hosios condition requires the equality of the worker share of the surplus, $\eta$, and the worker's contribution to matching, $\varepsilon$. This implies that congestion and trading externalities that characterize the search and matching process exactly cancel out, leading to efficient job creation and destruction. In the presence of other distortions, the basic Hosios condition $\eta=\varepsilon$ must be adjusted to include an appropriate additional term in order to deliver efficiency. For simplicity of exposition and consistency with much literature (for instance, Arseneau and Chugh, 2012), we simply refer to the condition $\eta=\varepsilon$ as the Hosios condition.

${ }^{33}$ The exact level of either the inflation target or the bound on the interest rate is not central for our results. What we need is that a lower bound for the policy rate exists, thus preventing the monetary authority from providing additional stimulus. Our results are unaffected is we set $i^{z l b}=0$. The only difference relative to the baseline scenario is that the size of the risk-premium shock that makes the ZLB binding has to be rescaled.

${ }^{34}$ None of our results are significantly affected if we calibrate the coefficient of the monetary policy rule using historical values for the euro area estimated by Gerdesmeier and Roffia (2003). This requires setting the inflation and GDP gap weights equal to 1.93 and 0.075, respectively, and the smoothing parameter equal to 0.87.

${ }^{35}$ The absence of trade barriers from our model is consistent with the operation of the European Union's Single Market. Transition to the euro narrowed price dispersion across country markets (Martin and Mejean, 2013), supporting the law of one price as a reasonable first approximation to reality.

${ }^{36}$ The implied entry cost at the producer level is a loss of 1.3 months of steady-state firm's output.
} 
expenditures are 1.97 percent of GDP (OECD, Science and Technology Database). ${ }^{37}$ We set the price-elasticity of the spending share on individual goods, $\sigma$, such that the steady-state markup, $\mu$, is 25 percent, a weighted-average for the euro area of the estimates provided by Thum-Thysen and Canton (2015). We calibrate the degree of home bias, $\alpha_{N}$, and the size of the tradable sector, $\alpha_{T}$, to match a steady-state import share of 15 percent (corresponding to the average within-eurozone import share) and a steady-state output share of 38 percent in manufacturing (from the EU-KLEMS database). Finally, we set the share of non-tradable goods in the production of tradables, $\xi$, such that the share of manufacturing value added from services averages forty percent, as documented by Boeri, Castanheira, Faini, and Galasso (2006). This implies setting $\xi=0.6$.

We now turn to the parameters that are specific to the conventional search and matching framework. We set unemployment benefits such that the average benefit replacement rate, $b / \tilde{w}$, is 32 percent (OECD, Benefits and Wages Database, 2013). ${ }^{38}$ We choose the cost of posting a vacancy, $\kappa$, such that the steady-state hiring cost is 13 percent of the average wage, as estimated by Abowd and Kramarz (2003) for France. Following the argument in den Haan, Ramey, and Watson (2000), we assume that firms experiencing exogenous separations attempt to refill the positions by posting vacancies in the ensuing matching phase. Accordingly, we choose the exogenous separation rate, $\lambda^{x}$, so that the percentage of jobs counted as destroyed in a given year that fail to reappear in the following year is 71 percent, as reported by Gomez-Salvador, Messina, and Vallanti (2004) for the euro area as a whole. We set home production, $h_{p}$, the matching function constant, $\chi$, and firing costs, $F$, to match the total separation rate, $\lambda^{\text {tot }}$, the unemployment rate, $U$, and the probability of filling a vacancy, $q$. We set $U=0.09$, the average unemployment rate in our sample period, $q=0.6$, as reported by Weber $(2000)$, and $\lambda^{t o t}=0.036$, in line with the estimates in Hobijn and Sahin (2009). With these calibration targets, firing costs and home production amount, respectively, to 11 and 23 percent of the average wage. ${ }^{39}$

Three parameters are left to calibration: the lognormal scale and shape parameters, $\mu_{z_{i}}$ and $\sigma_{z_{i}}$, and the investment adjustment costs, $\nu$. As standard practice we choose $\nu$ such that the model reproduces the variability of investment in physical capital, $I_{K, t}$. Following den Haan, Ramey, and Watson (2000) and Krause and Lubik (2007), we normalize $\mu_{z_{i}}$ to zero and set $\sigma_{z_{i}}$ to match the

\footnotetext{
${ }^{37}$ The implied cost of non-regulatory entry barriers at the producer level is 65 percent of output per worker, a midpoint of the values used by Barseghyan and DiCecio (2011) for the U.S. economy.

${ }^{38}$ As before, we consider a weighted average of the unemployment benefits across euro area member countries.

${ }^{39}$ The implied value of $F$ is lower than the average value estimated for European countries, which is typically around 25 percent of yearly wages; see Doing Business Database, World Bank (2008). The reason for this discrepancy is that empirical estimates include severance payments, while, as explained before, the model does not.
} 
variability of unemployment relative to output. The model calibration is summarized in Table 2 .

\section{Market Reforms in Normal Times}

We begin to investigate the consequences of structural reforms by studying the dynamic adjustment to market deregulation assuming that the economy is at the non-stochastic steady state. We consider a permanent reduction of policy parameters in a perfect foresight environment: the policy shock comes as an initial surprise to agents, who then have perfect foresight from that moment on. ${ }^{40}$ Given the large size of the shocks, transition dynamics from the initial equilibrium to the final equilibrium are found by solving the model as a nonlinear, forward-looking, deterministic system using a Newton-Raphson method, as described in Laffargue (1990). This method solves simultaneously all equations for each period, without relying on low-order, local approximations.

We assume that policy parameters are lowered to their corresponding U.S. levels. ${ }^{41}$ To recalibrate entry costs related to regulation, $f_{R}$, we apply the same procedure described in Section 4 on U.S. data. The implied loss of steady-state firm's output is equal to 1 month. We assume that unemployment benefits corresponds to 28 percent of the average wage (OECD, Benefits and Wages Database, 2013), and set firing costs to zero as in Veracierto (2008). Since in the model unemployment benefits are financed with lump-sum taxes, the aggregate resource constraint is not directly affected by a cut in unemployment benefits. That is, in the model a cut in unemployment benefits only affects the worker's outside option at the bargaining stage, without directly changing household's income. In order to address this issue, we consider an alternative labor market reform which reduces the value of home production. We assume the same percentage reduction implied by the cut in unemployment benefits. ${ }^{42}$

The bottom panel of Figure 1 (continuous lines) shows the effects of a permanent decrease in barriers to entry $\left(f_{R}\right)$. In the aftermath of the reform, output and inflation increase. The reason is that producer entry initially increases aggregate demand, since in order to pay for sunk entry costs producers need to purchase final output. In turn, this boosts hiring, putting upward pressure

\footnotetext{
${ }^{40}$ Market reforms are usually the outcome of legislative processes such that implementation is anticipated by agents when it happens. This notwithstanding, treating reforms as unanticipated shocks remains a useful benchmark for analysis.

${ }^{41}$ We take the United States as the benchmark for market flexibility, but we make no presumption that U.S. market regulation levels should be optimal for other countries - or, for that matter, that they are optimal for the U.S. We leave optimal market regulation and reform in a dynamic stochastic macroeconomic framework as a topic for future study.

${ }^{42}$ Alternatively, we could change the baseline model assuming that both home production and unemployment benefits are exogenous endowments that contribute to household's income. The adjustment to a reduction in unemployment benefits in this case would be isomorphic to a reduction in home production
} 
on wages and the real marginal cost. Consumption declines in the short term, because profitable investment opportunities in new firms induce households to save more, offsetting the positive impact of higher expected future income on current consumption. With an open capital account, increased entry can also be financed by borrowing from abroad. As a result, the deregulating economy runs a current account deficit during the first part of the transition.

As new firms enter the market, fiercer competition in the non-tradable sector erodes the market share of incumbents, who downsize. This reduces the demand for the intermediate input, increasing job destruction. Since remaining jobs have higher productivity, the average real wage increasesaveraging out the wage equation (6) yields:

$$
\tilde{w}_{t}=\eta\left[(1-\alpha) Z_{t} \tilde{z}_{t}\left(\frac{K_{t}}{L_{t}}\right)^{\alpha}+F_{t}-(1-\lambda) E_{t}\left(\beta_{t, t+1} F_{t+1}\right)\right]+(1-\eta) \varpi_{t} .
$$

Other things equal, higher average wages increase the real marginal cost, $\varphi_{t}$ - see the job creation equation (4) - further contributing to maintain inflation above its pre-deregulation level. Labor market frictions further propagate the adjustment to deregulation. Since job creation induced by new entrants is a gradual process, the slow reallocation of workers across producers increases unemployment and lowers aggregate output. Once the number of producing firms in the deregulating economy has increased, the reduction in red-tape implies that more resources can be devoted to consumption and investment in physical capital. In addition, as jobs are reallocated to new entrants, unemployment falls, further boosting aggregate demand at Home and abroad. The larger number of available products results in higher goods substitutability and lower markups in the long run. ${ }^{43}$

The bottom panel of Figure 2 (continuous lines) plots the dynamic adjustment to a permanent reduction in firing costs. Deregulation, in this case, presents a different intertemporal trade-off. Lower firing costs reduce the profitability of low productive matches, increasing job destruction. At the same time, however, lower firing costs reduce the expected cost of terminating a match, boosting job creation. Since destroying existing jobs is an instantaneous process, while matching firms and workers takes time, employment, output, and consumption decrease in the aftermath of the reform but recover over time. Inflation is essentially unaffected following the removal of firing costs. The reason is that two offsetting forces are at work. On one side, lower aggregate demand reduces prices, other things equal. On the other, since only the more productive workers keep their

\footnotetext{
${ }^{43}$ In the Appendix, we present impulse responses for the Foreign economy. Home deregulation leads to a temporary reduction in Foreign GDP and employment. In the long run, there are positive, yet small, international spillovers.
} 
jobs, and because remaining workers are better paid, marginal labor costs rise. On net, the two effects largely cancel out.

It takes about one year for unemployment to fall below its pre-deregulation level. This happens because the expected present discounted value of job creation increases slowly over time, reflecting the production lag for new matches and the initial reduction in aggregate demand induced by firing. In the long run, GDP increases and unemployment falls. ${ }^{44}$

In contrast to a reduction in entry barriers or firing costs, a reform that lowers unemployment benefits does not have short-run contractionary effects. The reason is that lower unemployment benefits reduce the workers' outside option and boost job creation without increasing job destruction. Thus, as shown in the bottom panel of Figure 3 (continuous lines), unemployment gradually falls over time, with beneficial effects for aggregate consumption, output, and investment. Yet, the dynamics of inflation remain muted. This reflects again the existence of offsetting effects. Namely, while the reduction in the value of unemployment leads to wage moderation, higher job creation puts pressure on wages. Moreover, the reduction in job destruction lowers the average productivity of the pool of employed workers. ${ }^{45}$

As noted above, unemployment benefits can be either modeled as a transfer from the government financed by lump sum taxes or as an exogenous income endowment distributed to unemployed workers. In the former case, unemployment benefits do not directly affect aggregate demand in our representative household setup because benefits and lump sum taxes offset each other in the household's budget constraint. However, as shown in the Appendix, when considering a reduction in home production, $h_{P}$, the short-run adjustment mirrors the dynamics following a cut in unemployment benefits. This result suggests that, in a highly regulated economy, the beneficial effects on job creation and the destruction implied by a reduction of the worker's outside option dominate the potential costs associated with lower household consumption.

Finally, the bottom panel of Figure 4 (continuous lines) shows the adjustment to a joint reform in product and labor markets. Such a reform has inflationary effects in the first phase of the transition, and it stimulates output and employment immediately.

\footnotetext{
${ }^{44}$ As for product market deregulation, there are positive but small international spillovers from asymmetric deregulation. See the Appendix for details.

${ }^{45}$ Notice that both labor market reforms imply that the deregulating economy initially runs a current account surplus, which then turns into a deficit. Following the removal of firing costs, the surplus reflects the initial contractionary effects of the reform-Foreign households find it more profitable to invest domestically. By contrast, following the reduction in unemployment benefits, the initial current account surplus reflects the depreciation of Home's terms of trade and the corresponding surplus in the trade balance. Intuitively, wage moderation reduces the marginal cost of production at Home relatively to Foreign, inducing expenditure switching toward Home tradables goods.
} 
So far our analysis has not addressed an issue that has received significant attention in policy debates: the consequences of market reforms for productivity dynamics. Figure 5 presents the response of aggregate and sectoral labor productivity. We measure aggregate labor productivity as GDP per worker: $l p_{t} \equiv Y_{t} / L_{t}$. Sectoral labor productivity corresponds to the ratio of sectoral value added to sectoral employment. Thus, labor productivity in the non-tradable sector is $l p_{t}^{N T} \equiv$ $\rho_{t}^{N} Y_{t}^{N} / L_{t}^{N}$, where $L_{t}^{N}$ denotes the number of workers employed to produce the non-tradable output, while labor productivity in the tradable sector is $l p_{t}^{T} \equiv\left[\rho_{D, t}^{T}\left(C_{D, t}^{T}+\tau_{t} C_{X, t}^{T}\right)-\rho_{t}^{N} Y_{T, t}^{N}\right] / L_{t}^{T}$, where $L_{t}^{T}$ denotes the number of workers employed to produce the tradable output. ${ }^{46}$

To understand the dynamics in Figure 5, notice that three factors determine the dynamics of labor productivity. First, market reforms affect job destruction, with consequences for the average productivity of existing matches, $\tilde{z}_{t}$. Second, variety gains in the non-tradable sector induce efficiency gains in the production of both tradable and non-tradable consumption. Third, labor productivity responds to changes in capital per worker (due to time-varying capital utilization).

The first row in Figure 5 presents the dynamics of $l p_{t}$ across reforms. A reduction in barriers to entry (first column) leads to the largest long-run productivity gains, while a reduction in firing costs (second column) and unemployment benefits (third column) have more modest effects. Product market deregulation raises labor productivity mostly by increasing the number of non-tradable varieties. Importantly, higher labor productivity is not associated with lower prices because the initial increase in intermediate input demand is strong enough to increase the real marginal cost faced by final producers. The removal of firing costs increases the average productivity of existing matches, since relatively less productive jobs are destroyed. Finally, lowering unemployment benefits has an opposite effect, since the pool of relatively less productive workers increases due to lower wages. This explains why long-run productivity displays a small decline following the reduction of unemployment benefits.

Figure 5 also shows that the short-run response of labor productivity is larger relative to the long run. In the case of product market deregulation, short-run productivity gains are larger because of higher capital utilization (an increase in capital per worker)-producers rent more capital in order to meet the intermediate-input demand from new entrants, leading households to increase the capital utilization rate. The removal of firing costs leads to stronger short-run productivity

\footnotetext{
${ }^{46}$ Notice that GDP is not equal to the sum of sectoral value added, since aggregate value added also includes vacancy and firing costs. However, since the share of vacancy and firing costs over GDP is negligible, the dynamics of labor productivity are in practice equal to the sum of sectoral labor productivity (weighted by the corresponding employment share).
} 
gains because job destruction is not immediately accompanied by higher job creation, increasing the average productivity of existing matches.

Finally, the second and third rows in Figure 5 present the dynamics of sectoral productivitythe second row refers to $l p_{t}^{T}$, while the third row refers to $l p_{t}^{N T}$. There are two key messages. First, sectoral labor productivities comove positively in response to market reforms. Second, labor productivity in the tradable sector responds more than non-tradable labor productivity - in particular following a reduction in barriers to entry. Both effects reflect input-output linkages, i.e., the productivity spillovers from the non-tradable sector to the tradable sector.

\section{Market Deregulation at the Zero Lower Bound}

We next investigate how the short-run transmission mechanism of structural reforms changes in the presence of the ZLB. In our crisis scenarios, we follow the recent literature and assume that an aggregate preference shock (the risk-premium shock $\Lambda_{a, t}$ ) hits the monetary union, depressing output and generating deflation. The central bank provides monetary stimulus until the interest rate hits the ZLB. We then study the consequences of market deregulation in such macroeconomic conditions.

\section{The Crisis and the ZLB}

We assume that at time 0 the risk-premium shock is realized. We calibrate the size of the shock to reproduce the peak-to-trough decline of euro-area output of about 4 percent following the collapse of Lehman Brothers in September 2008. We set the persistence of the shock such that, in the absence of market reform, the ZLB is binding for approximately two years.

Figure 6 shows the adjustment following the risk-premium shock. As implied by the first-order condition for bond holdings

$$
1+\psi a_{t+1}+\Lambda_{a t}=\left(1+i_{t+1}\right) E_{t}\left(\frac{\beta_{t, t+1}}{1+\pi_{C, t+1}}\right)
$$

an exogenous reduction in $\Lambda_{a, t}$ lowers the marginal cost of saving in the risk-free bond, thereby increasing the incentive to save and save through this vehicle rather than via capital accumulation or product creation. As shown by Fisher (2015), the reduction in $\Lambda_{a, t}$ is a reduced-form shock capturing increased household's preference for holding risk-free bonds - the one-period, risk-free assets $A_{t+1}$. Thus, as households demand more risk-free bonds, aggregate consumption, investment 
in physical capital, and producer entry fall. In turn, lower aggregate demand results in lower production in both tradable and non-tradable sectors, and higher unemployment.

The central bank immediately cuts the nominal interest rate to its zero lower bound and keeps this accommodative stance for 8 quarters. As the negative demand shock slowly reverts back, the central bank smoothly increases the policy rate toward its long-run value. Consumption, output, and GDP recover. ${ }^{47}$

\section{The Effects of Market Reforms at the ZLB}

We now study the consequences of market deregulation at the ZLB. We consider the following experiment. We assume that at quarter 0 both Home and Foreign are hit by the symmetric riskpremium shock described above. Next, we assume that at quarter 1 there is a permanent change in regulation. As before, we consider a permanent reduction in barriers to entry, firing costs, and unemployment benefits, and we treat this policy shock as unanticipated. ${ }^{48}$

The general message of our analysis is twofold. First, the effectiveness of implementing product or labor market reforms in a recession is reform-specific. This result confirms the analysis in Cacciatore, Duval, Fiori, and Ghironi (2016b). Second, and central to the present paper, the inability of monetary policy to deliver large interest rate cuts because of the ZLB is not a relevant obstacle to reform, since reforms do not have noticeable deflationary effects. On the contrary, we find that reforms can indeed be more effective in boosting economic activity when the ZLB is binding relative to normal times, stimulating the recovery from the recession and ensuring a faster transition to the new long-run equilibrium.

Consider first the case of a product market reform. The top panel of Figure 1 presents the adjustment when the recession is followed by a reduction in barriers to entry (dashed lines) versus the dynamics in the absence of market reform (continuos lines). The reform has an expansionary effect, since it immediately boosts output and employment. The reason is that, as mentioned above, product market deregulation is inflationary in the short run. Higher inflation, in turn, lowers the real interest rate, as monetary policy does not offset the inflationary pressure since the economy is in a liquidity trap. Ultimately, investment and aggregate demand increase. Notice that consumption

\footnotetext{
${ }^{47}$ The fact that the nominal interest rate returns to its steady-state value smoothly depends on the persistence of the risk-premium shock. We could consider the alternative possibility of a series of i.i.d. realizations of $\Lambda_{a, t}$. In this case, the reversion to the steady state would occur more quickly. Our results are very similar across the two alternative calibrations of the risk-premium shock.

${ }^{48}$ This amounts to considering an unanticipated regulation shock assuming that all the state variables of the model take the value implied by the impact response to the risk-premium shock.
} 
falls by more initially relative to the scenario without deregulation, since households must finance product creation - although part of the financing comes from abroad, as Foreign households invest in the Home economy. Overall, the presence of the ZLB actually contributes to reducing the magnitude of the recession and to a more rapid recovery toward the new steady state.

The bottom panel of Figure 1 (dashed lines) shows the net effect of lowering entry barriers when the economy is in a recession in which the ZLB is binding. We construct the net effect of deregulating markets in a recession as the difference between the dynamics implied by the risk premium shock followed by market reform and the dynamics of the risk premium shock in the absence of deregulation. ${ }^{49}$ Relative to normal times (continuos lines), the reform is more expansionary on impact. The reason, once again, relates to the inflationary effect of product market reform. In normal times, the central bank responds to this inflationary pressure by raising the policy rate. By contrast, when the reform occurs in the recession, aggregate demand and inflation are already low. As a consequence, the response of the central bank does not offset the inflationary pressure brought about by the reduction in barriers to entry.

Figure 2, shows the effects of a reduction in firing costs. In contrast to product market deregulation, lowering firing costs deepens the recession. The removal of firing costs further depresses economic activity because increased firing lowers aggregate demand in the short run. Intuitively, firing costs protect relative unproductive workers from layoffs. Thus, facilitating layoffs increases the share of unprofitable jobs that are destroyed, which further depresses aggregate demand and output in the short run. As a result, the reform entails larger and more persistent adverse shortrun effects on employment and output when implemented in a recession. Importantly, these initial negative effects do not depend on the presence of the ZLB on the policy rate. The presence of the ZLB actually mitigates output and employment losses. This can be easily seen by plotting the net effect of the removal of firing costs assuming that the central bank can push the policy rate in negative territory without any limit (dotted lines in the bottom panel of Figure 2). ${ }^{50}$ As shown in the Figure, the adjustment remains very similar to that observed in the presence of the ZLB. The reason is that, as discussed before, the reform has mild inflationary effects to begin with — although the inflationary effect is a bit more pronounced at the zero lower bound relative to normal times,

\footnotetext{
${ }^{49}$ The responses to the reform at the ZLB and the reform in normal times are aligned so the impact response to the reform at the ZLB (which happens in period 1) is aligned with the impact response to the reform in normal times (which happens in period 0). To show transparently the differences in responses in the same diagram, we are shifting the impulse responses to the reform at the ZLB to the left by one period.

${ }^{50}$ That is, we assume that initial conditions to those implied by the risk-premium shock in the presence of the ZLB, but let the central bank freely adjust the interest rate starting from period 1 on (when firing costs are removed).
} 
reflecting the larger firing of relative unproductive workers and therefore the higher wage of workers that survive job destruction.

Figure 3 shows the effects of a reduction in the level of unemployment benefits. Unlike the removal of firing costs, a reduction in unemployment benefits stimulates job creation by reducing the outside option of the workers and therefore leading to an increase in firm surplus. Implementing a reduction in unemployment benefits is more beneficial in a recession independently of the ZLB. Also in this case, this constraint is not central to the dynamics triggered by the labor market reform, since transition dynamics remain essentially unaffected in the counterfactual economy without ZLB. Finally, Figure 4 shows that a joint reform of product and labor markets is highly stimulative in the short-run - and more so when the ZLB is binding. ${ }^{51}$

The results presented in Figures 1-4 show that the consequences of product and labor market reforms in the presence of the ZLB in a model with explicit micro-level product and labor market dynamics are very different from those implied by the reduced-form modeling of structural reforms in Eggertsson, Ferrero, and Raffo (2014) and other studies. Key for the difference in results is the inflationary effect of reforms (or the absence of any significant deflationary pressure) once the relevant micro-level dynamics of products and labor markets are accounted for. These dynamics are also responsible for significant differences in the implications of reforms for international relative prices and external balances: While exogenous markup cuts automatically lead to terms of trade depreciation and an improvement in the current account, product and labor market reforms lead to stronger terms of trade and a current account deficit for significant portions of the transition dynamics. In the case of product market reform, for instance, this is a consequence of upward pressure wages from increased producer entry and the optimality of external borrowing to finance increased business creation.

Figure 5 shows that the dynamics of labor productivity are not qualitatively different when market reforms are implemented at the zero lower bound. However, quantitatively, short-run responses are larger. In the case of a reduction in barriers to entry, this happens because the reform is more expansionary at the ZLB (implying a more pronounced increase in capital per worker). For labor market reforms, the stronger response does not depend on the ZLB itself, but rather on the fact that deregulation happens in a recession. In the case of firing costs, more unprofitable matches are destroyed when firing restrictions are lifted in a recession, resulting in stronger productivity

\footnotetext{
${ }^{51}$ In the Appendix, we study symmetric deregulation in Home and Foreign. Results are qualitatively very similar, except for the fact that symmetric reforms do not affect international relative prices and the current account.
} 
gains. By contrast, since the cut in unemployment benefits is more expansionary in a recession, labor productivity falls by more, as a larger pool of less productive matches survives job destruction.

\section{Conclusions}

We studied the consequences of structural reforms when the economy is in a deep recession that has triggered the ZLB on nominal interest rates. To this end, we built a two-country, two-sector model of a monetary union featuring endogenous producer entry, search-and-matching frictions in the labor market, and nominal rigidities. In contrast to the existing literature, we focused on primitive changes in market regulation, namely a reduction in regulatory costs of entry in the nontradable sector, employment protection legislation (firing costs), and a decline in the generosity of unemployment benefits. The main conclusion of our analysis is that while business cycle conditions at the time of deregulation matter for the adjustment, the presence of the ZLB itself does not induce recessionary effects of market reforms. In fact, reforms can be more beneficial when the ZLB is binding, as observed for product market reform and joint deregulation in products and labor markets. This result reflects the fact that reforms do not have deflationary effects in the first place, and some are indeed inflationary, at least in the short run.

\section{References}

[1] Abowd, J. M., and F. Kramarz (2003): "The Costs of Hiring and Separations," Labour Economics 10: 499-530.

[2] Alessandria, G., and A. Delacroix (2008): "Trade and the (Dis)Incentive to Reform Labor Markets: The Case of Reform in the European Union," Journal of International Economics 75: 151-166.

[3] Alvarez, F., and M. Veracierto (2000): "Labor-Market Policies in an Equilibrium Search Model," NBER Macroeconomics Annual 14: 265-316.

[4] Andolfatto, D. (1996): "Business Cycles and Labor-Market Search," American Economic Review 86: $112-32$.

[5] Andrés, J., Arce, Ó., and C. Thomas (2014): "Structural Reforms in a Debt Overhang," Banco de España Working Paper 1421.

[6] Arseneau, D. M., and S. K. Chugh (2012): "Tax Smoothing in Frictional Labor Markets," Journal of Political Economy 120: 926-985.

[7] Barseghyan, L., and R. DiCecio (2011): "Entry Costs, Industry Structure, and Cross-Country Income and TFP Differences, " Journal of Economic Theory 146: 1828-1851. 
[8] Baxter, M., and D. D. Farr (2005): "Variable Capital Utilization and International Business Cycles," Journal of International Economics 65: 335-347.

[9] Benigno, P. (2009): "Price Stability with Imperfect Financial Integration," Journal of Money, Credit and Banking 41: 121-149.

[10] Bentolila, S., and G. Bertola (1990): "Firing Costs and Labour Demand: How Bad Is Eurosclerosis?," Review of Economic Studies 57: 381-402.

[11] Bergin, P. R., and R. C. Feenstra (2000): "Staggered Price Setting, Translog Preferences, and Endogenous Persistence," Journal of Monetary Economics 45: 657-680.

[12] Bernard, A. B., S. J. Redding, and P. K. Schott (2010): "Multiple-Product Firms and Product Switching," American Economic Review 100: 70-97.

[13] Bilbiie, F., F. Ghironi, and M. J. Melitz (2008): "Monetary Policy and Business Cycles with Endogenous Entry and Product Variety," NBER Macroeconomics Annual 22: 299-353.

[14] Bilbiie, F., F. Ghironi, and M. J. Melitz (2012): "Endogenous Entry, Product Variety, and Business Cycles," Journal of Political Economy 120: 304 -345.

[15] Blanchard, O., and F. Giavazzi (2003): "Macroeconomic Effects of Regulation and Deregulation in Goods and Labor Markets," The Quarterly Journal of Economics 118: 879-907.

[16] Boeri, T., M. Castanheira, R. Faini, and V. Galasso (eds.) (2006): Structural Reforms Without Prejudices, Oxford University Press.

[17] Boeri, T., and J. F. Jimeno (2015): "Unemployment in Europe: What Does It Take to Bring It Down?" mimeo, Bocconi University.

[18] Broda, C., and D. E. Weinstein (2010): "Product Creation and Destruction: Evidence and Price Implications," American Economic Review 100: 691-723.

[19] Burnside, C., and M. Eichenbaum (1996): "Factor-Hoarding and the Propagation of BusinessCycle Shocks," American Economic Review 86: 1154-74.

[20] Cacciatore, M., R. Duval, G. Fiori, and F. Ghironi (2016a): "Short-Term Pain for LongTerm Gain: Market Deregulation and Monetary Policy in Small Open Economics," Journal of International Money and Finance 68: 358-385.

[21] Cacciatore, M., R. Duval, G. Fiori, and F. Ghironi (2016b): "Market Reforms in the Time of Imbalance," Journal of Economic Dynamics and Control 72: 69-93.

[22] Cacciatore, M., and G. Fiori (2016): "The Macroeconomic Effects of Goods and Labor Markets Deregulation," Review of Economic Dynamics 20: 1-24.

[23] Cacciatore, M., G. Fiori, and F. Ghironi (2016): "Market Deregulation and Optimal Monetary Policy in a Monetary Union," Journal of International Economics 99: 120-137.

[24] Christiano, L., M. Eichenbaum, and S. Rebelo (2011): "When Is the Government Spending Multiplier Large?," Journal of Political Economy 119: 78-121.

[25] den Haan, W. J., G. Ramey, and J. Watson (2000): "Job Destruction and Propagation of Shocks," American Economic Review 90: 482-498. 
[26] Djankov, S., R. L. Porta, F. Lopez-De-Silanes, and A. Shleifer (2002): "The Regulation Of Entry," The Quarterly Journal of Economics 117: 1-37.

[27] Doing Business Database (2008). World Bank.

[28] Draghi, M. (2015): "Structural Reforms, Inflation and Monetary Policy," Introductory Speech, ECB Forum on Central Banking, Sintra, May 22, 2015.

[29] Ebell, M., and C. Haefke (2009): "Product Market Deregulation and the U.S. Employment Miracle," Review of Economic Dynamics 12: 479-504.

[30] Eggertsson, G. (2010): "The Paradox of Toil," Staff Reports 433, Federal Reserve Bank of New York.

[31] Eggertsson, G. (2012): "Was the New Deal Contractionary?," American Economic Review 102: $524-555$.

[32] Eggertsson, G., A. Ferrero, and A. Raffo (2014): "Can Structural Reforms Help Europe?," Journal of Monetary Economics 61: 2-22.

[33] Erceg C., and J. Linde (2012): "Fiscal Consolidation in an Open Economy," American Economic Review 102:186-191.

[34] Everaert, L., and W. Schule (2008): "Why It Pays to Synchronize Structural Reforms in the Euro Area Across Markets and Countries," IMF Staff Papers 55: 356-366.

[35] Fang, L. and R. Rogerson (2011): "Product Market Regulation and Market Work: A Benchmark Analysis," American Economic Journal: Macroeconomics 3: 163-188.

[36] Feenstra, R. C. (2003a): “Advanced International Trade: Theory and Evidence," Princeton University Press.

[37] Feenstra, R. C. (2003b): "A Homothetic Utility Function for Monopolistic Competition Models without Constant Price Elasticity," Economics Letters 78: 79-86.

[38] Felbermayr, G., and J. Prat (2011): "Product Market Regulation, Firm Selection, and Unemployment," Journal of the European Economic Association 9: 278-317.

[39] Fernández-Villaverde, J., P. A. Guerrón-Quintana, and J. Rubio-Ramírez (2011): "Supply-Side Policies and the Zero Lower Bound," NBER Working Paper 17543.

[40] Fiori, G. (2012): "Lumpiness, Capital Adjustment Costs and Investment Dynamics," Journal of Monetary Economics 59: 381-392.

[41] Fisher, J. D. M. (2015): "On the Structural Interpretation of the Smets-Wouters Risk Premium" Shock," Journal of Money, Credit and Banking 47: 511-516.

[42] Gerali, A., A. Notarpietro, and M. Pisani (2015): "Structural Reforms and Zero Lower Bound in a Monetary Union," Temi di Discussione 1002, Bank of Italy.

[43] Gerdesmeier D., and B. Roffia (2004): "Empirical Estimates of Reaction Functions for the Euro Area," Swiss Journal of Economics and Statistics 140: 37-66.

[44] Gertler, M., and A. Trigari (2009): "Unemployment Fluctuations with Staggered Nash Wage Bargaining," Journal of Political Economy 117: 38-86. 
[45] Ghironi, F., and M. J. Melitz (2005): "International Trade and Macroeconomic Dynamics with Heterogeneous Firms," The Quarterly Journal of Economics 120: 865-915.

[46] Gomes, S. (2014): "Euro Area Structural Reforms in Times of a Global Crisis," Banco de Portugal Working Paper 8.

[47] Gomes, S., Jacquinot P., Mohr M., and M. Pisani (2013): "Structural Reforms and Macroeconomic Performance in the Euro Area Countries: A Model-Based Assessment," International Finance 16: 23-44.

[48] Gnocchi, S., A. Lagerborg, and, E. Pappa (2015): "Do Labor Market Institutions Matter for Business Cycles?," Journal of Economic Dynamics and Control, Elsevier, 51: 299-317.

[49] Greenwood, J., Z. Hercowitz, and G. W. Huffman (1988): "Investment, Capacity Utilization, and the Real Business Cycle," American Economic Review 78: 402-17.

[50] Griffith, R., R. Harrison, and G. Macartney (2007): "Product Market Reforms, Labour Market Institutions and Unemployment," Economic Journal 117: 142-166.

[51] Gómez-Salvador, R., J. Messina, and G. Vallanti (2004): "Gross Job Flows and Institutions in Europe," European Central Bank Working Paper 0318.

[52] Haltiwanger, J. C., S. Scarpetta, and H. Schweiger (2006): "Assessing Job Flows Across Countries: The Role of Industry, Firm Size and Regulations," NBER Working Paper 13920.

[53] Hobijn, B., and A. Sahin (2009): "Job-Finding and Separation Rates in the OECD," Economics Letters 104: $107-111$.

[54] Hopenhayn, H., and R. Rogerson (1993): "Job Turnover and Policy Evaluation: A General Equilibrium Analysis," Journal of Political Economy 101: 915-938.

[55] Imbs, J., and I. Mejean (2015): "Elasticity Optimism," American Economic Journal: Macroeconomics, 7: 43-83.

[56] IMF (2016): "Time for a Supply-Side Boost? Macroeconomic Effects of Labor and Product Market Reforms in Advanced Economies," World Economic Outlook, Chapter 3, International Monetary Fund.

[57] Kollmann, R., M. Ratto, W. Roeger, J. in’t Veld, and L. Vogel (2015): "What Drives the German Current Account? And How Does It Affect Other EU Member States?," Economic Policy 30: 47-93.

[58] Krause, M., and T. A. Lubik (2007): "The (Ir)Relevance of Real Wage Rigidity in the New Keynesian Model with Search Frictions," Journal of Monetary Economics 54: 706-727.

[59] Laffargue, J.-P. (1990): "Résolution d'un Modèle Macroéconomique avec Anticipations Rationnelles," Annales d'Economie et de Statistique 17: 97-119.

[60] Lee, Y., and T. Mukoyama (2008): "Entry, Exit and Plant-Level Dynamics over the Business Cycle," Federal Reserve Bank of Cleveland Working Paper 07-18.

[61] Martin, J., and I. Méjean (2013): "Price dispersion and the Euro: Micro Heterogeneity and Macro Implications," International Review of Economic and Finance 26: 70-86. 
[62] Mendoza, E. G. (1991): "Real Business Cycles in a Small Open Economy," American Economic Review 81: 797-818.

[63] Merz, M. (1995): "Search in the Labor Market and the Real Business Cycle," Journal of Monetary Economics 36: 269-300.

[64] Mian, A., and A. Sufi (2011): "House Prices, Home Equity-Based Borrowing, and the US Household Leverage Crisis," American Economic Review 101: 2132-56.

[65] Mitman, K., and S. Rabinovich (2015): "Optimal Unemployment Insurance in an Equilibrium Business-Cycle Model," Journal of Monetary Economics, 71(C): 99-118.

[66] Mortensen, D. T., and C. A. Pissarides (1994): "Job Creation and Job Destruction in the Theory of Unemployment," Review of Economic Studies 61: 397-415.

[67] Mortensen, D. T., and C. A. Pissarides (2002): "Taxes, Subsidies and Equilibrium Labor Market Outcomes," Centre for Economic Performance Discussion Papers 0519, London School of Economics.

[68] OECD (2013): "Benefits and Wages Database," Organisation for Economic Co-operation and Development.

[69] OECD (2015): "Economic Policy Reforms: Going for Growth," Organisation for Economic Co-operation and Development.

[70] Obstfeld, M., and K. Rogoff (1995): "Exchange Rate Dynamics Redux," Journal of Political Economy 103: 624-660.

[71] Petrongolo, B., and C. Pissarides (2006): "Scale Effects in Markets with Search," Economic Journal 116: 21-44.

[72] Rogerson, R., R. Shimer, and R. Wright (2005): "Search-Theoretic Models of the Labor Market-A Survey," Journal of Economic Literature 43: 959-988.

[73] Rotemberg, J.J. (1982): "Monopolistic Price Adjustment and Aggregate Output," Review of Economic Studies 49: 517-531.

[74] Smets, F., and R. Wouters (2004): "Forecasting with a Bayesian DSGE Model: An Application to the Euro Area," Journal of Common Market Studies 42: 841-867.

[75] Smets, F., and R. Wouters (2007): "Shocks and Frictions in US Business Cycles: A Bayesian DSGE Approach," American Economic Review 97: 586-606.

[76] Thum-Thysen, A., and E. Canton (2015): "Estimation of Service Sector Mark-Ups Determined by Structural Reform Indicators," European Commission, European Economy Eeconomic Papers 547.

[77] Turnovsky, S. J. (1985): "Domestic and Foreign Disturbances in an Optimizing Model of Exchange Rate Determination," Journal of International Money and Finance 4: 151-171.

[78] Varga, J., and J. in 't Veld (2011): “A Model-Based Analysis of the Impact of Cohesion Policy Expenditure 2000-06: Simulations with the QUEST III Endogenous R\&D Model," Economic Modelling 28: 647-663. 
[79] Veracierto, M. (2008): "Firing Costs and Business Cycle Fluctuations," International Economic Review 49: 1-39.

[80] Vogel, L. (2014): "Structural Reforms at the Zero Bound," European Commission, European Economy - Economic Papers 537.

[81] Weber, A. (2000): "Vacancy Durations-A Model for Employer's Search," Applied Economics 32: $1069-75$.

[82] Woodford, M. (2003): Interest and Prices: Foundations of a Theory of Monetary Policy, Princeton University Press, Princeton.

[83] Woodford, M. (2011): "Simple Analytics of the Government Expenditure Multiplier," American Economic Journal: Macroeconomics 3: 1-35. 


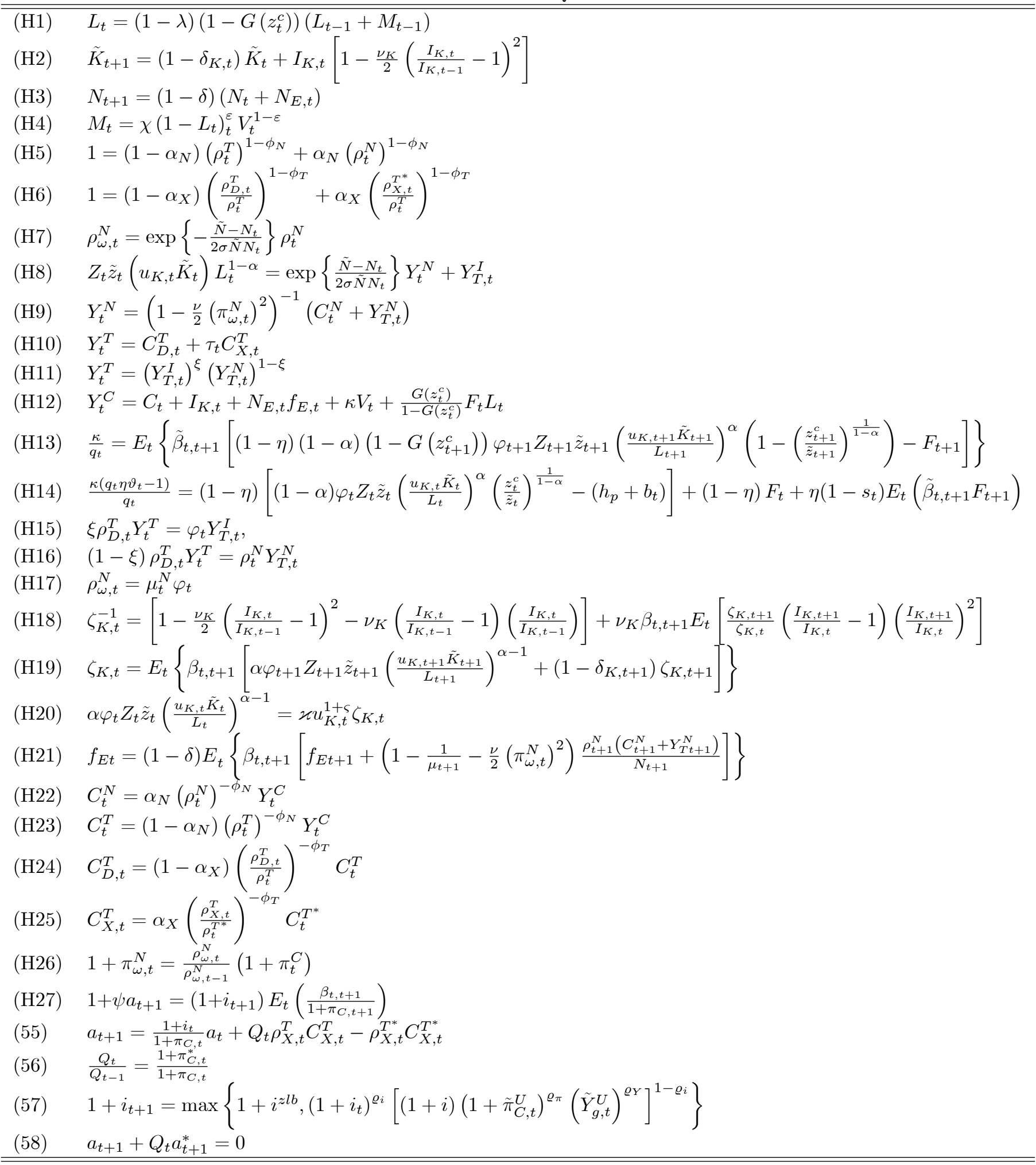

Note: Equations (F1)-(F27), omitted, are the Foreign counterparts of equations (H1)-(H27). 
TABLE 2: CALIBRATION

\begin{tabular}{llll}
\hline \hline Variety elasticity & $\sigma=0.34$ & Unemployment benefit & $b=0.33$ \\
\hline Risk aversion & $\gamma=1$ & Firing costs & $F=0.06$ \\
\hline Discount factor & $\beta=0.99$ & Matching function elasticity & $\varepsilon=0.5$ \\
\hline EOS, home and foreign goods & $\phi_{T}=1.5$ & Home bias & $1-\alpha_{T}=0.6$ \\
\hline EOS, tradables and non-tradables & $\phi_{N}=0.5$ & Share of non-tradables consumption & $\alpha_{N}=0.80$ \\
\hline Share of non-tradables in manufacturing & $\xi=0.6$ & Bond adjustment cost & $=0.0025$ \\
\hline Technological entry cost & $f_{T}=0.73$ & Workers' bargaining power & $\eta=0.5$ \\
\hline Regulation entry cost & $f_{R}=1.09$ & Home production & $h_{P}=0.6$ \\
\hline Plant exit & $\delta=0.004$ & Matching efficiency & $\chi=0.45$ \\
\hline Investment adjustment costs & $\nu=0.16$ & Vacancy cost & $k=0.11$ \\
\hline Capital depreciation rate & $\delta_{K}=0.025$ & Exogenous separation rate & $\lambda=0.036$ \\
\hline Capital share & $\alpha=0.33$ & Lognormal shape & $\sigma_{z_{i}}=0.14$ \\
\hline Capital utilization, scale & $\varkappa=0.035$ & Lognormal log-scale & $\mu_{z_{i}}=0$ \\
\hline Consumption habits & $h_{C}=0.6$ & Capital utilization, convexity & $\varsigma=0.41$ \\
\hline Interest Rate Smoothing & $\varrho_{\iota}=0.87$ & Inflation Response & $\varrho_{\pi}=1.93$ \\
\hline GDP Gap Response & $\varrho_{i}=0.075$ & Zero lower bound & $i^{z l b}=0.01$ \\
\hline \hline
\end{tabular}


Reduction in Barriers to Entry: Recession vs Recession with Reform
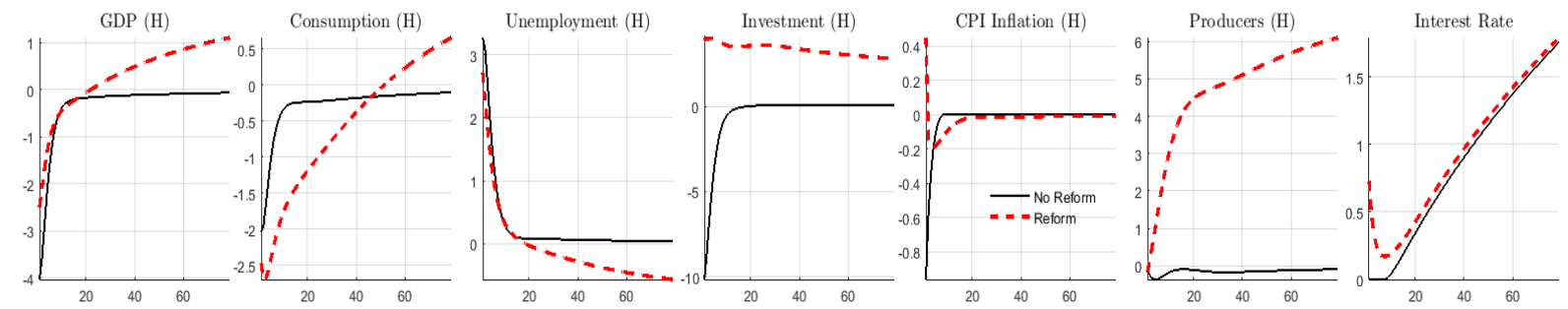

Reduction in Barriers to Entry: Cycle (Net Effect) vs Steady State
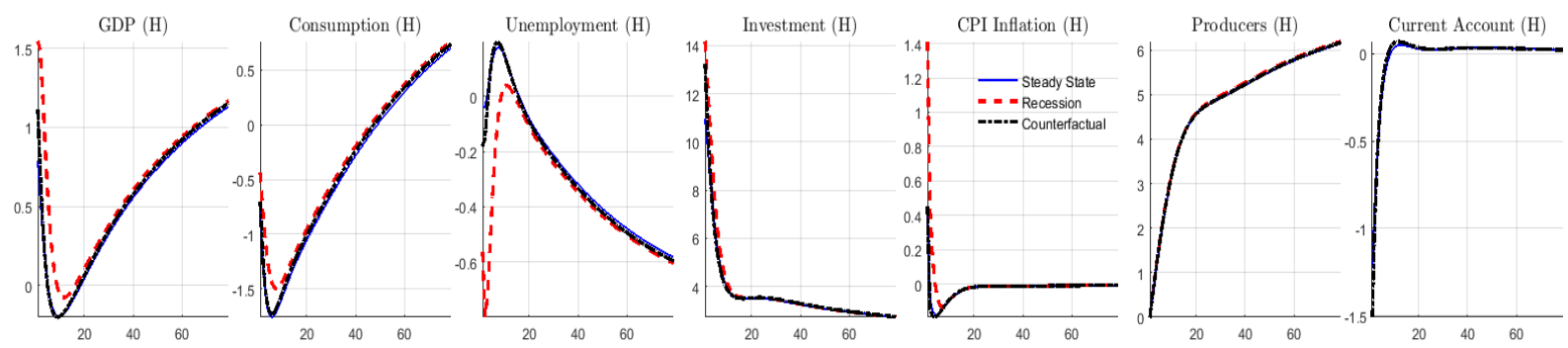

Figure 1. Top panel: recession (continuous lines) versus recession followed by product market reform (dashed lines); Bottom panel: net effect of product market reform in normal times (continuous lines), in a recession with binding ZLB (dashed lines), and in a recession where the interest rate is allowed to violate the ZLB (dotted lines). Responses show percentage deviations from the initial steady state. Unemployment is in deviations from the initial steady state. 
Reduction in Firing Cost: Recession vs Recession with Reform
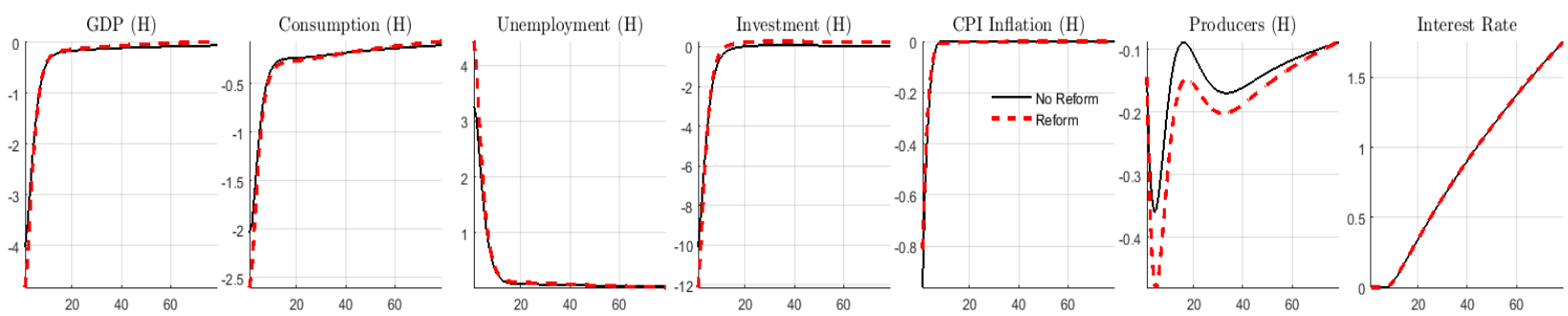

Reduction in Firing Cost: Cycle (Net Effect) vs Steady State
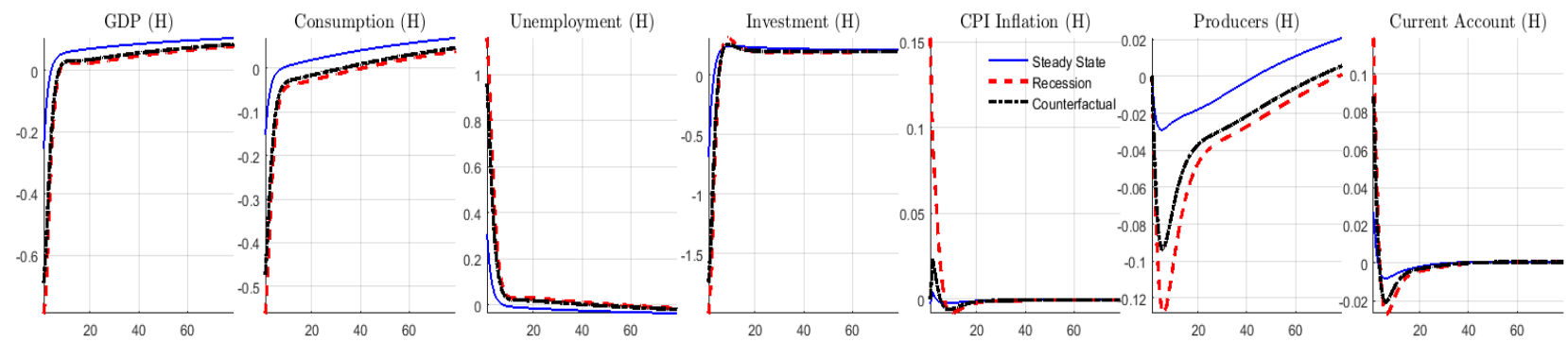

Figure 2. Top panel: recession (continuous lines) versus recession followed by firing cost reform (dashed lines); Bottom panel: net effect of firing cost reform in normal times (continuous lines), in a recession with binding ZLB (dashed lines), and in a recession where the interest rate is allowed to violate the ZLB (dotted lines). Responses show percentage deviations from the initial steady state. Unemployment is in deviations from the initial steady state. 
Reduction in Unemployment Benefit: Recession vs Recession with Reform
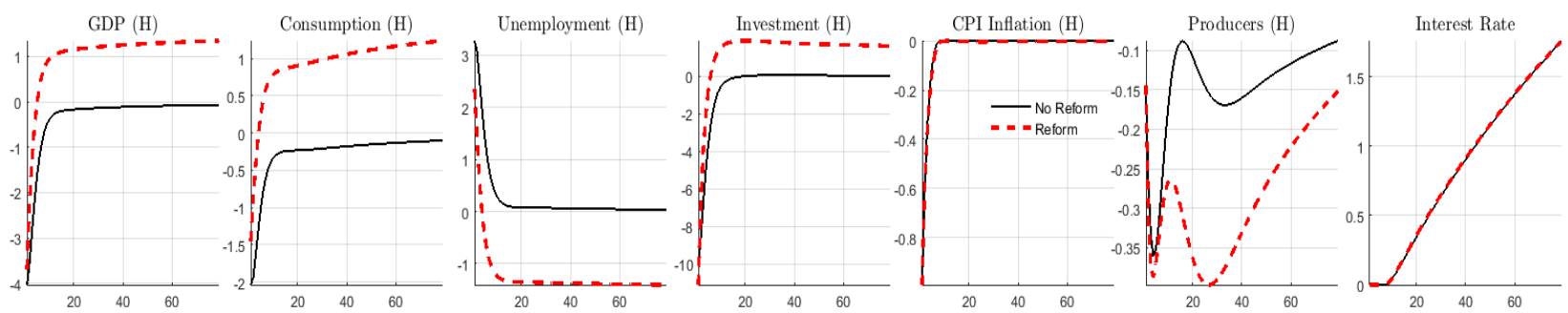

Reduction in Unemployment Benefit: Cycle (Net Effect) vs Steady State
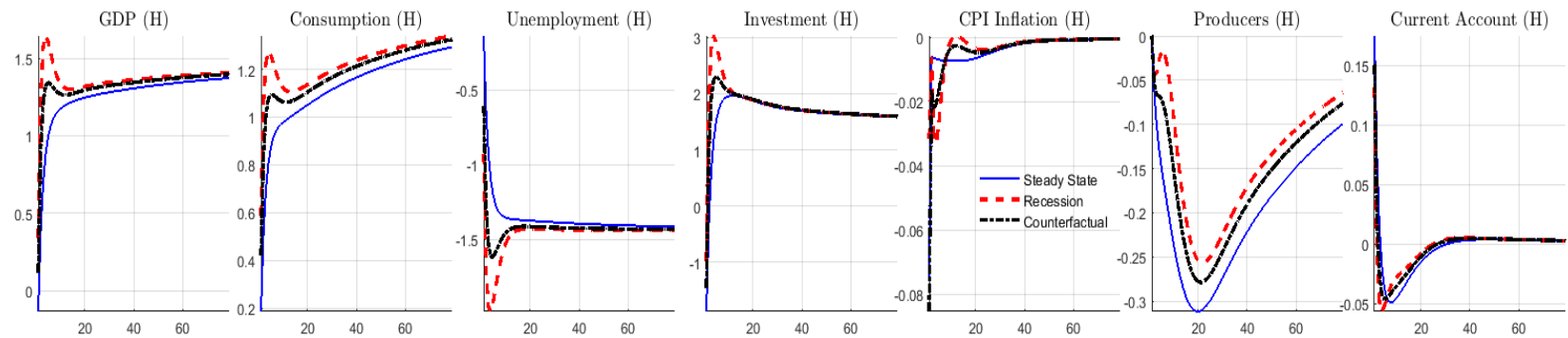

Figure 3. Top panel: recession (continuous lines) versus recession followed by unemployment benefit reform (dashed lines); Bottom panel: net effect of unemployment benefit reform in normal times (continuous lines), in a recession with binding ZLB (dashed lines), and in a recession where the interest rate is allowed to violate the ZLB (dotted lines). Responses show percentage deviations from the initial steady state. Unemployment is in deviations from the initial steady state. 
Joint Deregulation: Recession vs Recession with Reform
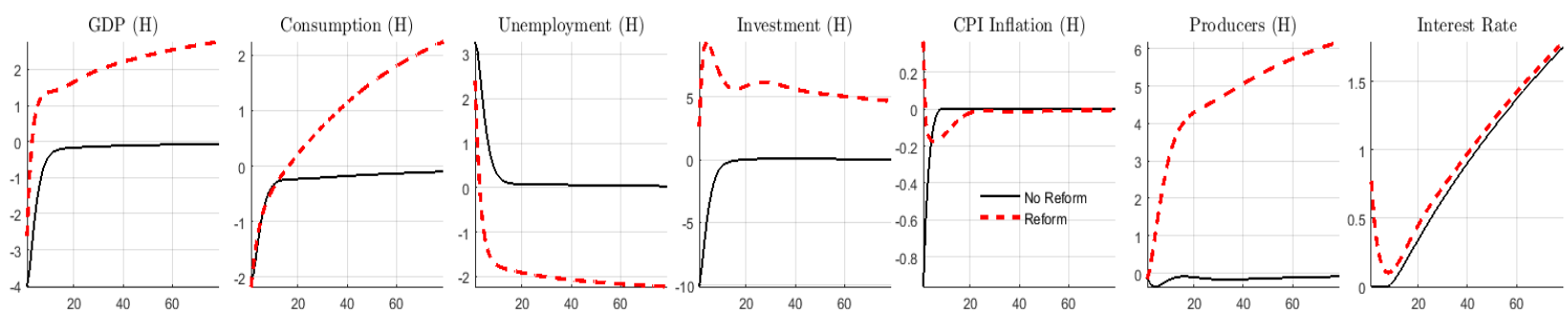

Joint Deregulation: Cycle (Net Effect) vs Steady State
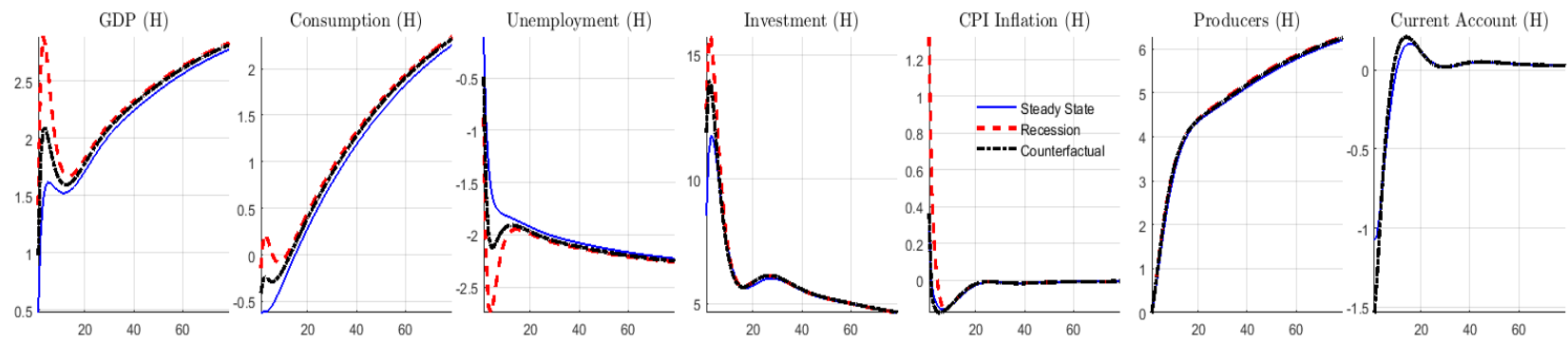

Figure 4. Top panel: recession (continuous lines) versus recession followed by joint product and labor market reform (dashed lines); Bottom panel: net effect of joint product and labor market reform in normal times (continuous lines), in a recession with binding ZLB (dashed lines), and in a recession where the interest rate is allowed to violate the ZLB (dotted lines). Responses show percentage deviations from the initial steady state. Unemployment is in deviations from the initial steady state. 

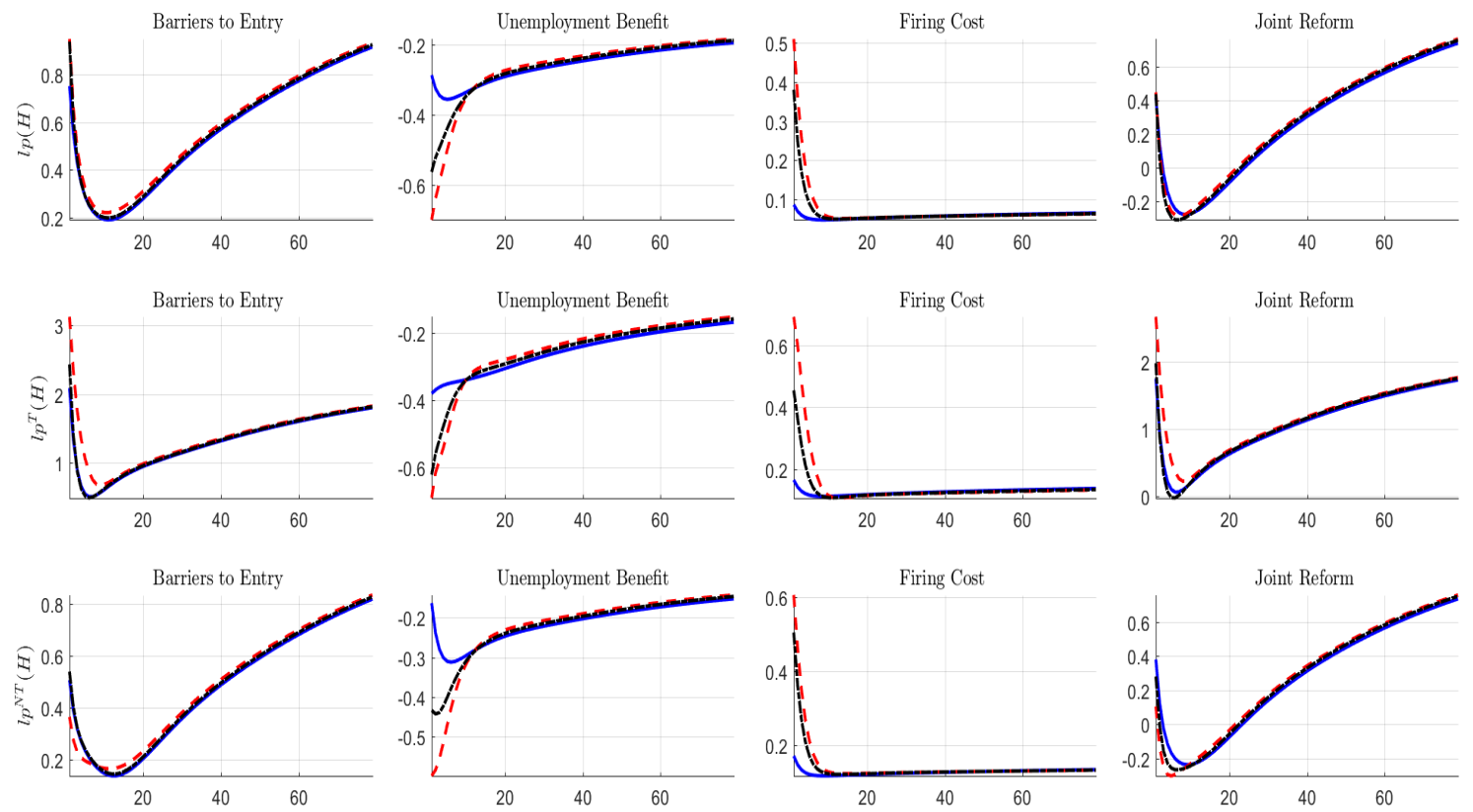

Figure 5. Aggregate and sectoral labor-productivity dynamics following market reforms in normal times (continuous lines), in a recession with binding ZLB (dashed lines), and in a recession where the interest rate is allowed to violate the ZLB (dotted lines). First row: aggregate labor productivity $\left(l p_{t}\right)$; Second row: labor productivity in the tradable sector $\left(l p_{t}^{T}\right)$; Third row: labor productivity in the non-tradable sector $\left(l p_{t}^{N T}\right)$.

Recession: Risk Premium Shock
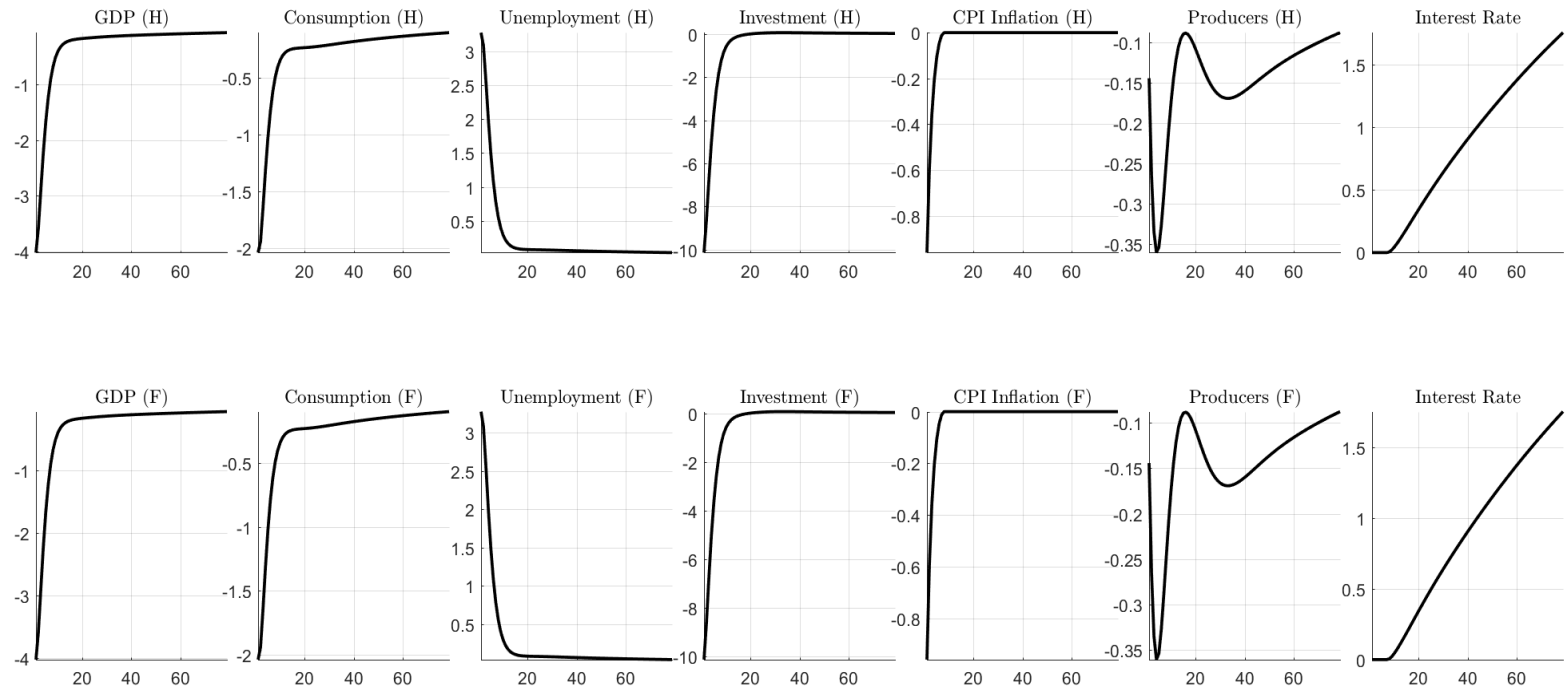

Figure 6. Risk-premium shock with high regulation. Responses show percentage deviations from the steady state. Unemployment is in deviations from the steady state. 


\section{Online Appendix to "Market Reforms at the Zero Lower Bound" Not for Publication}

\author{
Matteo Cacciatore* \\ HEC Montréal and NBER \\ Giuseppe Fiori ${ }^{\ddagger}$ \\ North Carolina State University
}

\author{
Romain Duval ${ }^{\dagger}$ \\ International Monetary Fund \\ Fabio Ghironi ${ }^{\S}$ \\ University of Washington, \\ CEPR. EABCN, and NBER
}

August 3, 2017

*HEC Montréal, Institute of Applied Economics, 3000, chemin de la Côte-Sainte-Catherine, Montréal (Québec). E-mail: matteo.cacciatore@hec.ca. URL: http://www.hec.ca/en/profs/matteo.cacciatore.html.

${ }^{\dagger}$ International Monetary Fund, 700 19th Street, N.W., Washington, D.C. 20431, U.S.A. E-mail: RDuval@imf.org. URL: https://ideas.repec.org/e/pdu64.html.

${ }^{\ddagger}$ North Carolina State University, Department of Economics, 2801 Founders Drive, 4150 Nelson Hall, Box 8110 , 27695-8110 - Raleigh, NC, USA. E-mail: gfiori@ncsu.edu. URL: http://www.giuseppefiori.net.

${ }^{\S}$ Department of Economics, University of Washington, Savery Hall, Box 353330, Seattle, WA 98195, U.S.A. E-mail: ghiro@uw.edu. URL: http://faculty.washington.edu/ghiro. 


\section{A Wage Determination}

Consider a worker with idiosyncratic productivity $z$. The sharing rule implies:

$$
\eta \Delta_{t}^{F}(z)=(1-\eta) \Delta_{t}^{W}(z)
$$

where $\Delta_{t}^{W}(z)$ and $\Delta_{t}^{F}(z)$ denote, respectively, worker's and firm's real surplus, and $\eta$ is the worker's bargaining weight. The worker's surplus is given by

$$
\Delta_{t}^{W}(z)=w_{t}(z)-\varpi_{t}+E_{t} \tilde{\beta}_{t, t+1}\left(1-G\left(z_{t+1}^{c}\right)\right) \tilde{\Delta}_{t+1}^{W},
$$

where $\tilde{\beta}_{t, t+1} \equiv(1-\lambda) \beta_{t, t+1}$, and

$$
\tilde{\Delta}_{t}^{W} \equiv\left[1-G\left(z_{t}^{c}\right)\right]^{-1} \int_{z_{t}^{c}}^{\infty} \Delta_{t}^{W}(z) g(z) d z
$$

represents the average surplus accruing to the worker when employed in firm. The term $\varpi_{t}$ is the worker's outside option, defined in the text:

$$
\varpi_{t} \equiv h_{p}+b_{t}+\iota_{t} E_{t}\left[\tilde{\beta}_{t, t+1}\left(1-G\left(z_{t+1}^{c}\right)\right) \tilde{\Delta}_{t+1}^{W}\right] .
$$

The firm surplus corresponds to the value of the job to the firm, $J_{t}(z)$, plus savings from firing costs $F$, i.e., $\Delta_{t}^{F}(z)=J_{t}(z)+F_{t}$-as pointed out by Mortensen and Pissarides (2002), the outside option for the firm in wage negotiations is firing the worker, paying firing costs. The value of the job to the firm corresponds to the revenue generated by the match, plus its expected discounted continuation value, net of the cost of production (the wage bill and the rental cost of capital):

$$
J_{t}(z)=\varphi_{t} Z_{t} z k_{t}^{\alpha}(z)-w_{t}(z)-r_{t}^{K} k_{t}(z)+E_{t} \tilde{\beta}_{t, t+1}\left[\left(1-G\left(z_{t+1}^{c}\right)\right) \tilde{\Delta}_{t+1}^{F}-G\left(z_{t+1}^{c}\right) F_{t+1}\right],
$$

where $\tilde{\Delta}_{t}^{F} \equiv\left[1-G\left(z_{t}^{c}\right)\right]^{-1} \int_{z_{t}^{c}}^{\infty} \Delta_{t}^{F}(z) g(z) d z$ corresponds to the Lagrange multiplier $\psi_{t}$ in the firm profit maximization.

For each job, the producer equates the marginal revenue product of capital to its rental cost:

$$
\alpha \varphi_{\omega t} Z_{t} z k_{\omega t}^{\alpha-1}(z)=r_{t}^{K}
$$

Let $\tilde{k}_{\omega t} \equiv\left[1-G\left(z_{\omega t}^{c}\right)\right]^{-1} \int_{z_{\omega t}^{c}}^{\infty} k_{\omega t}(z) g(z) d z$ be the average capital stock per worker. Equation (3) implies:

$$
\tilde{k}_{\omega t}=\left(\frac{r_{t}^{K}}{\alpha \varphi_{\omega t} Z_{t}}\right)^{\frac{1}{\alpha-1}} \tilde{z}_{\omega t}^{\frac{1}{1-\alpha}}
$$

where $\tilde{z}_{\omega t}$ is defined as in the main text: $\tilde{z}_{\omega t} \equiv\left[\int_{z_{\omega t}^{c}}^{\infty} z^{1 /(1-\alpha)} \frac{g(z)}{1-G\left(z_{\omega t}^{c}\right)} d z\right]^{1-\alpha}$. Let $\psi_{\omega t}$ be the Lagrange multiplier on the constraint $l_{\omega t}=\left(1-\lambda_{\omega t}\right)\left(l_{\omega t-1}+q_{t-1} v_{\omega t-1}\right)$, corresponding to the average 
marginal revenue product of a job. The first-order condition for $v_{\omega t}$ and $l_{\omega t}$ imply, respectively:

$$
\begin{gathered}
\frac{\kappa}{q_{t}}=E_{t}\left\{\tilde{\beta}_{t, t+1}\left[\left(1-G\left(z_{\omega t+1}^{c}\right)\right) \psi_{\omega t+1}-G\left(z_{\omega t+1}^{c}\right) F_{t+1}\right]\right\}, \\
\psi_{\omega t}=\varphi_{\omega t} \frac{y_{\omega t}}{l_{\omega t}}-\tilde{w}_{\omega t}-r_{t}^{K} \tilde{k}_{\omega t}+\frac{\kappa}{q_{t}}
\end{gathered}
$$

By combining equations (3) and (4), we obtain

$$
k_{\omega t}(z)=\tilde{k}_{\omega t}\left(\frac{z}{\tilde{z}_{\omega t}}\right)^{\frac{1}{1-\alpha}} .
$$

Using equations $(3),(7)$, and $(6), J_{t}(z)$ can then be written as

$$
J_{t}(z)=\pi_{t}(z)-w_{t}(z)+\frac{k}{q_{t}} .
$$

where

$$
\pi_{t}(z) \equiv(1-\alpha) \varphi_{t} \frac{y_{t}}{l_{t}}\left(\frac{z}{\tilde{z}_{t}}\right)^{1 /(1-\alpha)}
$$

denotes the marginal revenue product of the worker. Therefore, the firm surplus is equal to

$$
\Delta_{t}^{F}(z)=\pi_{t}(z)-w_{t}(z)+\frac{k}{q_{t}}+F_{t}
$$

Since the sharing rule in (1) implies that $\tilde{\Delta}_{t}^{W}=\tilde{\Delta}_{t}^{F} \eta /(1-\eta)$, the worker surplus can be written as:

$$
\Delta_{t}^{W}(z)=w_{t}(z)-\varpi_{t}+\frac{\eta}{1-\eta} E_{t}\left\{\tilde{\beta}_{t, t+1}\left[1-G\left(z_{t+1}^{c}\right)\right]\left(\tilde{J}_{t+1}(z)+F_{t+1}\right)\right\} .
$$

Using equation (5), we obtain:

$$
\Delta_{t}^{W}(z)=w_{t}(z)-\varpi_{t}+\frac{\eta}{1-\eta}\left[\frac{\kappa}{q_{t}}+E_{t}\left(\tilde{\beta}_{t, t+1} F_{t+1}\right)\right]
$$

Inserting equations (9) and (10) into the sharing rule (1), we finally obtain:

$$
w_{t}(z)=\eta\left\{\pi_{t}(z)+F_{t}-(1-\lambda) E_{t} \beta_{t, t+1} F_{t+1}\right\}+(1-\eta) \varpi_{t} .
$$

The average wage $\tilde{w}_{t}$ is then given by

$$
\tilde{w}_{t}=\eta\left\{\tilde{\pi}_{t}+F_{t}-(1-\lambda) E_{t} \beta_{t, t+1} F_{t+1}\right\}+(1-\eta) \varpi_{t} .
$$

Finally, notice that in the symmetric equilibrium the worker outside option reduces to:

$$
\varpi_{t} \equiv h_{p}+b_{t}+\frac{\eta}{1-\eta}\left[\kappa \vartheta_{t}+\iota_{t} E_{t}\left(\tilde{\beta}_{t, t+1} F_{t+1}\right)\right]
$$


Therefore, in equilibrium, the average wage is given by:

$$
\tilde{w}_{t}=\eta\left[\tilde{\pi}_{t}+\kappa \vartheta_{t}+F_{t}-(1-\lambda)\left(1-\iota_{t}\right) E_{t} \beta_{t, t+1} F_{t+1}\right]+(1-\eta)\left(h_{p}+b_{t}\right) .
$$

\section{B Market Regulation}

\section{Regulation in the Euro Area: Core and Periphery}

Table A.1 presents data on product and labor market regulation in core and periphery euro area countries.

\section{Calibration of Red Tape Costs}

Ebell and Haefke (2009) estimate the regulation cost of market entry for 17 advanced countries in the year 1997. They measure the average number of months of output lost due to administrative delays and fees. Data about administrative delays are taken from the Logotech S.A dataset, as reported by the OECD's 1998 "Fostering Entrepreneurship" Report and Pissarides (2003). Data on entry fees come from Djankov, Porta, Lopez-De-Silanes, and Shleifer (2002).

In the absence of more recent estimates, and in order to capture various product market reforms carried out in most advanced economies since 1997, we update the Ebell and Haefke's measure for 2013 by making use of the OECD's barriers to entrepreneurship indicators, which are available for the years 1998 and 2013 (see Koske, Wanner, Bitetti, and Barbiero, 2014 for details). The index, measured on a 0-6 scale, measures "administrative burdens on start-ups", capturing both delays and fees.

Our procedure is the following. First, for the year 1997, we regress the log of total entry costs in Ebell and Haefke (2009) on the OECD indicator of administrative burdens on start-up. The implied coefficient is 0.854 with a $t$-stat of 4.87 corresponding to a correlation coefficient of 0.78 . The constant term is -1.345 . Not surprisingly, there is a very strong correlation between Ebell and Haefke's quantitative estimate of total entry costs and the OECD indicator. ${ }^{1}$ Next, we then plug the numerical value of the OECD's indicator for 2013 into this regression, obtaining an updated estimate of Ebell and Haefke's total entry costs for each country in 2013.

Finally, we compute the relevant cross-country averages to calibrate the average value of regulatory entry costs. We consider a weighted average of the index values across euro area member countries, with weights equal to the contributions of individual countries' GDPs to euro area total GDP.

\footnotetext{
${ }^{1}$ Interestingly, there is no statistically significant cross-country correlation between Ebell and Haefke's estimate and the other components of the OECD's barriers to entrepreneurship indicators, such as "complexity of regulatory procedures" and "regulatory protection of incumbents". This clearly indicates that the "administrative burdens on start-ups" component does indeed capture firm entry costs.
} 


\section{Data-Consistent Variables}

First, recall that the welfare-based price indexes imply:

$$
\begin{gathered}
P_{t}=\left[\left(1-\alpha_{N}\right)\left(P_{t}^{T}\right)^{1-\phi_{N}}+\alpha_{N}\left(P_{t}^{N}\right)^{1-\phi_{N}}\right]^{\frac{1}{1-\phi_{N}}}, \\
P_{t}^{T}=\left[\left(1-\alpha_{X}\right)\left(P_{D, t}^{T}\right)^{1-\phi_{T}}+\alpha_{X}\left(P_{X, t}^{T^{*}}\right)^{1-\phi_{T}}\right]^{\frac{1}{1-\phi_{T}}} .
\end{gathered}
$$

Next, define the variety effect as

$$
\Delta_{t}^{N} \equiv \exp \left\{\frac{\tilde{N}-N_{t}}{2 \sigma \tilde{N} N_{t}}\right\}
$$

Therefore

$$
\begin{aligned}
P_{t}^{N} & =\Delta_{t}^{N} \tilde{P}_{t}^{N} \\
P_{D, t}^{T} & =\left(\Delta_{t}^{N}\right)^{\xi-1} \tilde{P}_{D, t}^{T}, \\
P_{X, t}^{T^{*}} & =\left(\Delta_{t}^{N^{*}}\right)^{\xi-1} \tilde{P}_{X, t}^{T^{*}} .
\end{aligned}
$$

Therefore

$$
P_{t}=\left[\left(1-\alpha_{N}\right)\left(P_{t}^{T}\right)^{1-\phi_{N}}+\alpha_{N}\left(\Delta_{t}^{N} \tilde{P}_{t}^{N}\right)^{1-\phi_{N}}\right]^{\frac{1}{1-\phi_{N}}}
$$

and

$$
P_{t}^{T}=\left[\left(1-\alpha_{X}\right)\left[\left(\Delta_{t}^{N}\right)^{\xi-1} \tilde{P}_{D, t}^{T}\right]^{1-\phi_{T}}+\alpha_{X}\left[\left(\Delta_{t}^{N^{*}}\right)^{\xi-1} \tilde{P}_{X, t}^{T^{*}}\right]^{1-\phi_{T}}\right]^{\frac{1}{1-\phi_{T}}}
$$

By combining the above results, we obtain:

$$
P_{t}^{1-\phi_{N}}=\left(1-\alpha_{N}\right)\left[\left(1-\alpha_{X}\right)\left(\left(\Delta_{t}^{N}\right)^{\xi-1} \tilde{P}_{D, t}^{T}\right)^{1-\phi_{T}}+\alpha_{X}\left(\left(\Delta_{t}^{N^{*}}\right)^{\xi-1} \tilde{P}_{X, t}^{T^{*}}\right)^{1-\phi_{T}}\right]^{\frac{1-\phi_{N}}{1-\phi_{T}}}+\alpha_{N}\left(\Delta_{t}^{N} \tilde{P}_{t}^{N}\right)^{1-\phi_{N}}
$$

The deflator is then given by

$$
\Omega_{t} \equiv\left(1-\alpha_{N}\right)\left\{\left(1-\alpha_{X}\right)\left[\left(\Delta_{t}^{N}\right)^{\xi-1}\right]^{1-\phi_{T}}+\alpha_{X}\left(\left(\Delta_{t}^{N^{*}}\right)^{\xi-1}\right)^{1-\phi_{T}}\right\}^{\frac{1-\phi_{N}}{1-\phi_{T}}}+\alpha_{N}\left(\Delta_{t}^{N}\right)^{1-\phi_{N}}
$$

As discussed in the main text, we construct an average price index as

$$
\tilde{P}_{t}=\Omega_{t}^{\frac{1}{\phi_{N}-1}} P_{t}
$$

In turn, given any variable $X_{t}$ in units of consumption, its data-consistent counterpart is:

$$
X_{R, t} \equiv \frac{P_{t} X_{t}}{\tilde{P}_{t}}=X_{t} \Omega_{t}^{\frac{1}{\left(1-\phi_{N}\right)}}
$$




\section{Impulse Responses for the Foreign Economy}

See Figures A.1-A.5. In the Foreign economy, GDP and employment temporarily fall relatively to the initial steady state, since there are fewer resources available for domestic production as Foreign households invest in the Home economy. Once the number of producing firms in the deregulating economy has increased, the reduction in red-tape implies that more resources can be devoted to consumption and investment in physical capital. In addition, as jobs are reallocated to new entrants, unemployment falls, further boosting aggregate demand at Home and abroad. The larger number of available goods results in higher goods substitutability and lower markups.

\section{E Impulse Responses for a Reduction in Home Production}

See Figure A.6.

\section{F Symmetric Reforms}

See Figures A.7-A.10.

\section{References}

[1] Djankov, S., R. L. Porta, F. Lopez-De-Silanes, and A. Shleifer (2002): "The Regulation Of Entry," The Quarterly Journal of Economics, 117: 1-37.

[2] Koske, I., I. Wanner, R. Bitetti, and O. Barbiero (2014): "The 2013 Update of the OECD Product Market Regulation Indicators: Policy Insights for OECD and non-OECD Countries," OECD Economics Department Working Papers.

[3] Ebell, M., and C. Haefke (2009): "Product Market Deregulation and the U.S. Employment Miracle," Review of Economic Dynamics 12: 479-504.

[4] Mortensen, D. T., and C. A. Pissarides (2002): “Taxes, Subsidies and Equilibrium Labor Market Outcomes," CEP DP 0519.

[5] Pissarides, C. A. (2003): "Company Startup Costs and Employment," in Aghion, P., R. Frydman, J. Stiglitz, and M. Woodford, eds., Knowledge, Information, and Expectations in Modern Macroeconomics: In Honor of Edmund S. Phelps, Princeton University Press, Princeton, NJ, pp. $479-504$. 
TABLE A.1: REGULATION IN THE EURO AREA

\begin{tabular}{lll}
\hline \hline & Core & Periphery \\
\hline Product Market Regulation, OECD Regulation Index Retail Industry, 2013 & 2.58 & 2.94 \\
\hline Unemployment Benefits, Gross Replacement Rate, 2013 & 29.4 & 34.9 \\
\hline Employment Protection Legislation, OECD Index, 2013 & 2.59 & 2.34 \\
\hline \hline
\end{tabular}

A-6 
Reduction in Barriers to Entry: Recession vs Recession with Reform
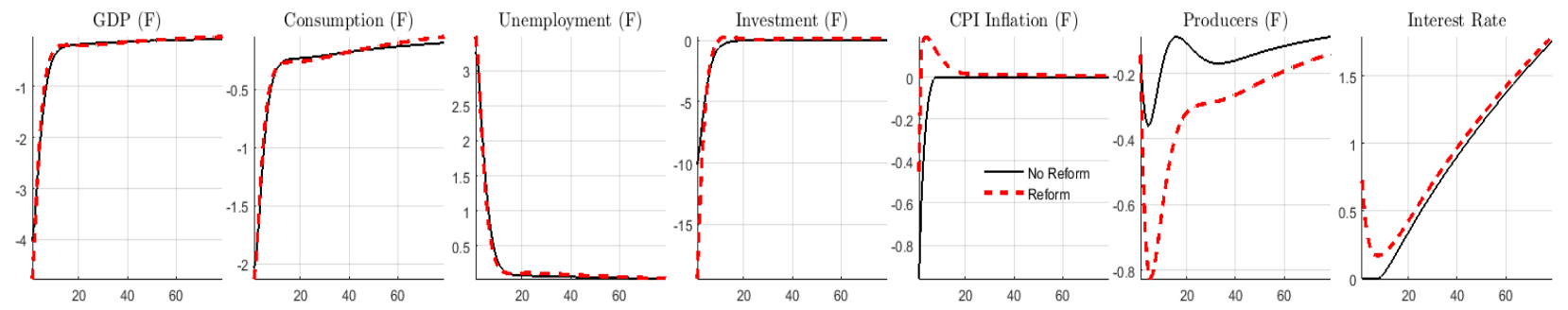

Reduction in Barriers to Entry: Cycle (Net Effect) vs Steady State
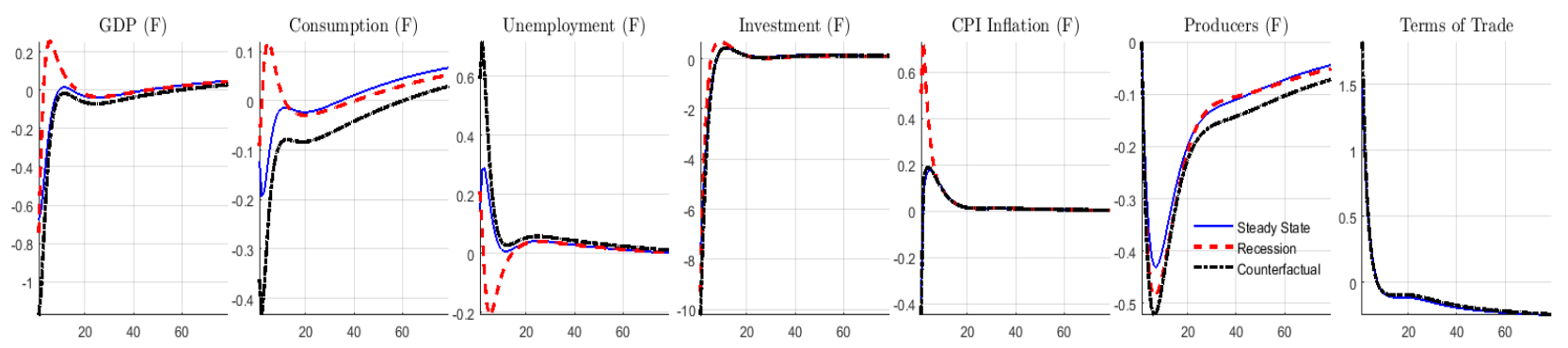

Figure A1. Foreign dynamics following Home product market reform. Top panel: recession (continuous lines) versus recession followed by Home product market reform (dashed lines); Bottom panel: net effect of Home product market reform in normal times (continuous lines), in a recession with binding ZLB (dashed lines), and in a recession where the interest rate is allowed to violate the ZLB (dotted lines). Responses show percentage deviations from the initial steady state. Unemployment is in deviations from the initial steady state. 
Reduction in Firing Cost: Recession vs Recession with Reform
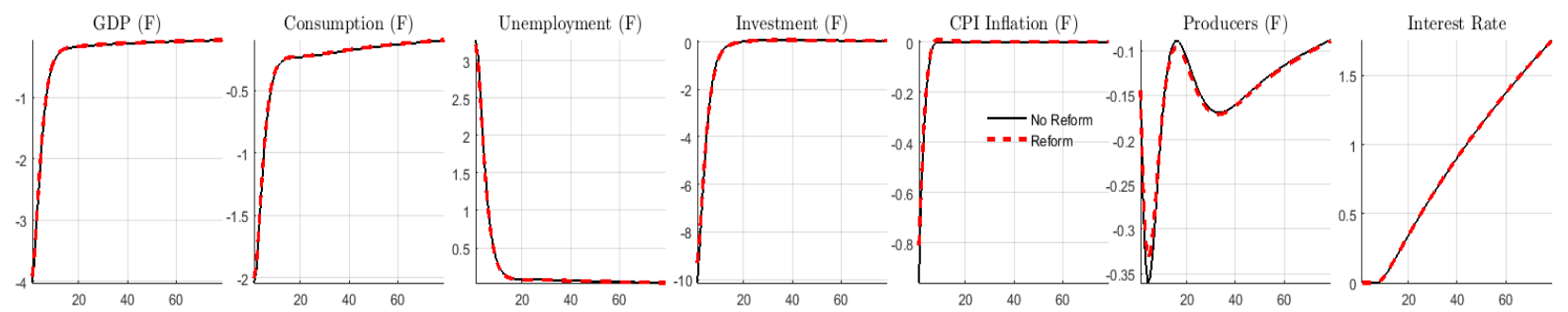

Reduction in Firing Cost: Cycle (Net Effect) vs Steady State

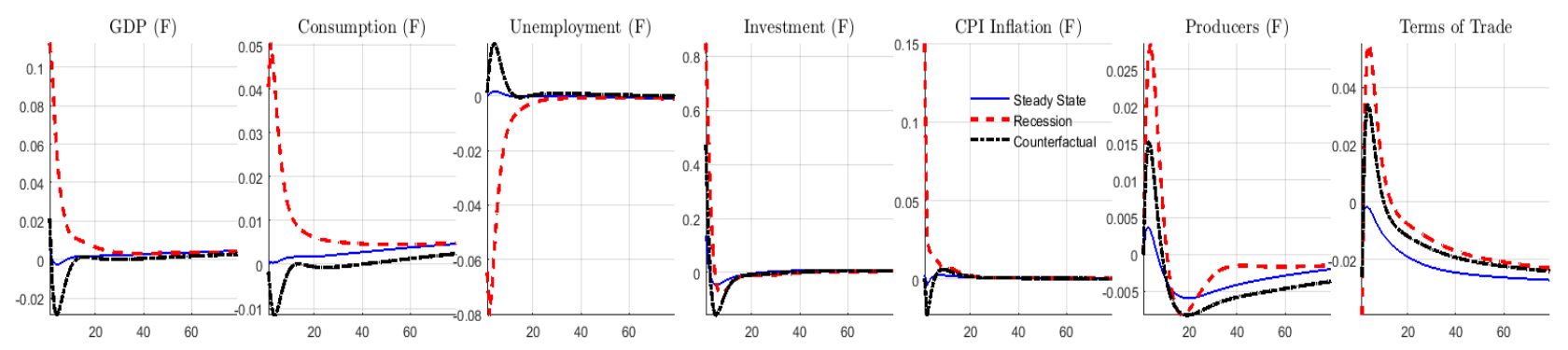

Figure A.2. Foreign dynamics following Home firing cost reform. Top panel: recession (continuous lines) versus recession followed by Home firing cost reform (dashed lines); Bottom panel: net effect of Home firing cost reform in normal times (continuous lines), in a recession with binding ZLB (dashed lines), and in a recession where the interest rate is allowed to violate the ZLB (dotted lines). Responses show percentage deviations from the initial steady state. Unemployment is in deviations from the initial steady state. 
Reduction in Unemployment Benefit: Recession vs Recession with Reform
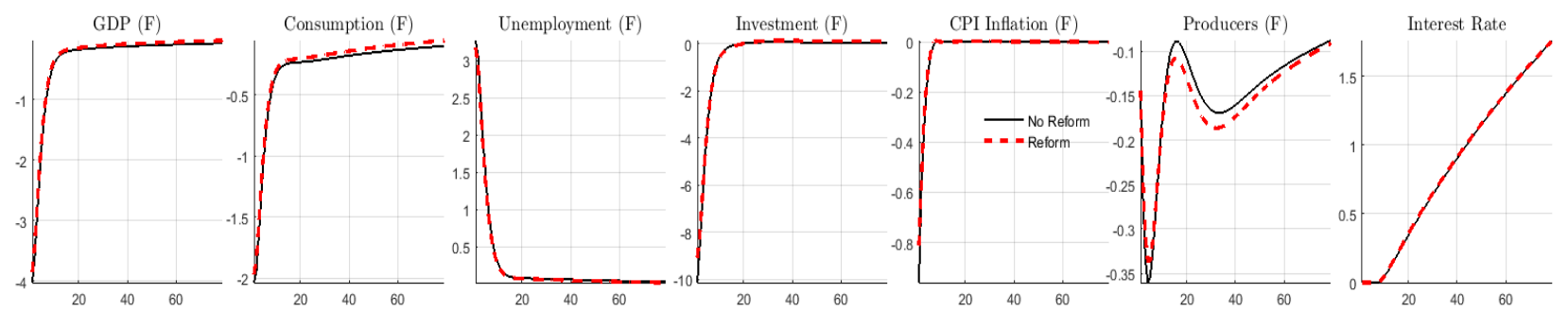

Reduction in Unemployment Benefit: Cycle (Net Effect) vs Steady State

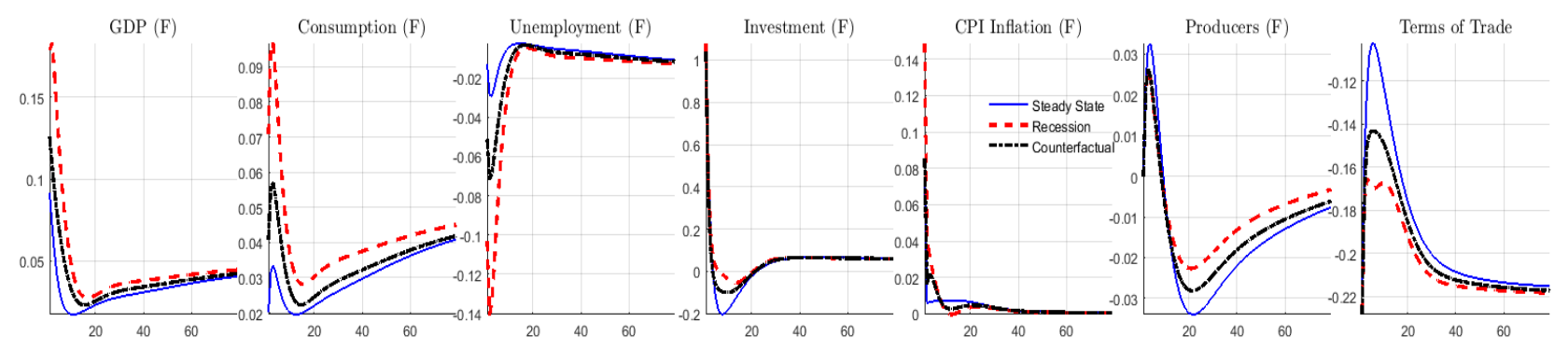

Figure A.3. Foreign dynamics following Home unemployment benefit reform. Top panel: recession (continuous lines) versus recession followed by Home unemployment benefit reform (dashed lines); Bottom panel: net effect of Home unemployment benefit reform in normal times (continuous lines), in a recession with binding ZLB (dashed lines), and in a recession where the interest rate is allowed to violate the ZLB (dotted lines). Responses show percentage deviations from the initial steady state. Unemployment is in deviations from the initial steady state. 
Joint Deregulation: Recession vs Recession with Reform
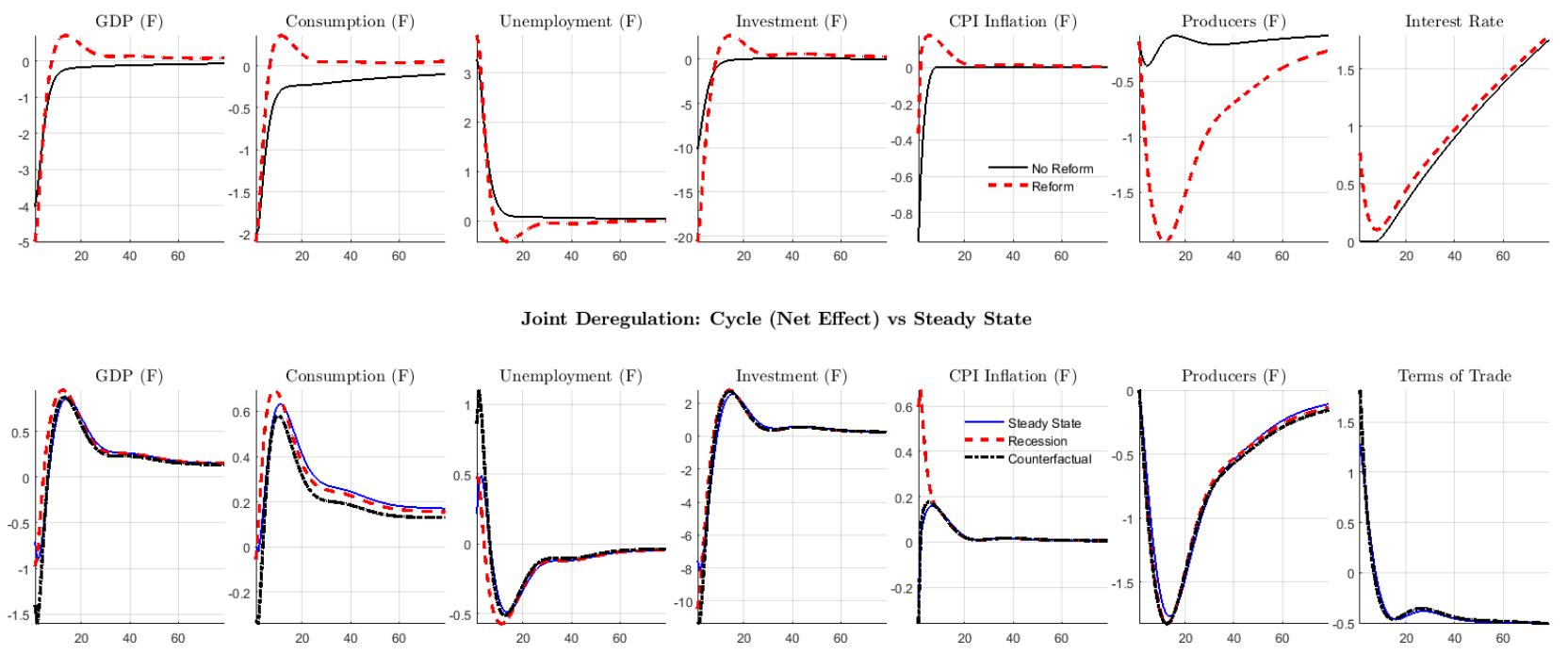

Figure A.4. Foreign dynamics following Home joint reform in product and labor market. Top panel: recession (continuous lines) versus recession followed by Home joint product and labor market reform (dashed lines); Bottom panel: net effect of Home joint product and labor market reform in normal times (continuous lines), in a recession with binding ZLB (dashed lines), and in a recession where the interest rate is allowed to violate the ZLB (dotted lines). Responses show percentage deviations from the initial steady state. Unemployment is in deviations from the initial steady state. 
Productivity Effects of Market Reforms
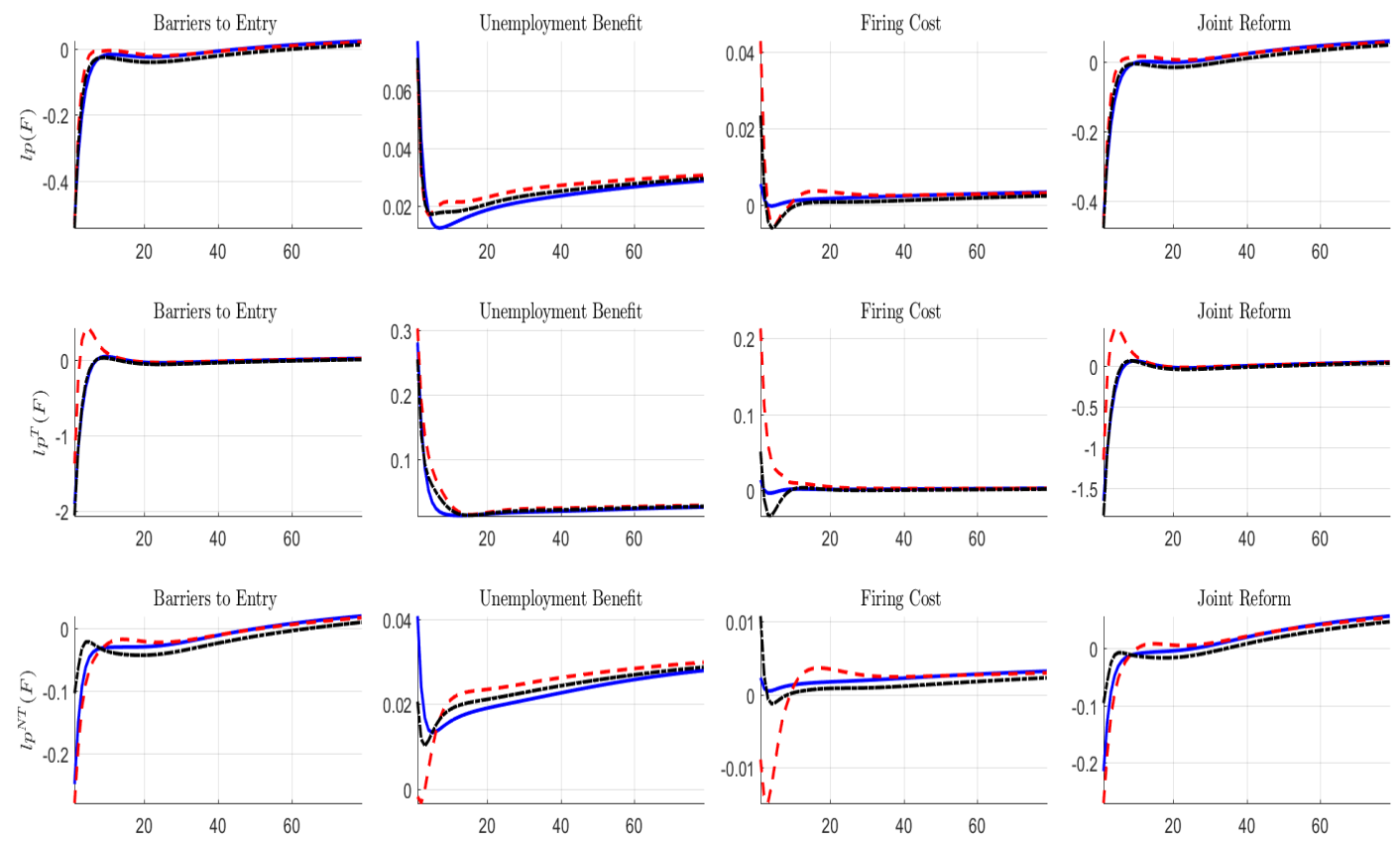

Figure A.5. Aggregate and sectoral labor-productivity dynamics in Foreign following Home market reforms in normal times (continuous lines), in a recession with binding ZLB (dashed lines), and in a recession where the interest rate is allowed to violate the ZLB (dotted lines). First row: aggregate labor productivity $\left(l p_{t}^{*}\right)$; Second row: labor productivity in the tradable sector $\left(l p_{t}^{T^{*}}\right)$; Third row: labor productivity in the non-tradable sector $\left(l p_{t}^{N T^{*}}\right)$. 
Reduction in Home Production: Recession vs Recession with Reform
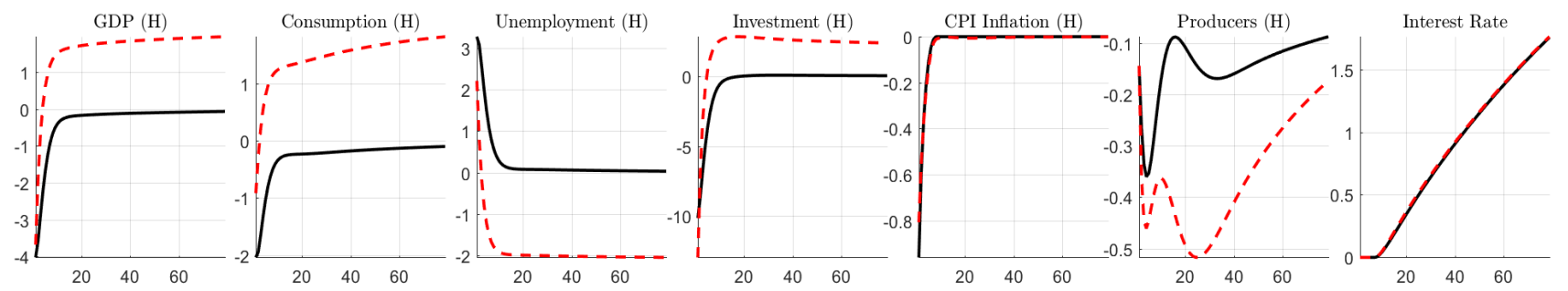

Reduction in Home Production: Cycle (Net Effect) vs Steady State
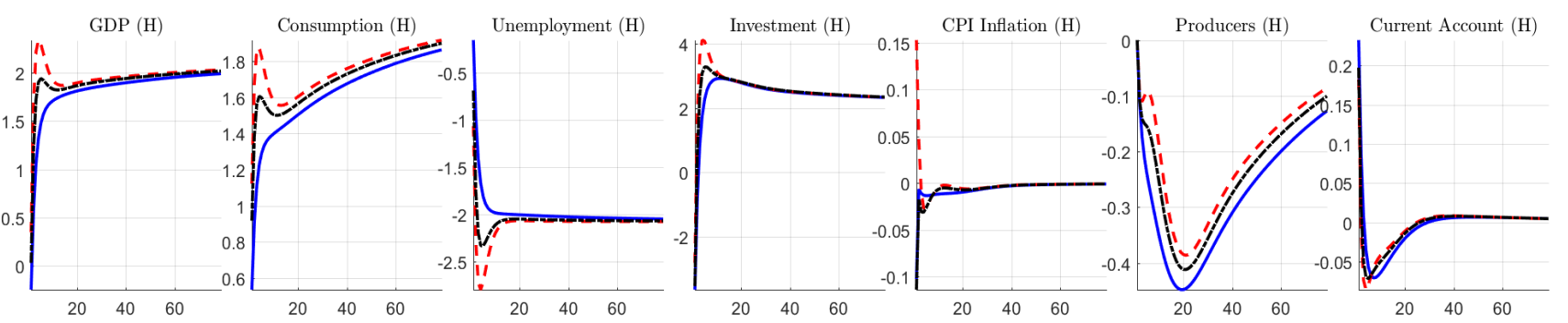

Figure A.6. Top panel: recession (continuous lines) versus recession followed by a reduction in home production (dashed lines); Bottom panel: net effect of a reduction in home production in normal times (continuous lines), in a recession with binding ZLB (dashed lines), and in a recession where the interest rate is allowed to violate the ZLB (dotted lines). Responses show percentage deviations from the initial steady state. Unemployment is in deviations from the initial steady state. 

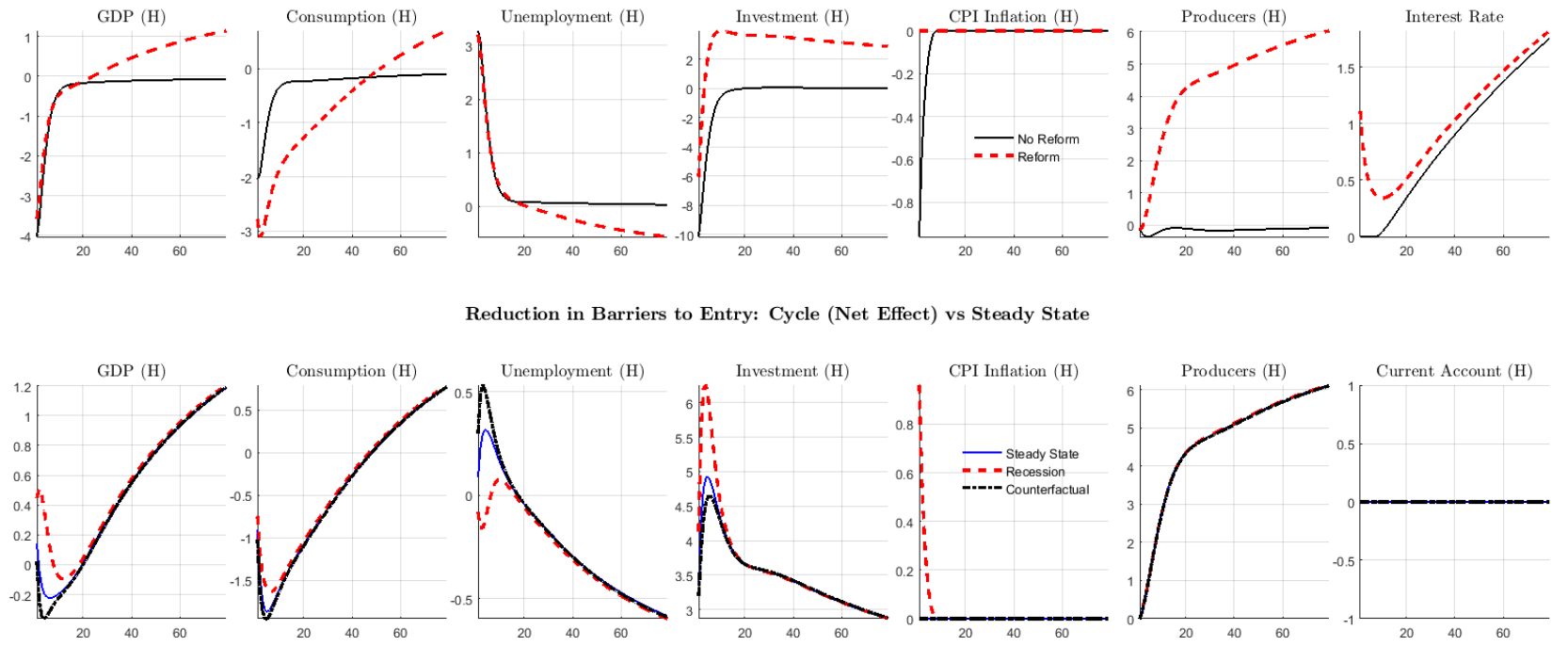

Figure A.7. Top panel: recession (continuous lines) versus recession followed by symmetric product market reform (dashed lines); Bottom panel: net effect of symmetric product market reform in normal times (continuous lines), in a recession with binding ZLB (dashed lines), and in a recession where the interest rate is allowed to violate the ZLB (dotted lines). Responses show percentage deviations from the initial steady state. Unemployment is in deviations from the initial steady state. 

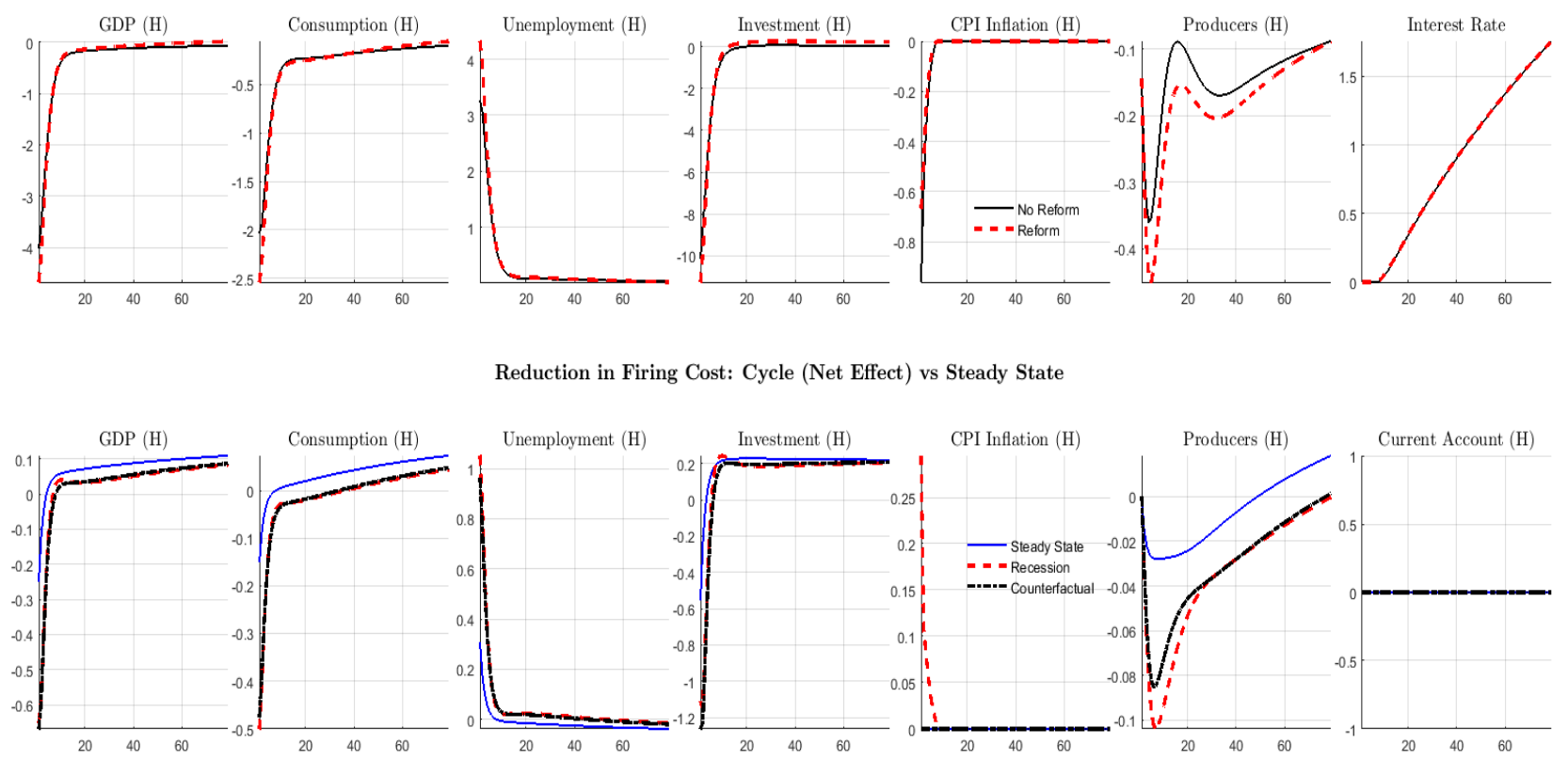

Reduction in Firing Cost: Cycle (Net Effect) vs Steady State

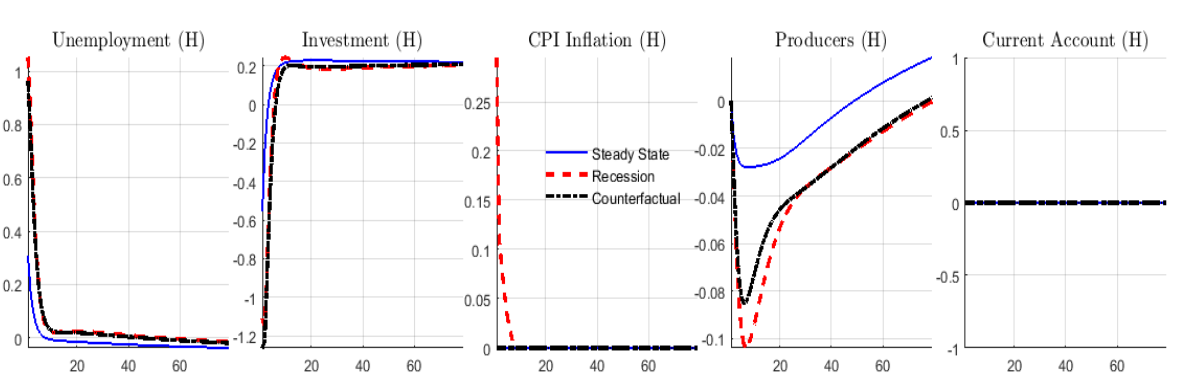

Figure A.8. Top panel: recession (continuous lines) versus recession followed by symmetric firing cost reform (dashed lines); Bottom panel: net effect of firing cost reform in normal times (continuous lines), in a recession with binding ZLB (dashed lines), and in a recession where the interest rate is allowed to violate the ZLB (dotted lines). Responses show percentage deviations from the initial steady state. Unemployment is in deviations from the initial steady state. 
Reduction in Unemployment Benefit: Recession vs Recession with Reform
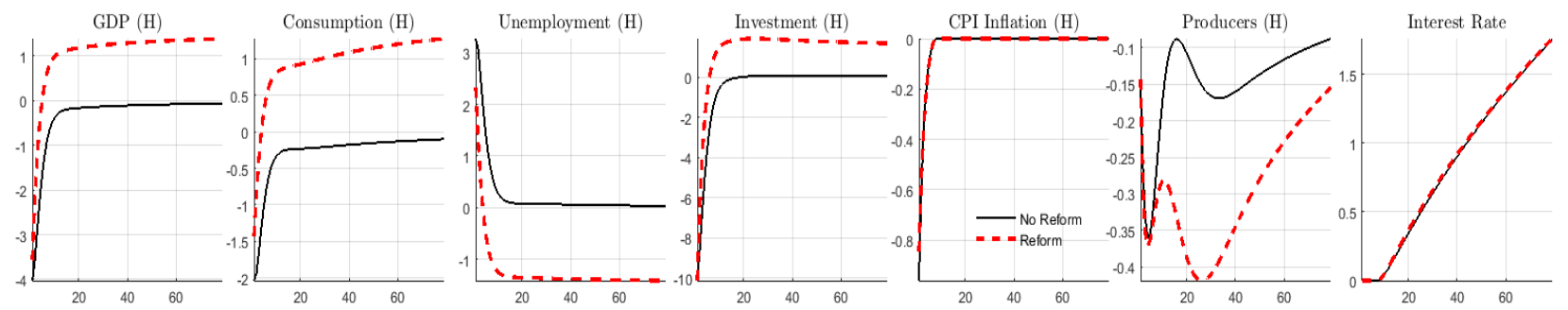

Reduction in Unemployment Benefit: Cycle (Net Effect) vs Steady State
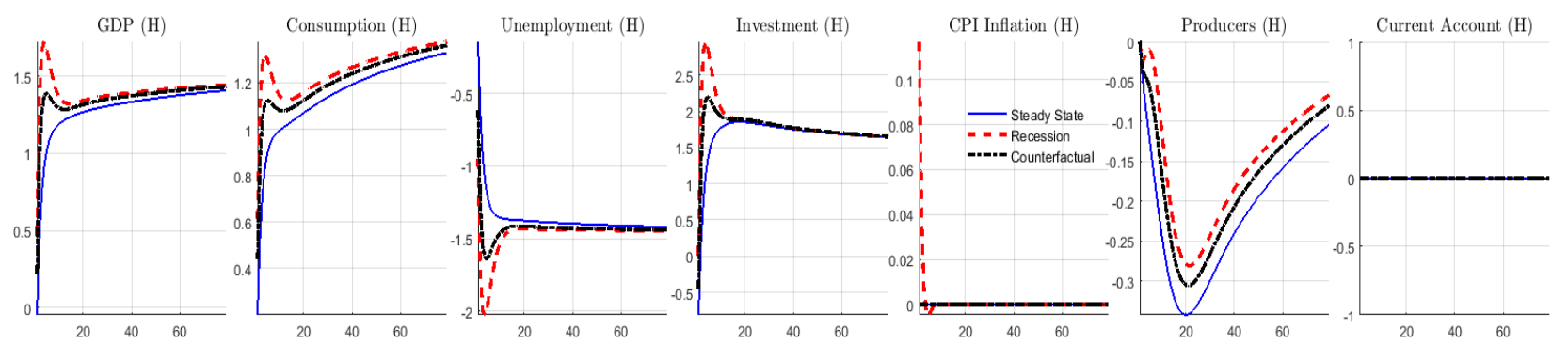

Figure A.9. Top panel: recession (continuous lines) versus recession followed by symmetric unemployment benefit reform (dashed lines); Bottom panel: net effect of unemployment benefit reform in normal times (continuous lines), in a recession with binding ZLB (dashed lines), and in a recession where the interest rate is allowed to violate the ZLB (dotted lines). Responses show percentage deviations from the initial steady state. Unemployment is in deviations from the initial steady state. 
Joint Deregulation: Recession vs Recession with Reform
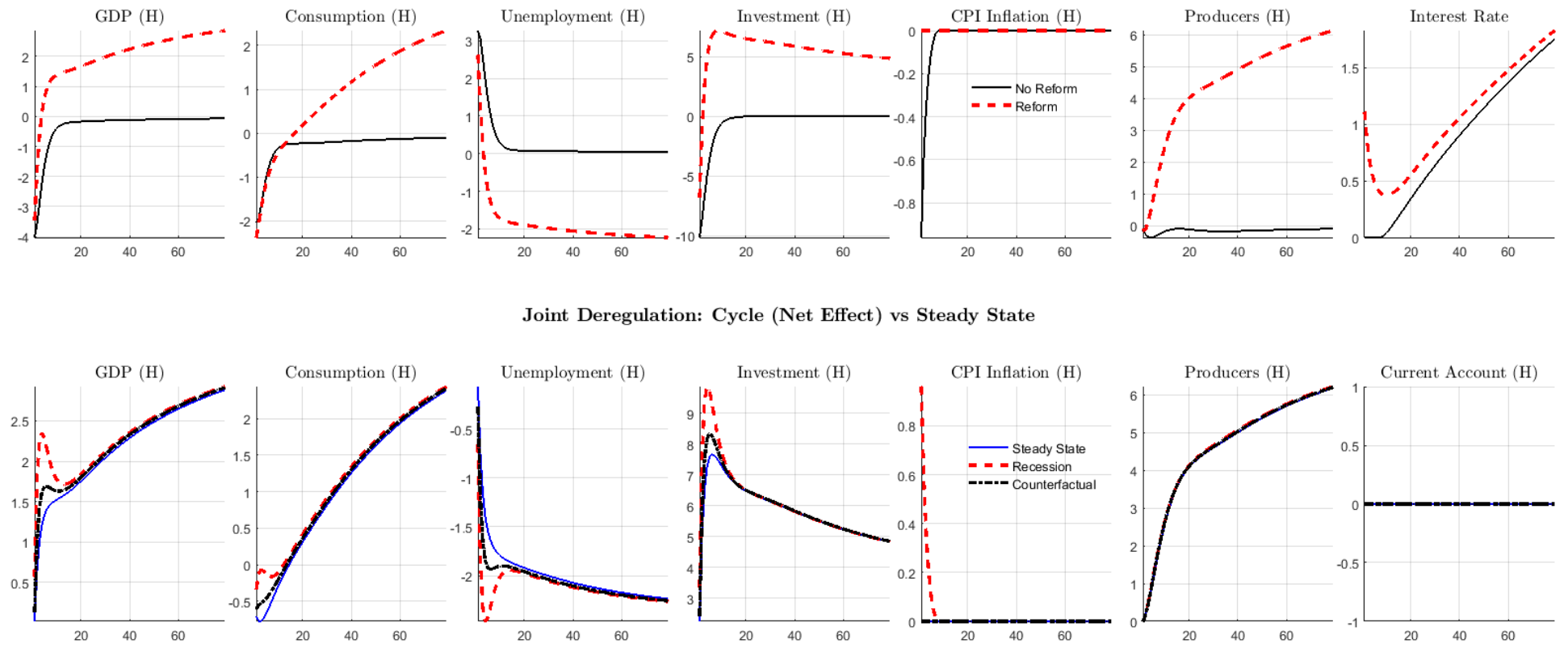

Joint Deregulation: Cycle (Net Effect) vs Steady State
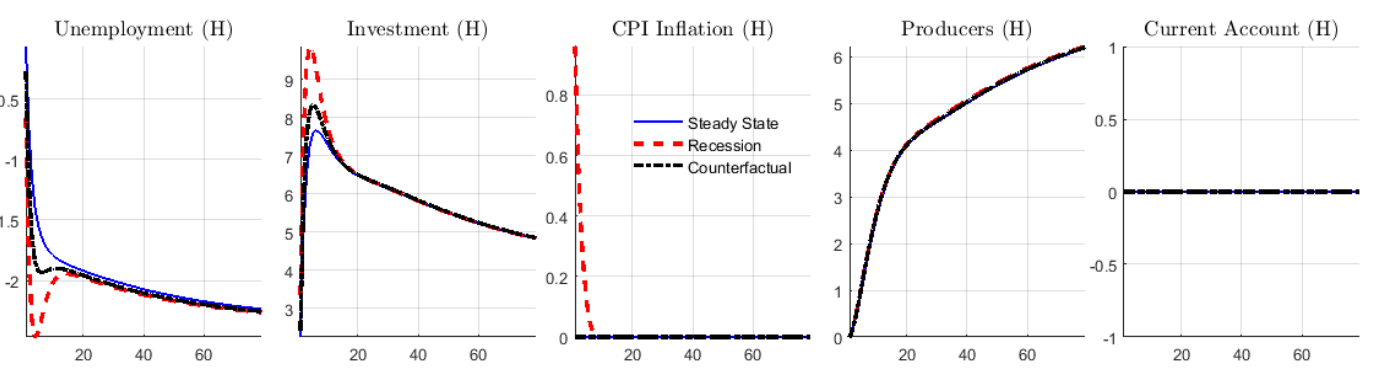

Figure A.10. Top panel: recession (continuous lines) versus recession followed by symmetric joint product and labor market reform (dashed lines) Bottom panel: net effect of joint product and labor market reform in normal times (continuous lines), in a recession with binding ZLB (dashed lines), and in a recession where the interest rate is allowed to violate the ZLB (dotted lines). Responses show percentage deviations from the initial steady state. Unemployment is in deviations from the initial steady state. 